\section{NAT'L INST OF STAND \& TECH}

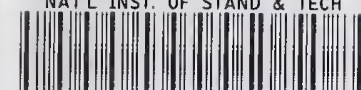

A」ll0b 220373

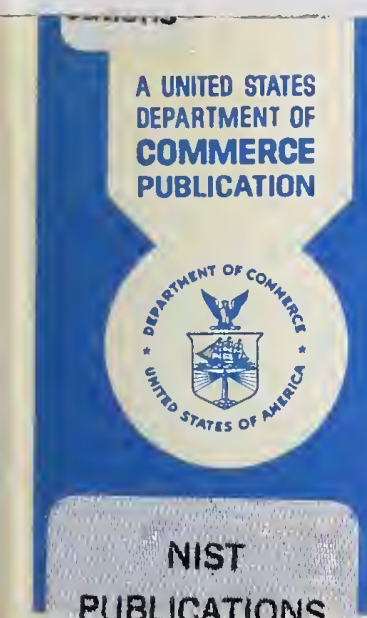

PUBLICATIONS

REFERECE

$=T A-$

435

.458

No.O

U.S. DEPARTMENT OF COMMERCE National Bureau of Standards
National Bureau of Stanciarcte

Library, E-01 Admin. Blig.

NOV 231970
Reference

taken fir.

\section{BUILDING SCIENCE SERIES}
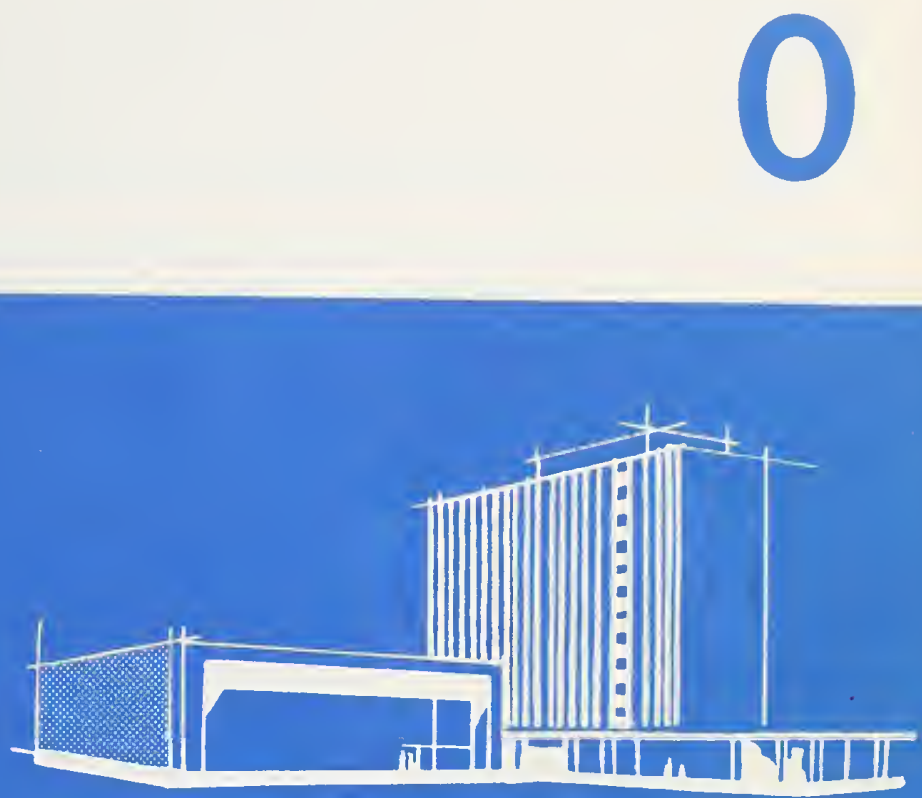

Building Research at the National Bureau of Standards 


\section{Announcing-The Building Science Series}

The "Building Science Series" disseminates technical information developed at the Bureau on building materials, components, systems, and whole structures. The series presents research results, test methods, and performance criteria related to the structural and environmental functions and the durability and safety characteristics of building elements and systems.

These publications, similar in style and content to the NBS Building Materials and Structure Reports (193859), are directed toward the manufacturing, design, and construction segments of the building industry, standards organizations, officials responsible for building codes, and scientists and engineers concerned with the properties of building materials.

The material for this series originates principally in the Building Research Division of the NBS Institute for Applied Technology. Published or in preparation are:

BSS0. Building Research at the National Bureau of Standards. This publication.

BSS1. Performance of Buildings-Concept and Measurment. Man and His Shelter. \$2.75

BSS2. Interrelations Between Cement and Concrete Properties: Part 1, Materials and Techniques, Water Requirements and Trace Elements. 35 cents

BSS3. Doors as Barriers to Fire and Smoke. 15 cents

BSS4. Weather Resistance of Porcelain Enamels: Effect of Exposure Site and Other Variables After Seven Years. 20 cents

BSS5. Interrelations Between Cement and Concrete Properties: Part 2, Sulfate Expansion, Heat of Hydra. tion, and Autoclave Expansion. 35 cents

BSS6. Some Properties of the Calcium Aluminoferrite Hydrates. 20 cents

BSS7. Organic Coatings. Properties, Selection, and Use. \$2.50

BSS8. Interrelations Between Cement and Concrete Properties: Part 3, Compressive Strengths of Portland Cement Test Mortars and Steam-Cured Mortars. 55 cents

BSS9. Thermal-Shock Resistance for Built-Up Membranes. 20 cents

BSS10. Field Burnout Tests of Apartment Dwelling Units. 25 cents

BSS11. Fire Resistance of Steel Deck Floor Assemblies. 25 cents

BSS12. Performance of Square-Edged Orfices and Orifices-Target Combinations as Air Mixers. 15 cents

BSS13. Shrinkage and Creep in Prestressed Concrete. 15 cents

BSS14. Experimental Determination of Eccentricity of Floor Loads Applied to a Bearing Wall. 15 cents

BSS15. Interrelations Between Cement and Concrete Properties: Part 4, Shrinkage of Hardened Portland Cement Pastes. 75 cents

BSS16. Techniques for the Survey and Evaluation of Live Floor Loads and Fire Loads in Modern Office Buildings. 40 cents

BSS17. Causes of Variation in Chemical Analyses and Physical Tests of Portland Cement. 40 cents

BSS18. Smoke and Gases Produced by Burning Aircraft Interior Materials. 35 cents

BSS19. A Study of the Variables Involved in the Saturating of Roofing Felts. 30 cents

BSS20. Proceedings of a Seminar on the Durability of Insulating Glass. 75 cents

BSS21. Algorithms for Pschyrometric Calculations. 55 cents

BSS22. Investigation of Performance Characteristics for Sanitary Plumbing Fixtures. 70 cents

BSS23. Hail Resistance of Roofing Products. 25 cents

BSS24. Natural Weathering of Mineral Stabilized Asphalt Coatings on Organic Felt. 30 cents

BSS25. Structural Performance Test of a Building System. \$1.25

BSS26. Radiation Errors in Air Ducts Under Nonisothermal Conditions Using Thermocouples, Thermistors, and a Resistance Thermometer. 25 cents

BSS27. Performance of Louvered Devices as Air Mixers. 30 cents

BSS28. Exploratory Studies of Early Strength Development in Portland Cement Pastes and Mortars. 25 cents

BSS29. 1964 Exposure Test of Porcelain Enamels on Aluminum--Thrce Year Inspection. 25 cents

BSS30. Proceedings of Technical Meeting Concerning Wind Loads on Buildings and Structures. (In press)

BSS31. Flexural Behavior of Prestressed Concrete Composite Tee-Beams. 25 cents

Send orders with remittance to: Superintendent of Documents, U.S. Government

Printing Office, Washington, D.C. Remittances from foreign countries

should include an additional one-fourth of the purchase price for postage.

[See mailing list announcement on last page.] 
UNITED STATES DEPARTMENT OF COMMERCE - Maurice H. Stans, Secretary NATIONAL BUREAU OF STANDARDS - Lewis M. Branscomb, Director

\title{
Building Research
}

\section{At the National Bureau of Standards}

\author{
Paul R. Achenbach \\ Building Research Division \\ Institute for Applied Technology \\ National Bureau of Standards \\ Washington, D. C. 20234
}

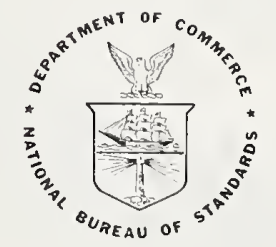

Building Science Series 0

Nat. Bur. Stand. (U.S.), BIdg. Sci. Ser. 0, 59 pages (Oct. 1970)

CODEN: BSSNB

Issued October 1970

For sale by the Superintendent of Documents, U.S. Government Printing Office

Washington, D. C. 20402 (Order by SD Catalog No. C 13.29/2:0), Price 60 cents 
NATIONAL BUREAY CF STANDARDS

$$
\begin{array}{r}
\text { SEP } 121971 \\
\text { Wof ace. } \\
\text { coing } 1
\end{array}
$$

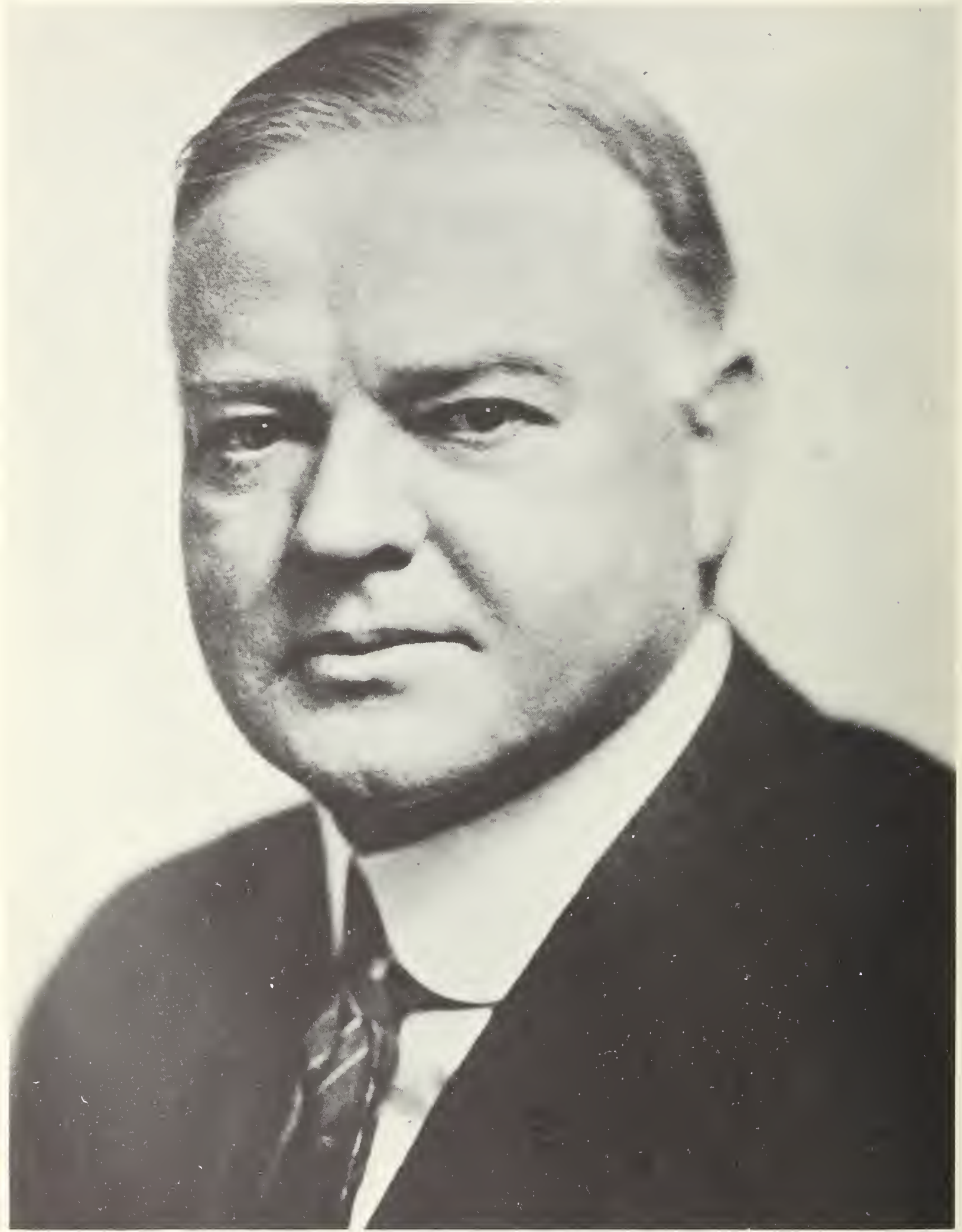

Hon. Herbert Clark Hoover

Secretary of Commerce 1921-1928 - President of the United States 1929-1933 


\section{Foreword}

The continuing program on building science at the National Bureau of Standards is a tribute to the foresight of Herbert Hoover. From its beginning in 1901 the Bureau had carried out studies to meet specific, recognized needs for technical information on properties of building materials. When Hoover became Secretary of Commerce in 1921 he brought together and greatly enlarged these activities with the creation of a Division of Building and Housing. The functions of the new division were to coordinate scientific, technical, and economic research in building; to engage in simplification and standardization of building materials; and to aid in the revision of state and municipal codes. These same broad functions have been exercised up to the present by the different organizational units that have succeeded the original division.

Hoover's purpose was to stimulate the building industry as a means of promoting industrial recovery after World War I. In this activity the new Division of Building and Housing made a major contribution, as indicated by the number, the broad scope and the wide distribution of publications of the Building and Housing Series from 1922 to 1932, and by the incorporation of information from these publications into many building codes and standards. In the 1930's the emphasis shifted to technical aspects of building science as indicated by the content of a series of Building Materials and Structures Reports published over a period of two decades.

Following the specially oriented activities in World War II there was a further change in emphasis accompanying the organization of the present Building Research Division in 1947, with a mission that authorized a wide range of original investigations. Beginning in 1959, the results of these investigations were published in the Bureau's Journal of Research and industry journals until the Building Science Series of publications was initiated in 1965. This Series provides a specific medium for disseminating technical information principally developed at the Bureau on building materials, equipment, systems, and whole structures.

The present publication has been prepared as the basic document of the Building Science Series. Its purpose is to serve as a key to the work of the previous 69 years and as an introduction to the future. Included are a statement of the mission of the Building Research Division, a history of the Bureau's previous activities in the area, a description of the current program, and a summary of future objectives, together with a comprehensive bibliography. Recent reorientation of Division objectives toward the development of performance requirements and performance evaluation techniques for building components and systems, in support of the national trend toward industrialized building construction, is emphasized.

This publication will be useful to builders, engineers, architects, students, Government officials, experts in the environmental sciences, and individuals who may wish to draw upon the experience and the large fund of information on building science available at the National Bureau of Standards.

Lewis M. Branscomb, Director 
Library of Congress Catalog Card No. 76-605161 


\section{Table of Contents}

Page

Foreword -

1. Introduction _-

1.1. Mission of the Building Research Division .

a. Physical and Functional Environment

b. Strength and Safety in Structures

c. Materials Durability and Analysis

d. Exploratory Research _.

e. Building Systems Development

f. Building Codes and Standards _.

g. Professional Training and Information Exchange

h. Consultative and Advisory Services

i. Research Associate Programs

1.2. The Building Science Series Publications ..

2. History -

2.1. Structures

2.2. Fire Research

2.3. Environmental Engineering

a. Heat and Moisture Transfer

b. Mechanical Systems _-

c. Thermal Environment in Structures

d. Architectural Acoustics

e. Plumbing and Water Systems

2.4. Materials and Composites

a. Organic Materials and Composites _-

b. Inorganic Building Materials

c. Ceramic and Metallic Building Materials

2.5. Codes, Standards, and Specifications

3. Current Programs and Objectives _- 30

3.1. Organizational Change

3.2. Occupation of New Facilities

3.3. Changes in Program Emphasis

3.4. Current Research and Development Programs

4. Future Objectives _-

4.1. Performance Requirements and Standards

4.2. Broadening the Disciplinary Scope

4.3. Technological Support to Federal Agencies.

4.4. Professional Liaison and Information Exchange

4.5. New Facilities

5. References -

5.1. Structures

5.2. Fire Research

5.3. Heat and Moisture Transfer

5.4. Mechanical Systems

5.5. Thermal Environment in Structures

5.6. Architectural Acoustics

5.7. Plumbing and Water Systems

5.8. Organic Materials and Composites _-

5.9. Inorganic Materials

5.10. Ceramic and Metallic Materials

5.11. Building Systems and Subsystems

6. Index 



\title{
Building Research at the National Bureau of Standards
}

\author{
Paul R. Achenbach
}

\begin{abstract}
The history of building research and technology at the National Bureau of Standards is as long as the history of the institution itself. The participation of the Bureau in the application of science and engineering to building materials and components played an early and important role in the development of steel and reinforced concrete as structural materials; in the understanding of the physics and chemistry of cement, lime and gypsum; in the evaluation of the fire propertics of building components; in safe plumbing practices; in laboratory evaluation of the effects of weather on deterioration of building materials; and in measurement of the heat and sound transmission properties of building materials and constructions. The central and continuing objectives of the building research program are shown to be the development of new technical information and new measurement methods for building materials, components, and systems, and the application of this knowledge to the specifications for Federal procurement, to the national standards of the building industry, and to the building code structurc of the nation. The Bureau has served as a major technical resource in three large-scale national efforts to accelerate the construction of economical and effectivc buildings for housing and commercial purposes. One of these efforts is currently in progress and is characterized by an emphasis on the design of buildings to meet the performance requirements of the user rather than through the specification of the properties of the materials used.
\end{abstract}

Key words: Building materials; building performance; building research; building systems; building technology; history.

\section{Introduction}

The National Bureau of Standards has been actively engaged in the scientific study of building materials and systems throughout its history. In the third decade of the twentieth century and again in the fourth decade, the Bureau served as an important technical resource in national efforts to stimulate and encourage the building industry to produce a larger amount of economical and effective housing and other buildings. A third such effort is currently in progress, with a strong emphasis on evaluation of the perform. ance of building systems as a basis for accepting innovative constructions into practice.

Soon after the Bureau was established in 1901, the departments and agencies of the Federal Government recognized the value of having building materials being procured for government use tested by the $\mathrm{Na}$ tional Bureau of Standards. Although the testing of proprietary products was not identified as a function of the Bureau in its founding legislation, this activity became a dominant one in the first two decades of its existence. During this same period the need for standardized test procedures became urgent because of the rapid industrial growth of the United States and the competition between well-established European industries and new industries in this country.

The programs that began as simple testing were gradually reoriented to include the development of test procedures, new instrumentation, and specifications, and finally into full-fledged technological research programs. This evolutionary progress from testing to research took place with respect to many building materials including cement, clay, lime, structural iron and steel, reinforced concrete, brick, building tile, gypsum, insulation, protective coatings such as asphalt, paints and varnishes, and other products. Through such a process, the National Bureau of Standards became a major contributor to the early application of science and technology to building materials and to the building process.

The Bureau's building research and technology program has been carried out under a number of different organizational arrangements during its 68-year history, but it has been administered principally by a single technical division since 1947. The Building Research Division, one of several technical divisions of the Institute of Applied Technology, is comprised of seven sections with responsibilities in the areas of structures, fire research, environmental engineering, materials durability and analysis, codes and standards, building systems, and scientific and professional liaison. Some technical programs of less direct interest to the build. ing industry are still conducted in divisions of the National Bureau of Standards other than the Building Research Division. The mission, present activities, and future objectives of the Building Research Division will be discussed within the framework of present-day programming and organization, whereas the history of building research at the National Bureau of Standards will be described under technical subjects on which there has been continuous identifiable effort for some decades in the past.

\subsection{Mission of the Building Research Division}

The legislative authority for the National Bureau of Standards to carry out building research and technology is contained in Public Law 177 enacted on March 3, 1901, and the complete restatement of the Bureau's functions contained in Public Law 619, enacted on July 22, 1950. The portions of this latter enactment relating to building research and technology are as follows:

"Sec. 2. The Secretary of Commerce (hereinafter referred to as the "Secretary') is authorized to undertake the following functions: 
(c) The development of methods for testing materials, mechanisms, and structures, and the testing of materials, supplies, and equipment, including items purchased for use of Government departments and independent establishments.

(d) Cooperation with other Governmental agencies and with private organizations in the establishment of standard practices, incorporated in codes and specifications.

(e) Advisory service to Government agencies on scientific and technical problems.

(f) Invention and development of devices to serve special needs of the Government.

"In carrying out the functions enumerated in this section, the Secretary is authorized to undertake the following activities and similar ones for which need may arise in the operations of Government agencies. scientific institutions, and industrial enterprises:

(2) The testing, calibration, and certification of standards and standard measuring apparatus;

(14) the study of new technical processes and methods of fabrication of materials in which the Government has a special interest; also the study of methods of measurement and technical processes used in the manufacture of optical glass and pottery, brick, tile, terra cotta, and other clay products;

(15) the determination of properties of building materials and structural elements, and encouragement of their standardization and most effective use, including investigation of fire-resisting properties of building materials and conditions under which they may be most efficiently used, and the standardization of types of appliances for fire prevention;

(18) the prosecution of such research in engineering, mathematics. and the physical sciences as may be necessary to obtain basic data pertinent to the functions specified herein; and

(19) the compilation and publication of general scientific and technical data resulting from the performance of the functions specified herein or from other sources when such data are of importance to scientific or manufacturing interests or to the general public, and are not available elsewhere, including demonstration of the results of the Bureau's work by exhibits or otherwise as may be deemed most effective."

In the broadest sense, the Building Research Division seeks to promote economy and effectiveness in the design. construction. and use of buildings and in the manufacture of building materials and systems by pursuing the following activities:

1. Aiding designers, manufacturers, builders, and users, through scientific investigation, to a better understanding of the technical characteristics of building materials, components, and systems with respect to strength, safety. durability, and environmental effectiveness;

2. Collaborating with manufacturer, consumer, professional, governmental, and regulatory groups in defining logical performance requirements for building materials, components, and systems:

3. Developing test procedures to evaluate these tech- nical characteristics that will serve as an equitable measure of performance;

4. Advising, assisting, and leading committees of code-writing organizations, and groups that prepare standards and specifications, in the adoption and use of performance language in the commerce of building construction, so as to promote innovation in the design and use of building elements and to provide buildings more fully responsive to the needs of the user.

In carrying out its mission the Building Research Division utilizes the disciplines of engineering, mathematics, and the physical sciences in the study of build. ing materials and systems themselves, and employs the evaluative techniques of architecture and the behavioral and social sciences to determine how well the total structure meets the needs of the user.

In its relation to the building industry the Division serves as a technical resource in elucidating the important characteristics of building materials and systems, as an advocate and collaborator in the standardization process, and to a significant degree as a service organization in the development of test procedures and scientific data that can be used in standards and specifications. The Division does not develop new products, materials, or systems for commercial use, nor establish the performance limits that determine their acceptability for particular applications.

The program of the Division has eight subelements, each comprising a type of service or a functional aspect of building performance. Many of these subelements cover activities carried out in more than one administrative Section. The eight program subelements are:

a. Physical and Functional Environment

b. Strength and Safety in Structures

c. Materials Durability and Analysis

d. Exploratory Research

e. Application of the Systems Engineering Process

f. Building Codes and Standards

g. Professional Training and Information Exchange

h. Consultation and Advisory Services

A brief description of the scope of each of these eight program subelements follows.

\section{a. Physical and Functional Environment}

The principal subdivisions of this program sub. element are (a) development of technical information, test methods, and performance criteria for the components of the building itself and the service systems installed therein that combine to determine the interior physical environment, and (b) studies of the reactions, responses, and behavior of the building occupants as a basis for determining the user's needs in his living and working environments.

Areas of investigation currently being emphasized include the following:

(a) The shielding properties of the building envelope with respect to heat and moisture transfer, noise and light absorption and transmission, and air and dust infiltration.

(b) Analysis of the parameters of outdoor climate and the frequency and duration of simultaneous 
occurrences of the various factors at significant design levels.

(c) Performance of the environmental control systems and equipment.

(d) The parameters and thresholds of visual, acoustical, and thermal discomfort of building occupants, and their correlation with the physical environment in a building.

(e) Environmental performance of whole buildings of innovative design.

(f) The hydraulic capacity of water and plumbing systems and the load patterns and diversity which they must accommodate in use.

(g) Field and laboratory studies of the character. istics of noise sources inside and outside of buildings, and the noise transmission properties of building elements or whole buildings.

(h) Systems and techniques for improving the quality of the air in buildings.

\section{b. Strength and Safety in Structures}

This program subelement is comprised of investi. gations of the properties of building materials, subsystems, components, and whole structures that affect their strength, deformation, and integrity under normal exposure to climate and usage, and under the unusual conditions of fire and seismic disturbance. Laboratory and field investigations are conducted to

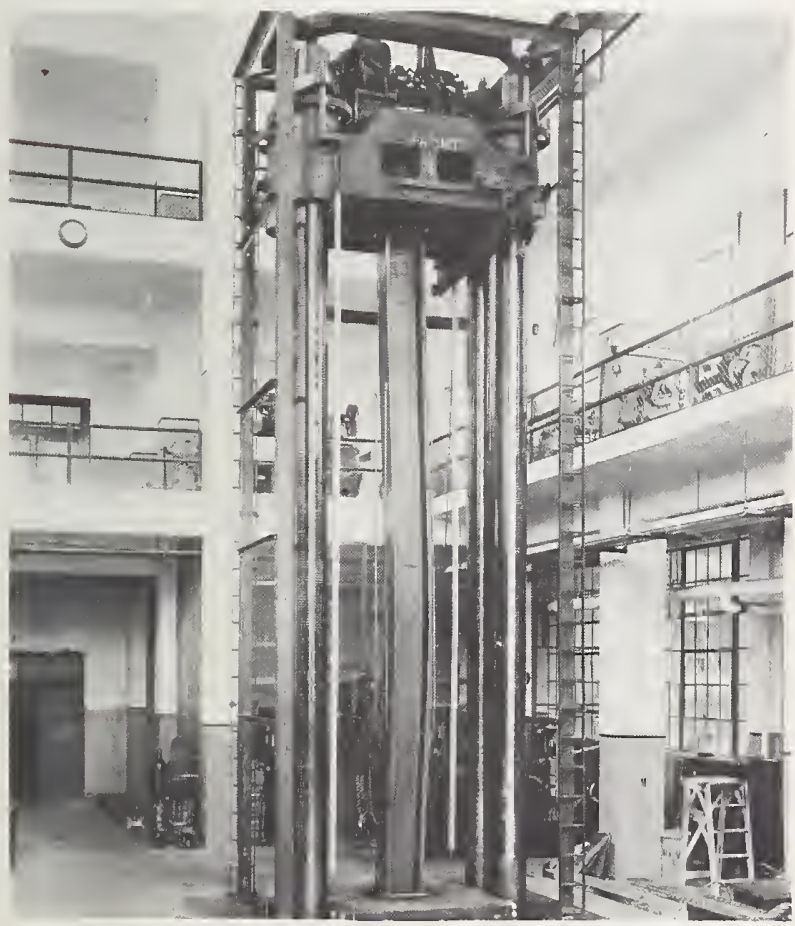

This column specimen is one of 69 tested during an investigation of the strength of large $H$-shaped columns. It was part of a study of correlations between tensile properties of mate. rials, theories of column behavior, and experimental investigations. The failure shown here, after sustaining a load of $3,280,000-l b$. force, was in single curvature (note large deflection of the central portion to the right) and typical Euler column behavior for flat ended specimens. evaluate the statistical probability of various combinations and intensities of structural and combustible loads occurring in different types of building use and occupancy. Performance requirements and test procedures are developed to evaluate strength, deflection, and safety characteristics independently or in combination at various levels of structural complexity.

The program incorporates the following broad categories of activities and utilizes laboratory and field experiments, and analytical and computer techniques for their execution:

(a) Investigation of the behavior of structural sys. tems of masonry, concrete, metal, wood, plastics, and various combinations of these materials as a basis for developing test methods, improved design criteria, and performance requirements for these systems.

(b) Studies of the loading of various types of buildings with respect to dead load, live load, wind load, shock and vibration, seismic load, and combustible contents as a basis for statistical criteria for the severity of structural and fire exposure during use.

(c) Investigations of the properties and performance of materials, systems and structures with respect to ignition, flame spread, smoke generation. toxic combustion products, smoke distribution, fire penetration, and structural failure under fire conditions, as a basis for development of test methods and performance requirements for their fire resistance and safety characteristics.

\section{c. Materials Durability and Analysis}

The broad objective of this program subdivision is to investigate the physical and chemical properties of organic, inorganic, and metallic building materials in all types and levels of aggregation, that are related to durability and deterioration when exposed to indoor environment and to normal and probable abnormal climatic conditions and usage, as a basis for predicting useful life. The scope of these investigations covers all the major components of buildings such as floors, walls, roofs, foundations, windows. and doors as well as metals, coatings, films, sealants, and composites of two or more materials. Five avenues of exploration are involved:

(a) Observation of the deterioration of buildings and building elements in use in a real-time scale and in the existing environment of human activities and climate.

(b) Exposure and periodic examination of samples of materials or systems on racks in selected climatic zones representative of rather severe values of certain weather parameters.

(c) Development of accelerated laboratory test procedures in which materials are exposed to cyclic patterns of conditions that simulate to a greater or lesser degree the natural weather cycles of the country.

(d) Research to more adequately reproduce natural weather phenomena and existing air contamin- 
ants in the laboratory apparatuses used for accelerated weathering tests.

(e) Efforts to correlate the observed results from the four techniques in items (a) to (d).

\section{d. Exploratory Research}

Exploratory research to improve the understanding of physical or chemical processes that may have application to building science is carried out in selected areas such as the following:

(a) Analysis of combustion products of inhibited flames using gas chromatography and other techniques to develop information and hypotheses on the reaction mechanisms present in inhibited flames and those that can be used as flame inhibitors.

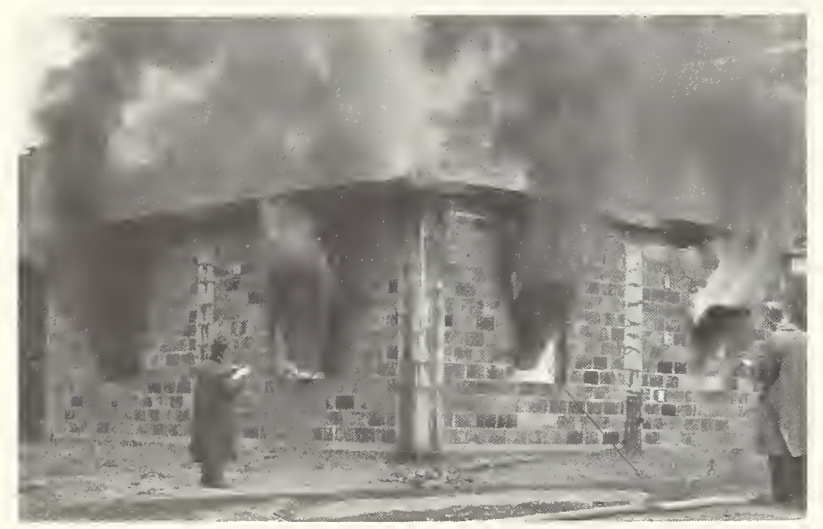

Measuring the duration and intensity of a fire during a burnout test simulating a severe fire in a storage warehouse, with known amounts of combustible loading on the interior. Tests of this type determine the temperatures to which it is proper to subject building materials and constructions in fire test furnaces, and serve as a guide in applying the results of such furnace tests to building design.

(b) Investigate the basic mechanisms of simultaneous transfer of heat, vapor, and air through fibrous, porous, and composite building constructions.

(c) Study the modeling of natural convection in room-shaped cavities with one or more surfaces heated or cooled relative to the other surfaces. Develop analytical and photographic techniques for displaying or representing convection patterns.

\section{e. Building Systems Development}

In this program subdivision, the systems engineering process is applied to the design and construction of Federal buildings through studies of the physical and functional interrelationships among building components and subsystems, as a means for detecting and developing potential economies and improvements by designing the building as a unified system. This process involves utilization of a segment of selected fullscale Federal building programs to investigate the functional requirements of the users and to develop performance specifications responsive to these require- ments to stimulate the development of innovative systems by industry to meet these requirements; to evaluate the proffered systems for compliance with the specifications and for potential cost benefits; to investigate the effectiveness and economy of selected systems by incorporating them in a portion of a Federal building program; and to provide feedback of performance results into the design process for later building programs.

\section{f. Building Codes and Standards}

Most of the technical information and the test procedures developed in the Division are suitable for use by public and private organizations that draft and promulgate standards, codes and specifications. The dissemination of this information takes place principally through publications and through membership and participation of the professional staff in committees and task groups of national scientific and professional societies, national standards organizations, manufacturers' associations, and code and specification groups. The committee activity includes interpretation of technical information, recommending test procedures. leadership in the preparation of technical documents, furnishing administrative support and sponsorship of standardizing activities, and cooperation in efforts to attain uniformity in building standards and regulations. International activities involve representation of the United States position in international and Pan-American standards-writing bodies and in technical assistance to underdeveloped countries in the preparation of national standards and codes.

Another activity in this program area is the operation of reference laboratories for cement, concrete, aggregates, soils, and bituminous materials. In accordance with a prearranged schedule and when requested. teams of trained personnel from the Division visit testing laboratories for these materials at recurring intervals to check test equipment and calibrations and to observe the techniques followed by the staff in carrying out the test procedures. A letter report is furnished to the laboratory stating the observations of the review team, setting forth any deficiencies noted, and providing recommendations for their elimination. To assist the laboratories in assessing their overall performance, pairs of reference samples are distributed periodically, from which the individual laboratory can judge its operations.

\section{g. Professional Training and Information Exchange}

The purpose of this program subelement is to promote the application of the technical information in building science generated in the Division and elsewhere, to the needs of the Government, industry, and the nation through various channels of communication, including:

(a) Publication of information in the regular periodicals and special publication series of the National Bureau of Standards, and in handbooks and professional society and trade journals; 


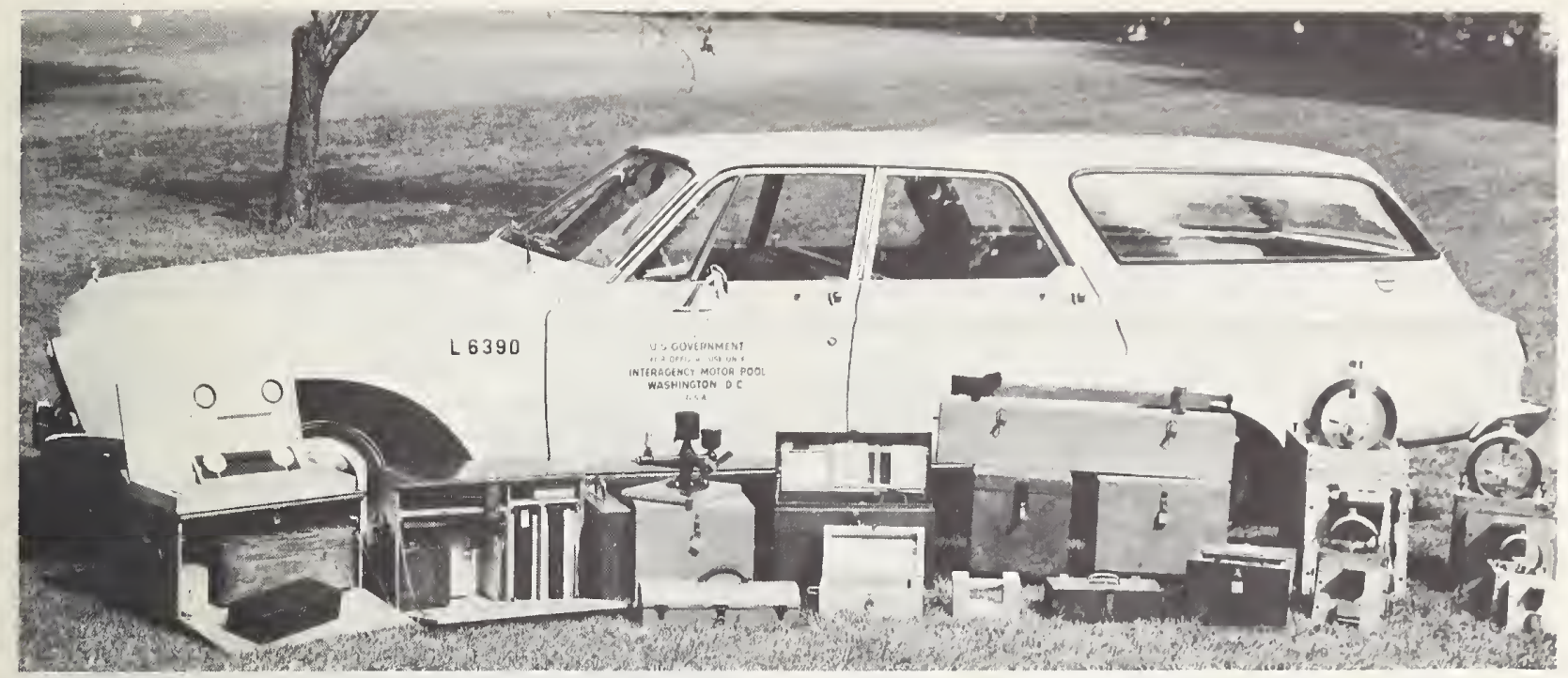

The equipment employed by the NBS Cement and Concrete Reference Laboratory, sponsored by ASTM, to check test methods and apparatus used in cement and concrete testing laboratories throughout the United States and Canada.

(b) Participation in professional society committees, standards committees, seminars, and conferences related to building science;

(c) Investigation and analysis of foreign building technology, and support of information classification and retrieval activities;

(d) Organization of interdisciplinary seminars to foster interaction between different segments of the building industry and research workers;

(e) Participation of professionals in the building industry as guest workers in the scientific programs of the Division; and

(f) Temporary assignment of Division personnel to active work in selected parts of the building industry.

\section{h. Consultative and Advisory Services}

The services of the Division staff are available to Federal agencies, the technical community, and the building industry, through consultation and conference. To maintain the competence of the staff in the development of test methods, and to make this competence available to agencies of the Federal govern. ment, a program of testing building products for qualification relative to established standards and specifications or to evaluate the important characteristics of new materials or systems, is conducted on a reimbursable basis.

In-house research and contacts with outside experts contribute to the formulation of appropriate long-range technical programs for the Division. Consultation with individuals engaged in similar research activities, and in the application of technical knowledge to building design and construction, keeps $\mathrm{Di}$ vision personnel informed on current problems in the building industry.

\section{i. Research Associate Programs}

The Research Associate Program of the National
Bureau of Standards provides a mechanism for cooperation between research workers in the building industry and their counterparts in the Division on technical investigations of mutual interest. Under this program a manufacturer, a manufacturers' association, or a technical group supports one or more employees working in the Division laboratories under the supervision of Division staff on the development of test procedures, performance requirements, or technical data related to some type of building material or system. The results of the studies are published for general use under the same procedures employed for other Division programs. Current and recently completed programs of this type are related to the durability of asphalt roofing assemblies, plastics, and porcelain-enameled metals; measurement of the heat flux at the interior surfaces of buildings; smoke measurement methods and the effect of geometry of an enclosure on the gas flow pattern produced by an internal fire; the performance of masonry wall systems made with organic-inorganic mortar; and the application of systems engineering to building design.

\subsection{The Building Science Series Publications}

The Building Science Series of publications was initiated in 1965 to provide a specific medium for dis. seminating technical information developed at the $\mathrm{Na}$ tional Bureau of Standards on building materials, equipment, systems, and whole structures. The series presents principally new technical data on building materials, results of investigations of important performance characteristics of building subsystems, quantitative analysis of the interaction of the various functional characteristics of building subsystems, identification of performance criteria for building systems and subsystems, and the development of analytical and laboratory test procedures for evaluating their performance in relation to use. These publications are directed toward the design, manufacturing. 
and construction segments of the building industry; standards organizations; officials responsible for building codes and specifications; architects, engineers, and technologists concerned with the properties of building materials and systems.

This publication describes the organization and mission of the Building Research Division, presents a brief history of building research at the National Bureau of Standards, cites some of the principal contributions made to building science in the past, and suggests how the present and future programs in building research can more adequately respond to the needs of the industry and the nation.

\section{History}

A number of different eras can be recognized in the building technology and research program during the 69 years of the Bureau's existence. While the terminal boundaries of these eras are not clearly defined, their beginnings were usually dependent on the initiation of some new national program related to building construction, to the involvement of the United States in war, or to a change in the organizational structure of the Bureau.

During the first two decades of its operations, the National Bureau of Standards made many contributions to standards and methods of measurement that were of interest to the building industry. However, these studies were carried out to meet specific recognized needs for new technical information on the physical properties of building materials, and were not conducted as a coordinated program in building tech. nology.

In 1921 a Division of Building and Housing was created at the National Bureau of Standards to coordinate scientific, technical, and economic research in building; to simplify and standardize building materials; and to revise state and municipal building codes. The information produced by these programs was used by a Building Code Committee established in the Department of Commerce, and by a Division of Building and Housing established the same year in Secretary of Commerce Herbert Hoover's office to stimulate the building industry and postwar industrial recovery. In the same year Secretary Hoover established Divisions of Simplified Practice, Specifications, and Trade Standards at the Bureau. These four Divisions had a strong influence on building practices for the next decade, until the depression forced a large reduction in activity and personnel.

In 1921 the Research Associate plan, previously described, was implemented by the National Bureau of Standards to provide a means for cooperation between industry and the Bureau in carrying out research studies of mutual interest. In many cases the industry. sponsored research personnel who were employed as Research Associates returned to an industry laboratory after a few years at the Bureau to provide leadership there. Some of the earliest Research Associateships represented facets of the building industry, and a number of these associateships have functioned continously over several decades.
In 1937, soon after federal insurance programs for house construction were initiated, a coordinated program on low-cost housing research at the National Bureau of Standards was authorized by the Congress. This program was formulated in cooperation with representatives of the Federal housing agencies through a subcommittee of the Central Housing Committee. It included investigations of the structural properties, fire properties, and durability of building components; the chemical, physical, and engineering properties of building materials and mechanical equipment; simplified practice recommendations; and commercial standards. The onset of World War II caused this program to be altered into studies of the methods and means for conserving strategic materials in building construction and in serving the emergency needs of the construction industry under war conditions.
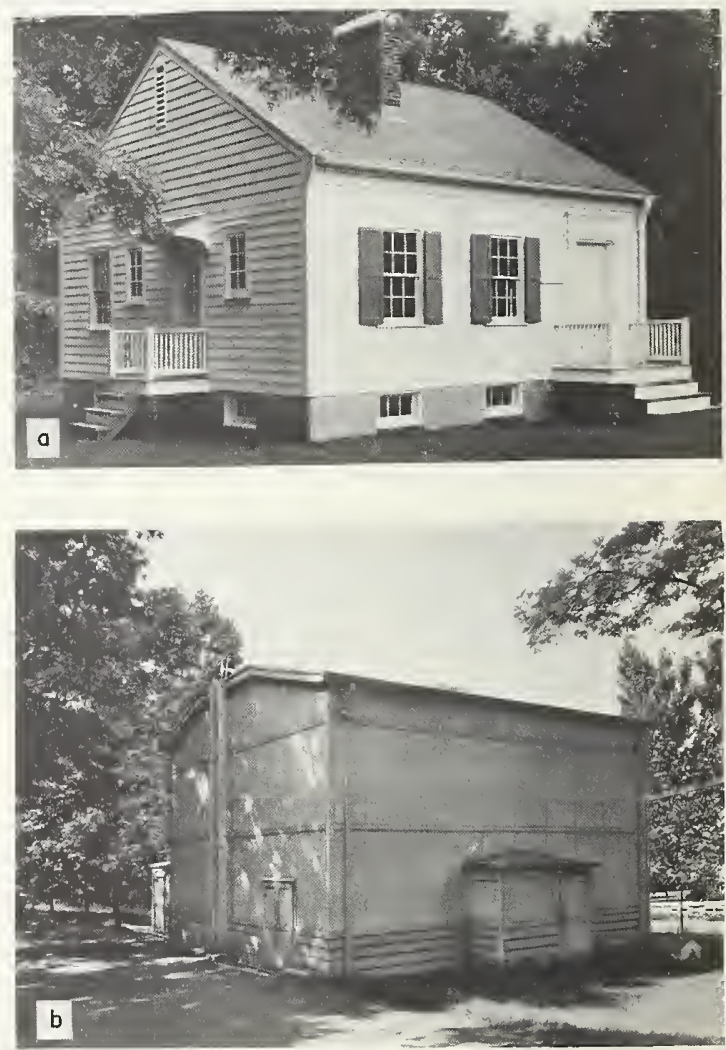

(a) A four-room house built on the Bureau grounds in Washington in 1940 to study air infiltration, heat pump performance, and the temperature distribution produced by various heating systems used in low-cost housing.

(b) An insulated enclosure built around the test house shown above to permit summer or winter temperatures to be maintained around the house at any time during the year.

When the low-cost housing research program was initiated in 1937, a new series of publications, the Building Materials and Structures Reports (BMS). was inaugurated to serve as a principal publication organ through which the technical and scientific information on building technology produced by the program could be effectively distributed to the building 
industry and the public. This series of publications, comprising 152 separate reports during the twenty. one years of its existence, was eminently successful for the purpose, and was highly regarded by the building industry. It included issues on the functional properties of building components, design information, handbook data, results of field surveys, and several comprehensive manuals on technical properties of building materials and systems.

In 1947 a Building Technology Division was formed under the leadership of D. E. Parsons, by bringing together smaller organizational units devoted to structural engineering; fire research; heat transfer and mechanical systems; wall, floor, and roof coverings; and codes and standards; that had previously been located in other divisions of the Bureau. The name of the Division was later changed to the Building Research Division, and its scope was augmented by stepwise accretion of working units on paints and organic coatings, organic flooring materials, inorganic building materials, metallic building materials, plumbing, and building systems. In accordance with broad Bureau policy during this era, the principal effort of the staff was directed away from extensive study of proprietary materials and assistance in the preparation of specifications for building materials and systems, toward investigation of more fundamental principles of structural engineering, fire safety, durability of materials, and environmental systems and the development of test procedures for materials and systems that would be useful in national standards and building codes.

A reorganization of the National Bureau of Standards into three Institutes in 1964 placed the Building Research Division in the Institute for Applied Technology, and resulted in some broadening of mission and reorientation of objective. The current activities and future objectives of the Division program are described in later chapters of this report.

\subsection{Structures}

Early research at the National Bureau of Standards in structures and structural engineering pertained to masonry, reinforced concrete, and steel. In 1911 Humphrey and Losse [1] ${ }^{1}$ published the results of their pioneering investigation of strength and related properties of 333 reinforced concrete beams. The data obtained in this investigation assisted materially in the formulation of the first widely used code of practice for the design of reinforced concrete structures, issued in 1916 as the Report of the Joint Committee on Concrete and Reinforced Concrete. In 1916 Bragg [2] investigated and reported the compressive strength of large brick piers, and subsequently Whittemore and Stang investigated the compressive strength of sandlime brick walls. In 1924 the Building Code Com. mittee of the Department of Commerce issued their "Minimum Requirements for Masonry Wall Construction." As part of the background for the Committee's selection of permissible working stresses for brick ${ }^{1}$ Figures in brackets indicate the literature references at the end
of this paper. masonry, a compilation of all available information on strength of brick masonry was prepared. The wide divergence in these data made it evident that additional information was needed. The Bureau, accordingly, in cooperation with the Common Brick Manufacturers' Association of America, constructed and tested a large number of full-scale brick walls in which the variables were the strength of brick, strength of mortar, effect of wetting, and workmanship. The work was carried out under the direction of Stang, Parsons, and McBurney, and the results of this cooperative study, published in 1928 [3], added substantially to the information needed in drafting model building codes $[4,5,6,7]$.

In the period from 1915 to 1917 the National Bureau of Standards conducted tests [8] of more than 200 steel columns, in collaboration with the American Society of Civil Engineers and the American Railway Engineering Association, to provide data on the ultimate strength and safe working strength of steel columns. Basquin [9] discusses in detail the semielastic behavior of steel columns under load, using the data from this group of tests. In a second series of tests reported by Tuckerman and Stang [10], the Bureau studied 69 H-shaped steel columns of three lengths and five different sections, in collabo. ration with the American Bridge Co. and two manufacturers. These tests showed that there was a good correlation between column strength and the yield point of the materials used, and that there was only a small decrease in strength with increasing slenderness of columns. Studies [11] in the early 1940's of 112 columns in which perforated cover plates were substituted for lattice bars or batten plates revealed the contribution of such cover plates of different width to thickness ratios to the strength and stiffness of boxtype columns. A survey and appraisal by Jakkula and Stephenson [12] of research work on columns between 1920 and 1947 indicates that approximately half of the column tests that produced significant contributions to design procedures were carried out by the National Bureau of Standards.

An extensive investigation [13] of the factors affecting the bond between mortar and brick showed that the pressure on the mortar joint, the type of mortar used, the degree of wetting of the brick, and the shrinkage of the mortar had more effect on the durability and strength of the bond than did the properties of the brick itself.

During the 1930's the Masonry Construction Section began an investigation of the durability of masonry, beginning with a study by McBurney and Richmond [14] of the properties of clay building bricks and their resistance to laboratory freezing and thawing, as well as to outdoor exposure. The data obtained in this study were the basis for the current requirements for durability in the ASTM specification for clay building brick.

During the period from 1937 to 1945 the Masonry Construction Section made extensive studies of the structural and water-permeability properties of a number of constructions of steel, masonry, and wood. in. tended for low-cost housing. The results of these studies 
were published in more than 40 issues of the Building Materials and Structures Reports. In the course of this long-range program, various test procedures were developed for testing both the materials and constructions. Many of these test methods received nationwide acceptance and became standard methods [15] for measuring the strength, stiffness, and resistance to abuse of constructions intended for walls, partitions, floors, and roofs in houses. Standard methods of testing various building materials were also developed and received wide acceptance. Methods of determining the structural properties of constructions were developed under the direction of Whittemore and Stang [16], while water-permeability studies of masonry walls were carried out by Fishburn. Watstein, and

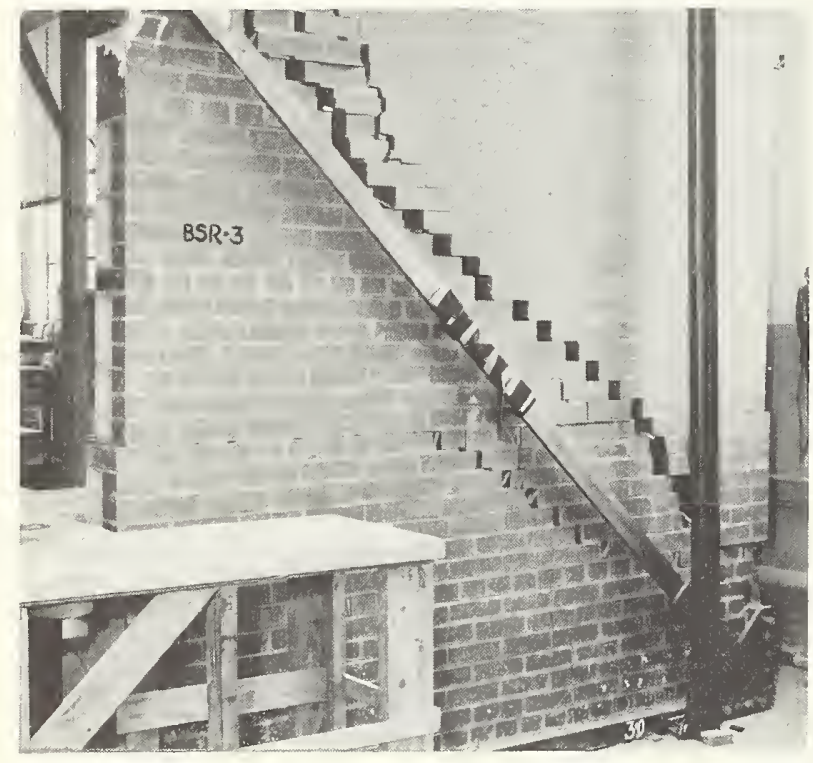

A typical zigzag path of failure of the bond between the mortar and individual masonry units of a composite wall sub. jected to a racking load.
Parsons [17].

Research on building stone was initiated in 1912 and was carried out by a separate section during the period between 1927 and 1952. The first publication [18] resulting from this program described the development of physical and chemical tests of marble and remains an important reference to architects and engineers up to the present time. Subsequent research has explored the physical properties and durability characteristics of limestone, slate, interior marble, stone flooring, and granites. The construction agencies of the Federal Government have continually used the experience and advice of the Bureau staff on problems related to the use of stone in buildings and monuments.

During the period from 1941 to 1945 , research was conducted in collaboration with the American Iron and Steel Institute to provide data that assisted the concrete reinforcing-bar industry in making important improvement in its products. The results of these studies were published by Clark [19], after which the industry agreed to produce bars that conformed to a new standard [20] for deformed reinforcing bars. The AISI Research Fellowship at the Bureau had also carried out a study that provided information for predicting the width and spacing of cracks in reinforced concrete. The investigations relating to bond, resistance to diagonal tension, and width of cracks [21, 22] stimulated many new research programs elsewhere, finally leading to major improvements in standards for design practice.

When high-yield-strength reinforcing bars became commercially available after World War II, the Building Technology Division initiated a study of reinforced concrete with high-strength deformed bars. This long-range study was carried out to determine the effects of differences in yield strengths and the nature of stress-strain relationships on the resistance of reinforced concrete beams to failure by flexure, diagonal tension, and bond. The results of these

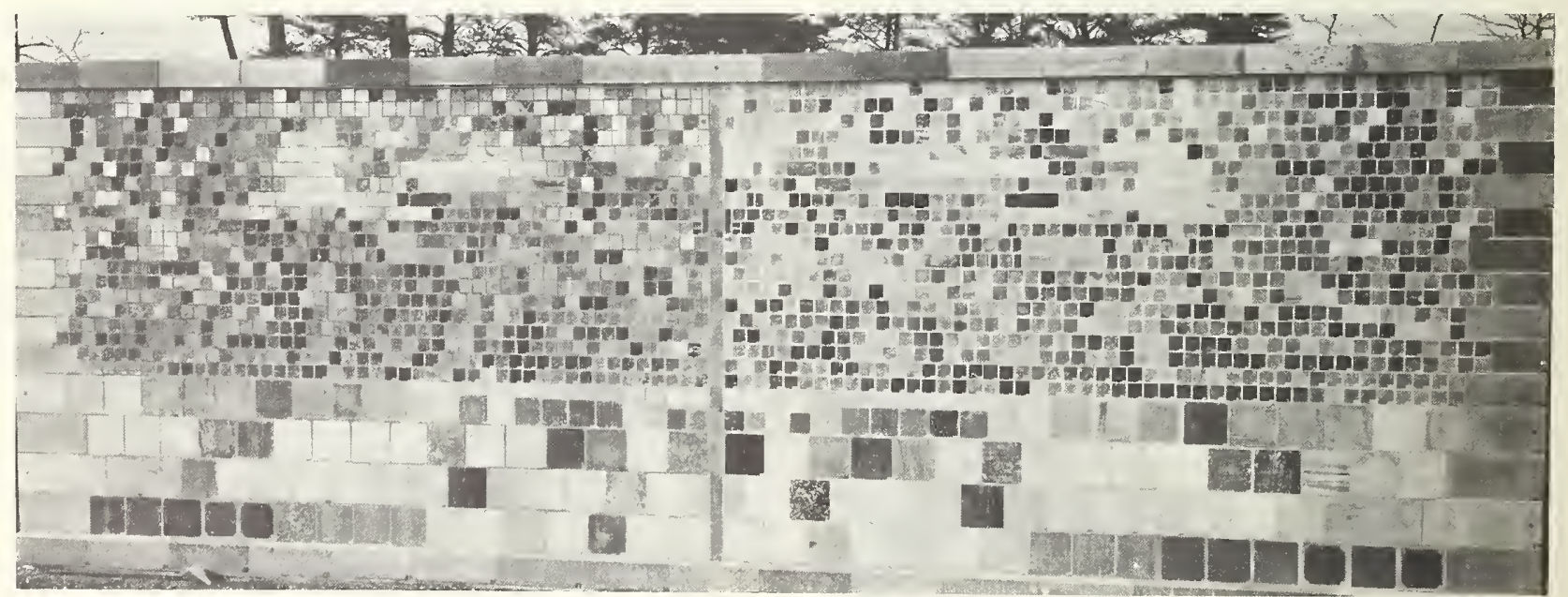

A test wall, comprised of 2352 samples of building stone supplied by 47 states in the U.S.A. and 47 foreign countries, was constructed on the Bureau grounds in 1948 to study the nature and rate of deterioration of the different stones. Structural features such as length changes, warpage, back waterproofing, and grade waterproofing were also observed in relation to weath. ering and discoloration. 


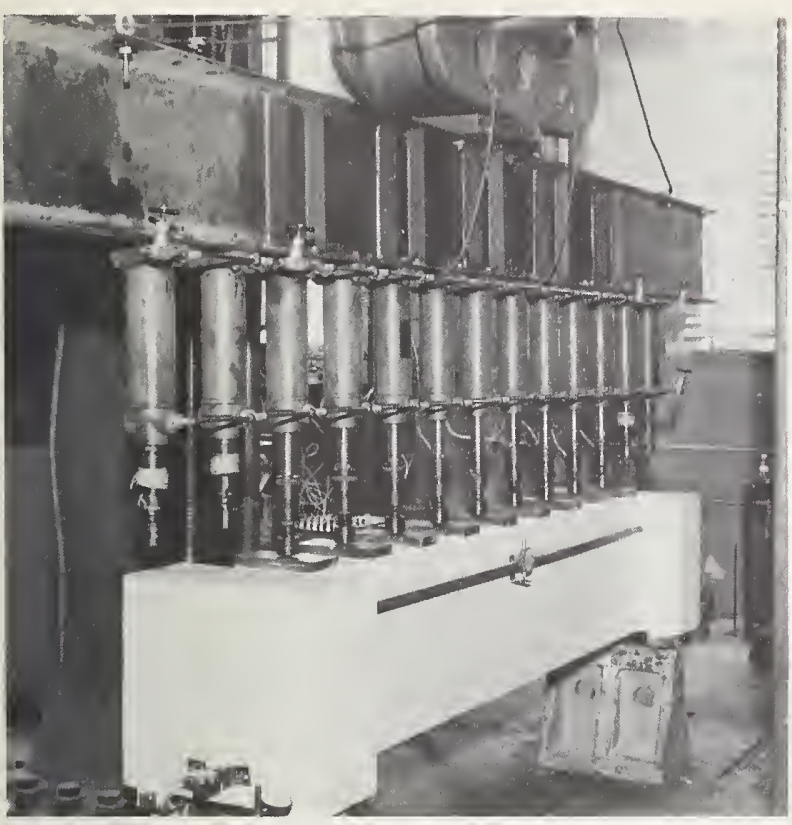

Testing a reinforced concrete beam to determine the strength of the bond between the concrete and deformed reiforcing bars. A uniform load of known magnitude was applied through nine hydraulic rams attached to a steel loading beam shown at the top of the photograph. The dial gage at midlength measured the deflection of the beam, and similar gages at the end measured the slip of the reintorcing bar and the displacement of the end of the beam. The integrity of a rein. forced concrete beam depends upon the strength and permanence of the bond between the concrete and the steel reinforcement.

studies were presented by Mathey and Watstein [23, $24,25]$.

As structural lightweight aggregate concrete became widely accepted, a need arose for information on its strength, elastic, and creep properties. During the early 1960's Reichard [26] carried out a series of studies of time-dependent deformations in concretes made with expanded clay and shale aggregates. The data obtained provide a basis for estimating creep in prestressed concrete, and a better understanding of creep phenomena.

A study of the structural properties of thin-shell constructions, a relatively new type of construction, was also carried out to provide the data needed to establish proper design stresses for building codes. The results of these studies led to the development of an American Concrete Institute standard [27] for thin-section precast concrete.

In another area of vital interest to structural engineers, the Division carried out a study of live loads in buildings [28], and in cooperation with the Weather Bureau prepared a map of wind pressures in the United States [29]. These investigations provided the data needed for establishing an American Standard [30] on design loads in buildings.

\subsection{Fire Research}

In 1910, the National Bureau of Standards, the As- sociated Factory Mutual Fire Insurance Company, and the National Board of Fire Underwriters initiated a joint undertaking to study the performance of building columns when exposed to fire. The furnace to be used for this investigation was built by the Underwriters' Laboratories in Chicago, and the Bureau em. ployed a structural engineer, S. H. Ingberg, in 1914 to carry out its part of the project. Less than a year later, a Fire-resistance Section was established at the Bureau and placed under Ingherg's leadership. A total of 106 fire tests were performed between 1917 and 1920, during this cooperative study [33].

About the same time Hull began a study [34.] of the behavior of various types of concrete when exposed to severe fire, in preparation for the construction of a group of 62 concrete columns for fire studies. This investigation [35] was carried out between 1917 and 1919 at the Pittsburgh laboratories of the Bureau in a furnace specifically designed for the purpose. The investigations on columns were quickly followed by similar studies on brick walls [36], gypsum partitions [37], hollow load-bearing wall tile [38], gypsum-protected columns [39], and treated and untreated wood partitions [40]. Many of these tests were performed on a cooperative basis, the structure or specimen being furnished by the manufacturer and the Bureau performing the laboratory work. Well over a thousand fire endurance tests were performed in all. During the course of these investigations the Bureau evolved a time-temperature curve which specified the furnace temperatures to which the elements of a structure were exposed at any time during a period of eight hours. This time-temperature curve was standardized through ASTM for use in fire tests of building constructions and has remained in use up to the present time. Building materials and constructions were classified with respect to fire endurance in relation to their behavior when exposed to this temperature pattern.

During the decade from 1920 to 1930 . Ingberg and Sale studied the compressive strength $[41,42]$ of structural steel and cast iron shapes at high temperature and the severity of fires in actual office occupancies and other types of structures [43, 44, 45]. Mitchell investigated the fire properties of proscenium curtains [46] at about the same time. The knowledge gained during this array of studies on the major components of buildings and in full-scale structures provided the foundation for a substantial fraction of the currently accepted fire endurance ratings used by building officials and incorporated in the four recog. nized model building codes $[4,5,6,7]$. In the late thirties, an interagency group was formed to sum. marize and report the findings which had developed during fire tests of building structures. The report of this committee, together with later Building Materials and Structures reports, presented the experimental results in a form suitable for use by building officials.

Since 1950, the Bureau has reduced its program of fire-endurance testing of proprietary designs of building elements to avoid competition with other laboratories. However, research in the area of fire endurance and development of test methods for fire endur. ance have continued as active projects of the Fire 


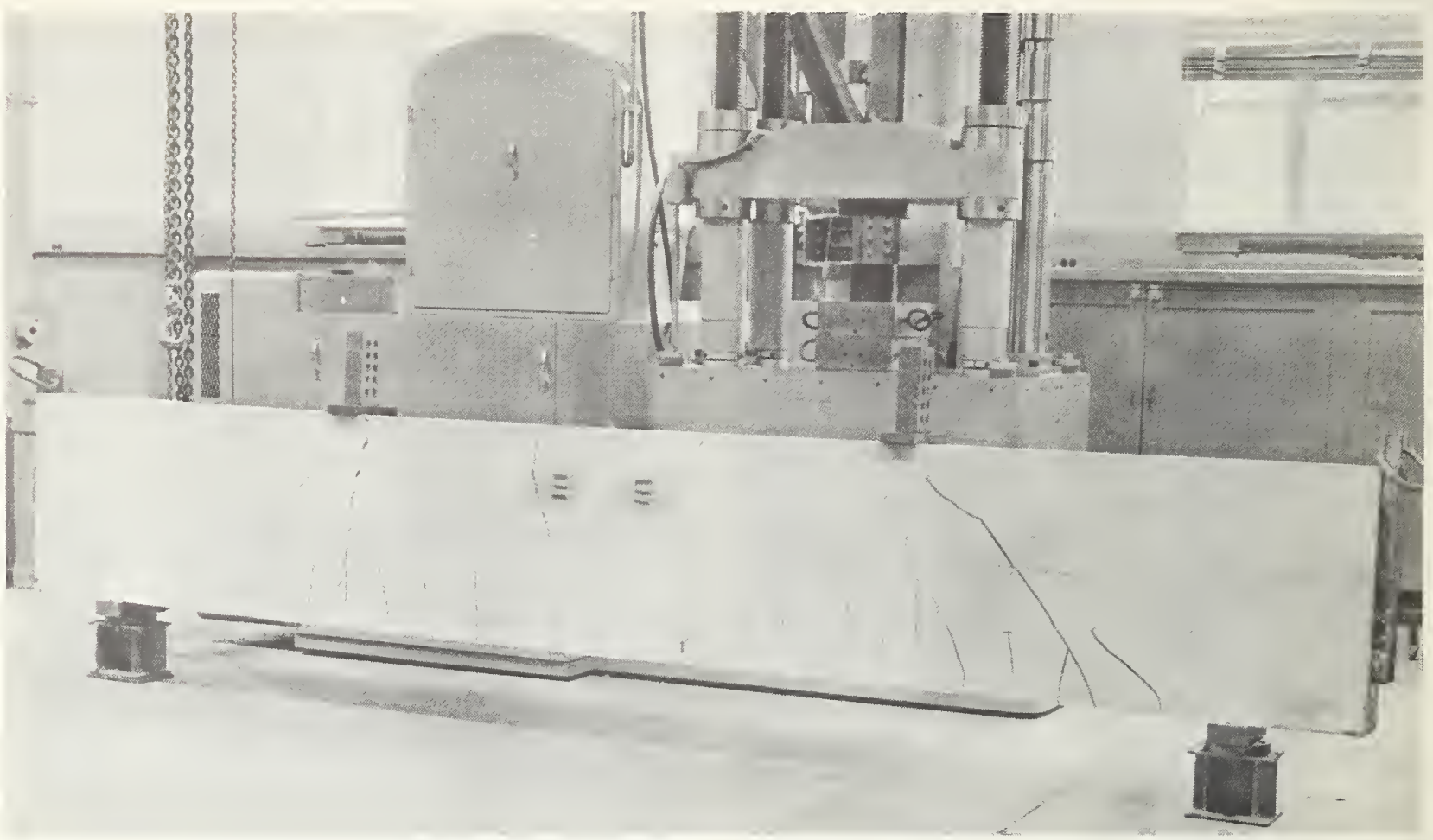

A typical crack pattern for a reinforced concrete beam is shown in this test specimen. Control of the width of cracks is an important factor in the design of reinforced concrete structures since crack width is related to the integrity and economy of reinforcement. Theoretical analysis and experimental study at NBS of the principal factors controlling the spacing and width of cracks in concrete beams have contributed to design practice.

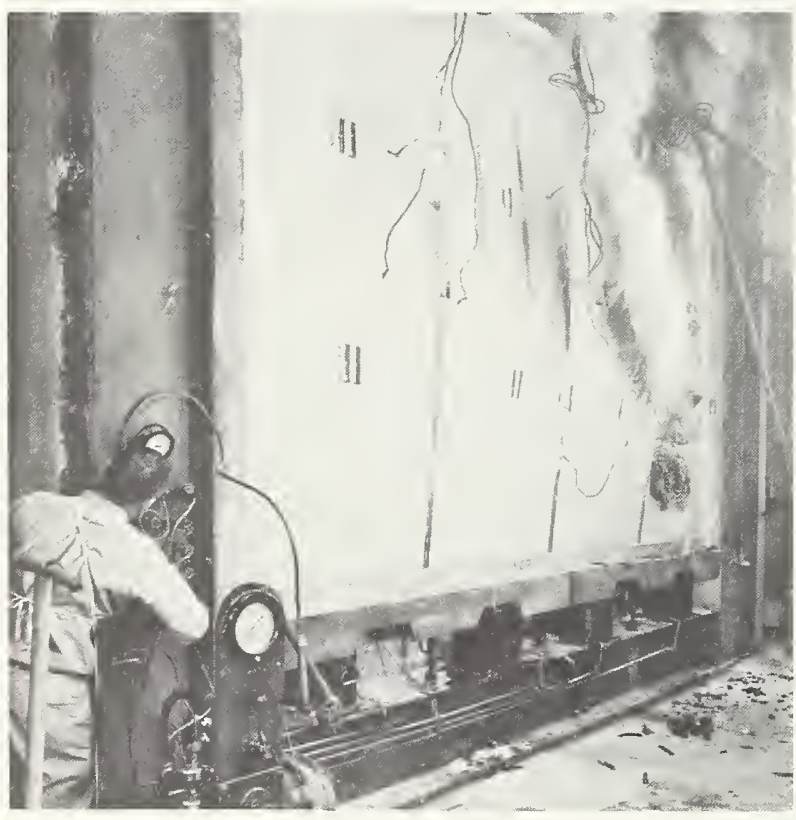

Fire endurance test of a prefabricated lightweight wall panel designed for use in arctic regions. This photograph shows the unexposed surface 55 minutes after the fire exposure started and shortly after flames broke through a joint. Initial failure, at 45 minutes, was due to excessive temperature rise as measured by thermocouples mounted under asbestos pads. The panel continued to support the structural load, applied by jacks at the bottom, throughout the duration of the test.
Research Section.

The earliest work on ignition temperature of materials was done by Brown [48] as a thesis study in the early thirties. Later Setchkin continued the development of methods for measuring ignition temperatures of liquids and solids. His methods $[49,50]$ have been adopted by other research workers and were the basis of a test method [51] for noncombustibility of elementary materials of the American Society for Testing and Materials. Cooperative studies with the U.S. Department of Agriculture were conducted on the heating and self-heating of jute and other vegetable fibers [52, 53]. Mitchell's report [54] on the selfignition behavior of fiber insulating board has been highly referenced. More recent work [55, 56] by Robertson and others has suggested new methods for measurement of the ignition or self-heating behavior of materials, and provided methods for estimating critical pile sizes and ambient storage conditions in relation to self-heating and ignition.

Mitchell made extensive investigations of the fire hazards associated with masonry chimneys [57] constructed of brick and other kinds of masonry units as well as prefabricated chimneys of metal and cementasbestos. These studies emphasized the importance of an air space between adjacent wooden members and the exterior of a chimney.

Recognition of the need for a simpler method of measurement of surface flammability of materials led to the development in the middle fifties of the now widely used radiant-panel flame-spread test method 
[58]. Research has continued on the flammability of various building finish materials, [59-62] using this method. This test method has provided manufacturers and testing laboratories with an economical means for studying flammability on a small scale for comparative purposes.

Considerable research has been directed toward understanding the mechanisms of extinguishment and inhibition of fire, and several basic and engineering studies have been reported by various investigators [63-67].

Through the years, building officials have needed means for assessing the degree to which building materials and the contents of buildings were capable of contributing to a fire. Early work [68] in this field formed the basis of a national standard [51]. More recently calorimetric methods [69] for measuring this

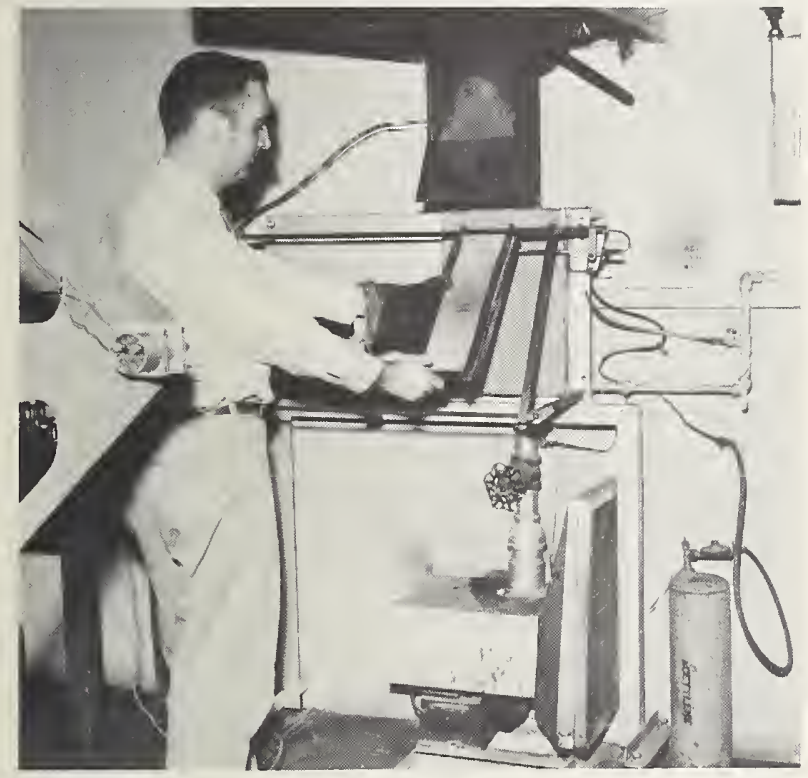

An apparatus used to study the surface flammability of materials. The specimen is mounted on the under side of the inclined panel near the center of the picture and exposed to a radiant panel at a controlled temperature immediately behind it. A sampling device and a thermocouple in the ex. haust duct above the sample are used to indicate the smoke production and rate of heat release. A flame spread index is calculated from the rate of propagation of the flame front on the specimen and the heat release rate.

property in quantitative terms have been explored, and a Building Materials and Structures Report [70] comprises one of the few published surveys of the combustible contents of buildings.

Throughout the fifty years that the National Bureau of Standards has conducted technical investigations on unwanted fires, it has made significant and useful contributions to many aspects of fire research. Staff members have served on and participated in the work of committees of the American Society for Testing and Materials, the American Standards Association, the National Fire Protection Association, and other similar organizations concerned with the fire-related properties of materials and assemblies.
Through these activities the Bureau has cooperated in the formulation of national standards and code requirements for fire safety, and these standards organizations have had ready access to the technical information and test procedures developed by the Bureau.

\subsection{Environmental Engineering}

a. Heat and Moisture 'Transfer

Work at the National Bureau of Standards on heat transfer through thermal insulation and building materials began about 1910 following a request by the American Society of Refrigerating Engineers to provide the coordinated and usable data pertaining to heat transmission in insulation needed for design pur. poses. However, a precise method for measuring heat transmission through insulation was not available, and the first guarded hot-plate apparatus for this purpose was conceived and built at the National Bureau of Standards in 1912.

Prior to the development of the guarded hot-plate, heat transfer through insulation had been determined by methods in which heat was transferred through panels of insulation from warm air on one side to cool air on the other. The results of tests of this type were in many cases expressed as thermal conductivities, but are now defined as thermal transmittance values. The first important publication in this field by Dickinson and Van Dusen in 1916 [76] was described as containing accurate determinations of heat flow through air spaces and through 30 insulating materials.

Since 1912, a number of improvements have been made in the hot-plate method of measuring thermal conductivity. The guarded hot-plate apparatus currently in use at the Bureau was built about 1929 by Van Dusen. In 1945 the American Society for Testing and Materials formally adopted the guarded hotplate method as a standard test method [77]. In 1947, Robinson and Watson extended the temperature range of the guarded hot-plate apparatus and in the next few years completed a round-robin of thermal conductivity tests of insulations among laboratories, jointly sponsored by the American Society of Heating and Ventilating Engineers and the Bureau [78]. This series of tests clearly demonstrated the need for suitable means to calibrate the apparatus of industrial and other laboratories. Shortly thereafter a program was devised for supplying measured samples of suitable insulating materials for calibration purposes. About 300 laboratories have been served to date, resulting in a considerable improvement in the quality of thermal conductivity data on insulating and build ing materials reported in technical journals and handbooks.

The Bureau has gained national and international recognition for leadership in the field of thermal conductivity measurement. Literally thousands of thermal conductivity tests on a variety of materials have been made available to the engineering and scientific professions and have been incorporated in handbook tabulations [79]. 
In the period from 1915 to 1934, Van Dusen and Shelton developed a comparative type of apparatus for measuring the thermal conductivity of metals up to a temperature of $600^{\circ} \mathrm{C}$. Thermal conductivity data on a number of irons and steels were published. Later, an absolute method for measuring the thermal conductivity of metals over a temperature range from -150 to $850{ }^{\circ} \mathrm{C}$ was developed by Robinson and Watson. Innovations, including computer analysis, improved results to an estimated inaccuracy of 1 per-

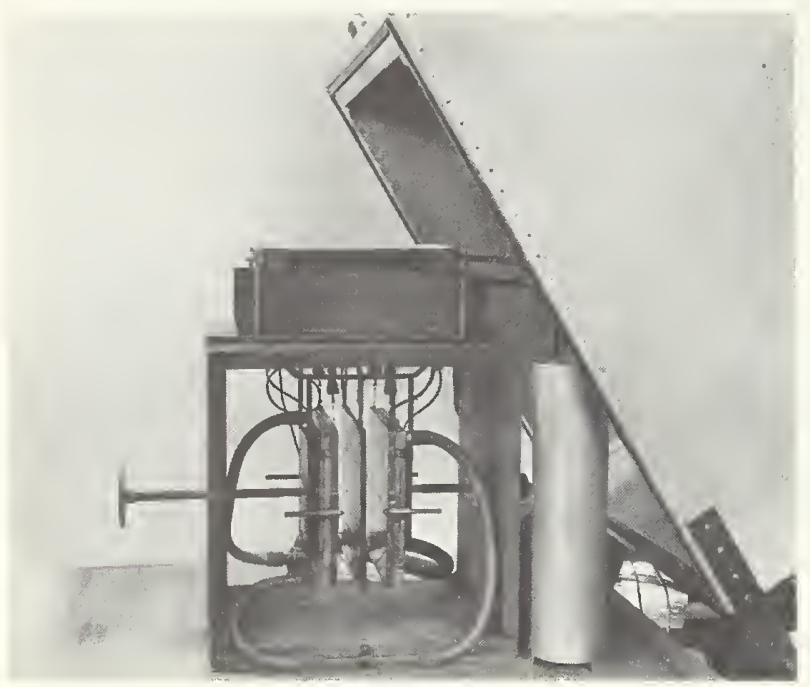

The National Bureau of Standards Guarded Hot Plate ap. paratus used to determine the thermal conductivity of samples of thermal insulation for buildings and as a reference standard for a round-robin series of thermal conductivity mea. surements among various U.S. and foreign laboratories. The central plate in the picture is the heating unit which is peripherally surrounded by separate guard portions to eliminate edge heat transfer. On either side of the heating unit is a cooled plate through which cold liquid is circulated. Identical specimens of insulation in sheet form are clamped between the two sides of the heating unit and the cooled plates. By careful control of the temperature of the guard sections during a test, the paths of heat flow through the insulation specimens are made perpendicular to the faces of the specimen.

cent. A description of the method, and a study of the effect on thermal conductivity of the percentage of nickel in iron-nickel alloys was published in 1961 [80].

A major effort to provide standard or reference thermal conductivity samples for calibration purposes over broad ranges of thermal conductivity and temperature of materials was initiated in 1958. This program involves development of new or improved test methods and apparatus, as well as selection of suitable materials. Illustrative examples include a new conductive disk method [81] for measuring the thermal conductivity of insulations which is relatively simpler in construction and operation than the standard guarded hot-plate method, and an apparatus [82] for accurate measurement of the thermal conductivity of loose-fill or powdered insulations to high temperatures.

Analytical mathematical solutions for- difficult practical engineering problems not readily suited to ex- perimental approaches have become more feasible with the application of digital computers. Such a case was the calculation [83] of the temperatures existing in vertical building columns that are exposed to some degree to weather variations. In multi-story buildings, differential thermal expansions between exposed columns and interior protected columns give rise to excessive seasonal differential movements between partitions and walls, floors, and ceilings. Information on the magnitude of these temperature differences enables designers to predict and avoid excessive differential movements.

In the two decades prior to 1935, Van Dusen developed a variety of calorimeters, hot-boxes, and heat flow meter methods for determining the heat flow and insulating value of composite assemblies of materials in the forms of walls, roofs, and floors. In connection with the low-cost housing research program initiated at the Bureau in 1937, Dill conceived use of the guarded hot-box method to determine the thermal insulating value of wall assemblies. Robinson built and developed the apparatus and in collaboration with Watson measured the heat transfer characteristics of about 120 walls prior to 1947 , with many of the results being published in the Building Materials and Structures Reports, together with the structural properties of the specimens.

A three-year program to determine the insulating value of reflective and nonreflective air spaces [84] was completed by Robinson, Powlitch, and Dill, using a newly built guarded hot-box apparatus that was rotatable. enabling thermal conductance determinations to be made for floor, wall, and sloped or flat ceiling orientations. The results of this study became generally available when they were summarized in the 1956 Guide, handbook of the American Society of Heating, Refrigerating and Air-Conditioning Engineers. At about the same time, the insulation industry decided to combine the merits of fibrous and reflective insulations in the form of new products after a further two-year study was completed [85]. In 1954, the

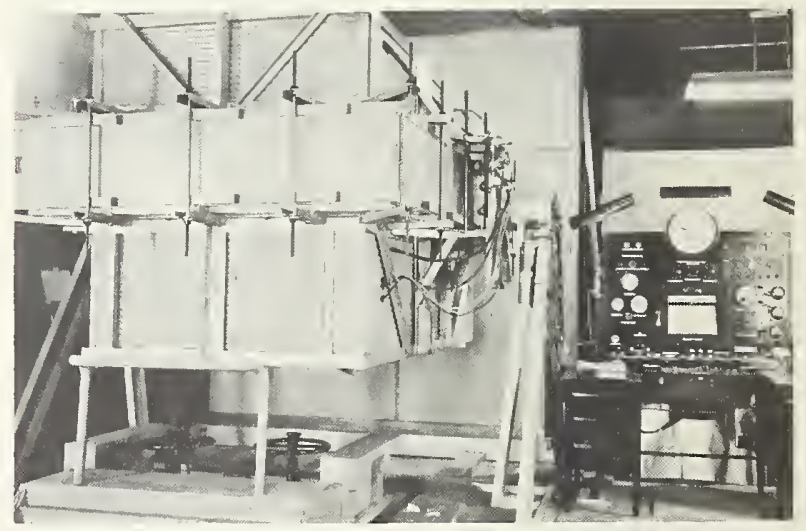

Trunnion-mounted guarded hotbox for measuring heat transmission coefficients of wall, floor, ceiling, or roof constructions. Photograph shows test panel in horizontal position with hot metering box on the bottom and cold box on top indicating heat flow upward as in a ceiling construction. Control panel and instrumentation for observation of test results are shown at the right. 

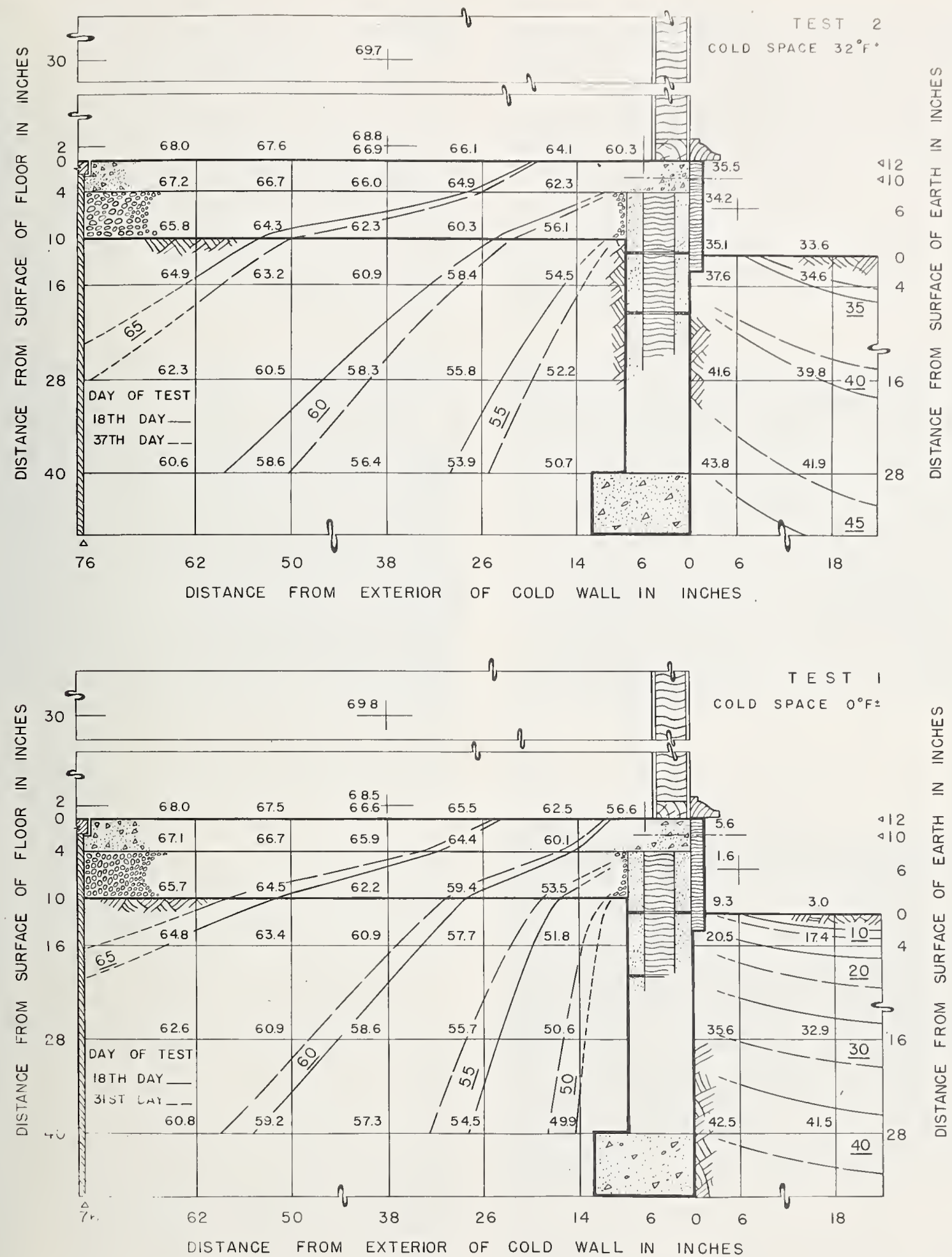

Temperature patterns and isothermal lines under winter conditions in a concrete floor slab construction laid over gravel and earth with insulation applied at the edge of the floor and foundation. The upper and lower figures show the temperature distributions under sustained outdoor temperatures of $32^{\circ} \mathrm{F}$ and $0{ }^{\circ} \mathrm{F}$, respectively.

guarded hot-box method and apparatus designed at the Bureau was used as the basis for ASTM Standard C-236.
A ten-year study of the effect of moisture on the insulating value of flat roof construction by Powell and Robinson [86] resulted in the development of 
two methods of measurement. The heat transfer characteristics for 73 different specimens of roofs under simulated summer and winter conditions were determined. A design concept was evolved that allowed self-drying of wetted roof insulations without removal. Criteria for testing the performance of selfdrying insulated roof constructions were developed. Applications of the findings from the above study are expected to yield large savings in repair and replacement of roofs by government and industry.

Analytical work by Woolley [87] illustrated the steady-state thermal conditions under which condensation of moisture would occur in wall constructions, and laboratory investigations by Dill and Cottony provided data on a number of conventional wall systems [88].

Some of the earliest investigations of heat transfer through concrete floor slabs for residential construction were carried out at the National Bureau of Standards. These investigations resulted in the development of handbook formulae for the computation of heat loss through floor slabs laid either over crawl spaces or in contact with the ground. Data were also developed on the effectiveness of various arrangements of edge insulation for concrete slabs on the ground in preventing floor condensation and in control of floor surface temperature. Results of these investigations were published in the Building $\mathrm{Ma}$ terials and Structures Series [89, 90].

For almost 60 years members of the Bureau staff have collaborated with and provided leadership to national standards committees, committees of professional societies, and agencies of the Federal Gov. ernment in the development of test methods and the generation of reliable technical information related

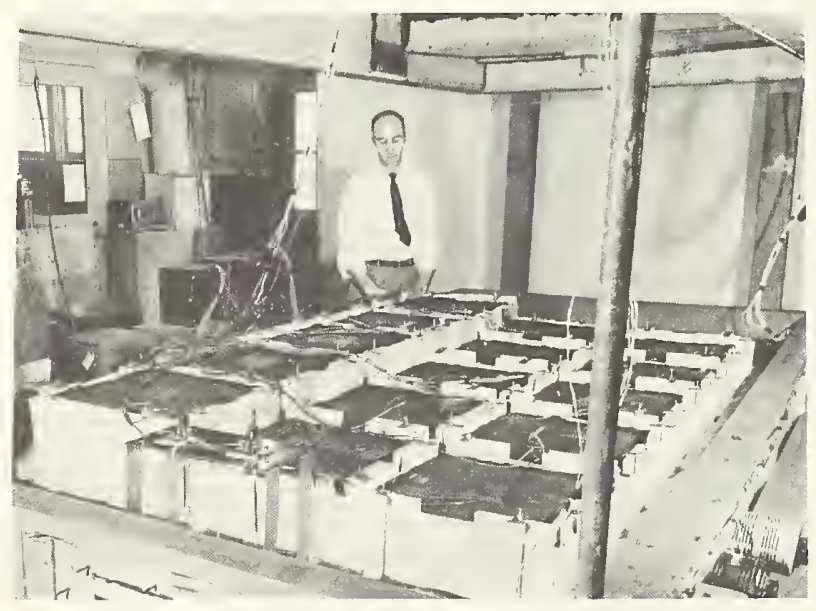

The effect of moisture on the insulating value of insulated concrete roofs was determined under simulated daily cycles of temperature representing summer and winter conditions. Fifteen specimens, each 18 inches square, with several types and thicknesses of roof insulation, were exposed simultaneously in this apparatus. The air in the box over the specimens was varied in a daily cycle from $75^{\circ} \mathrm{F}$ to $150^{\circ} \mathrm{F}$ to simulate solar heating in the summer, whereas the winter temperature range was from $20^{\circ} \mathrm{F}$ to $55 \mathrm{~F}^{\circ}$. The air in the chamber below the specimens was maintained at $90^{\circ} \mathrm{F}$ dry bulb temperature and $79{ }^{\circ} \mathrm{F}$ dewpoint temperature to augment the moisture transfer process. to heat and moisture transfer in building materials and systems.

\section{b. Mechanical Systems}

In the two decades prior to 1937 the National Bureau of Standards conducted major studies of the performance of gas burners [94, 95], steam radiators and radiator accessories, fire hazards of domestic heating installations [96], and the performance characteristics of roof ventilators [97]. These studies were carried out in various technical divisions of the Bureau to meet recognized needs of government and industry. The program on gas burners was conducted in close collaboration with the American Gas Association to develop information for industry standards. It included studies of the design factors that affect burner efficiency, the effect of altitude on the safety of gas burners, and performance characteristics of gas storage water heaters, hotel range burners, and propane burners. The studies of radiators and radiator accessories included the design and construction of an apparatus for measuring the performance of thermostatic valves, condensate traps, and air valves for steam radiators and the development of suitable environmental rooms for measuring the heating capacity of steam radiators.

When the low-cost housing research program was initiated at the National Bureau of Standards in 1937. laboratory work was started on test procedures for domestic boilers [98,99] furnaces, space heaters and hot water heaters using various fuels, and also on convectors, baseboard heating elements, and various types of fireplaces and fireplace units. These studies of heating equipment were carried out in close collaboration with the Federal Housing Admin. istration and with manufacturer's associations such as the Institute of Boiler and Radiator Manufacturers, the National Warm Air Heating and Air-Conditioning Association, the Convector Manufacturers' Association, and the Institute of Cooking and Heating Appliance Manufacturers, to develop technical information used in the FHA Minimum Property Requirements and in the preparation of industry standards and Commercial Standards [100-104].

In 1936 Dill conceived a new test method [105] for air cleaners which measured the arrestance of the cleaners in terms of change of opacity of filter papers as dusty air was drawn through them from stations upstream and downstream of the air cleaner in a test duct. In later years this test method became the method referenced in most Federal specifications for air cleaners. It was adopted in 1960 as a standard for high efficiency filters by the principal industry association [106] in the air filter industry, and in 1968 became a part of the ASHRAE Standard Method of Testing Air Cleaning Devices Used in General Ventilation for Removing Particulate Matter (52-68) promulgated by the American Society of Heating, Refrigerating and Air Conditioning Engineers.

An extensive study of the factors which affect the draft-producing capability of residential chimneys made of various kinds of masonry units and of insulated metal sections was carried out by Achenbach 
and others beginning in 1940. The technical information produced by these laboratory investigations has been published in professional or trade journals $[107,108]$ and constitutes one of the principal sources of handbook information [109] on the performance of domestic chimneys.

During World War Il efforts were concentrated on test procedures for and performance characteristics of the simpler heating devices that would conserve metal by the use of masonry and ceramics. The de. sign, installation, and operational factors of heating equipment and heat distribution systems that would effect savings in the use of gas and liquid fuels and make greater use of solid fuels were extensively investigated.

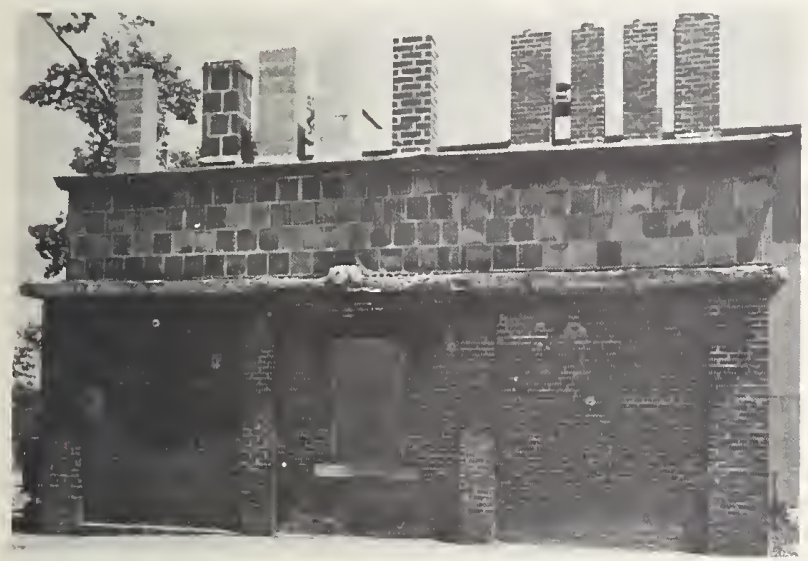

A wide variety of masonry chimneys were studied in this building to evaluate their fire hazard potential and their draft producing capabilities. The chimneys shown here differed in the size and shape of the chimney liner, the type of masonry unit, and the treatment of the air space between masonry and liner.

Beginning in 1954, Cole and Achenbach carried out a long-term study of underground heat distribution systems to elucidate the processes of heat and moisture transfer that controlled the effectiveness of the insulations used in such systems, and to develop laboratory test procedures for simulating their in-situ performance. Test methods were developed for study. ing the effect of ground moisture on heat transfer in pipe insulation; criteria were devised for air-drying wet insulation; calorimetric methods for measuring the heat loss of typical systems in dry and wet sur. roundings were developed; and test procedures for evaluating the effect of steam and boiling water on pipe insulation in typical installations were investigated. These studies were the principal source of new technical data and test procedures used in performance criteria $[110,111]$ developed by the National Academy of Sciences, and in specifications prepared by Federal agencies for underground heat distribution systems.

The Building Research Division has investigated the performance requirements for various items of portable and mobile refrigeration equipment for the Department of the Army for the last two decades. These studies have included complete pieces of equip- ment such as demountable warehouses, gasolinepowered refrigerating units, water coolers [112], household and commercial refrigerators, freezers, and also components of systems such as condensers, evaporators, expansion valves, water regulating valves and driers. Through studies of the functional requirements of equipment, development of test procedures for quantitative evaluation of performance, and the laboratory investigation of prolotype equipment, the Bureau has served as a significant resource for technical information for military and Federal specifica. tions and has participated in the standardization of the components of refrigeration systems for military use.

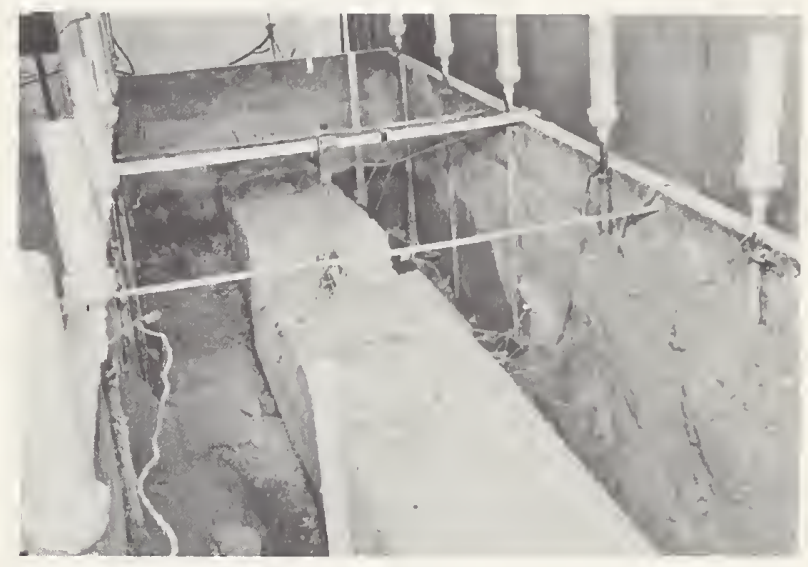

Heat and moisture transfer processes in insulated underground heat distribution systems were studied to find methods of alleviating acceleraled pipe corrosion, deterioration of the insulation, and excessive heat loss to the earth. In the photograph, a series of thermocouples is shown affixed at the midlength of an insulating concrete envelope to measure temperature distribution, and standpipes at either side were used to adjust the water table level by introducing water at the bottom.

Both laboratory and field studies [113.115] on the performance of air-to-air heat pumps for residential buildings have been conducted by Davis and others. The factors of design and operation that affect the capacity and efficiency of these units have been in. vestigated in the laboratory using calorimetric techniques. The field studies have developed information on electrical energy usage, performance factors, air distribution problems, diversity among the various electrical loads, and guidance in calculating heating and cooling loads and selection of equipment. These studies have constituted a major source of published information on the performance of residential air-toair heat pumps and have provided important guidance to the Federal Government in improving military specifications for heat pumps and to the industry at large in better application of heat pumps to residences.

Technical investigations to improve the accuracy of measurements involved in air conditioning calorimetry have been in progress for some time. These studies involve test methods for evaluating the effectiveness of air mixers $[116,117]$ and the turbulence produced 
in forced air mixing, studies of better techniques for measuring dry-bulb and wet-bulb temperatures under the conditions of convection, radiation, and conduction that exist in such calorimeters [118], and evaluation of various methods for accurate measurement of refrigerant flow rates. Information $[119,120]$ has been published on recommended techniques for airconditioning calorimetry and the probable accuracy of these test methods. lnformation on temperaturemeasuring techniques and forced air mixers from these investigations has been incorporated in a standard [121] of the American Society of Heating, Refrigerating and Air-Conditioning Engineers.

Two separate investigations of the performance requirements for ducts and duct systems for heating and air conditioning applications have been completed for the Federal Housing Administration since 1950. These investigations by Cole and Achenbach provided a basis for recommending test procedures for the various significant performance characteristics of ducts, performance data on the principal classes of materials used for ducts, and a specification which Federal agencies could use in evaluating both conventional and new materials. This specification [122] has been published by the Federal Housing Administration for discussion and comment.

The professional staff engaged in technical investigations of mechanical systems have participated extensively in the technical committees of the USA Standards Institute ${ }^{2}$ and the American Society of Heating, Refrigerating and Air Conditioning Engineers, and have also had a major role in keeping the technical requirements and test procedures in Federal specifications for mechanical equipment abreast of developing technology.

2 The name of the USA Standards Institute was changed to the American National Standards Institute (ANSI) in October, 1969.

\section{c. Thermal Environment in Structures}

When the low-cost housing research program was started at the National Bureau of Standards, the Federal agencies concerned with residential construction became interested in the thermal environment produced by various heating systems. In 1940 a fourroom frame test house was constructed at the Bureau for the purpose of studying full-scale heating systems for low-cost housing. This house was enclosed in a larger air conditioned structure in 1944 to permit year-round studies of heating systems under winter conditions. Investigations have been made in this facility of nearly all the conventional systems and a number of special systems for heating small houses. The factors affecting temperature distribution inside individual rooms in horizontal and vertical directions and the difference in temperature produced in different rooms were studied in relation to outdoor temperature, natural and forced convection of air, radiations physical shape and location of heat sources, pattern of air circulation, and the type and location of the room temperature control. The results of these studies, published in the Building Materials and Structures Series [123, 124, 125] were used by the Federal Housing Administration as a basis for describing in their Minimum Property Requirements the essential arrangement of partitions, inside doors, and supply and return grilles for simple heating systems.

The principles governing air infiltration in buildings and the factors of construction that affect air infiltration routes were investigated in various occupied houses [126] and in the test house on the Bureau grounds, employing a portable katharometer [127] designed and constructed by Coblentz. This instrumentation was made available, on loan, to various universities to assist them in getting started with

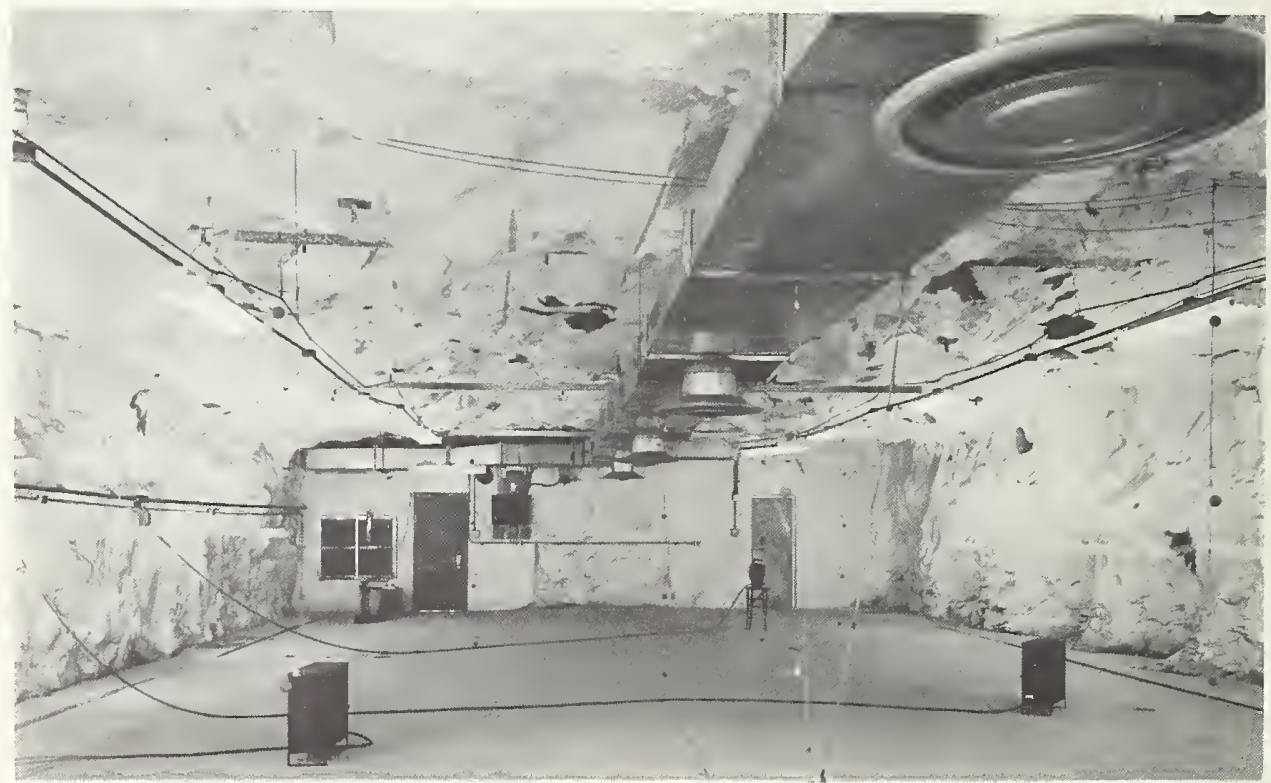

A deep underground chamber, in solid rock, employed to conduct experimental studies of the initial and long-term heating, air-conditioning, and dehumidifying requirements of such chambers used to house personnel, communications equipment, and other heat-generating apparatus. 


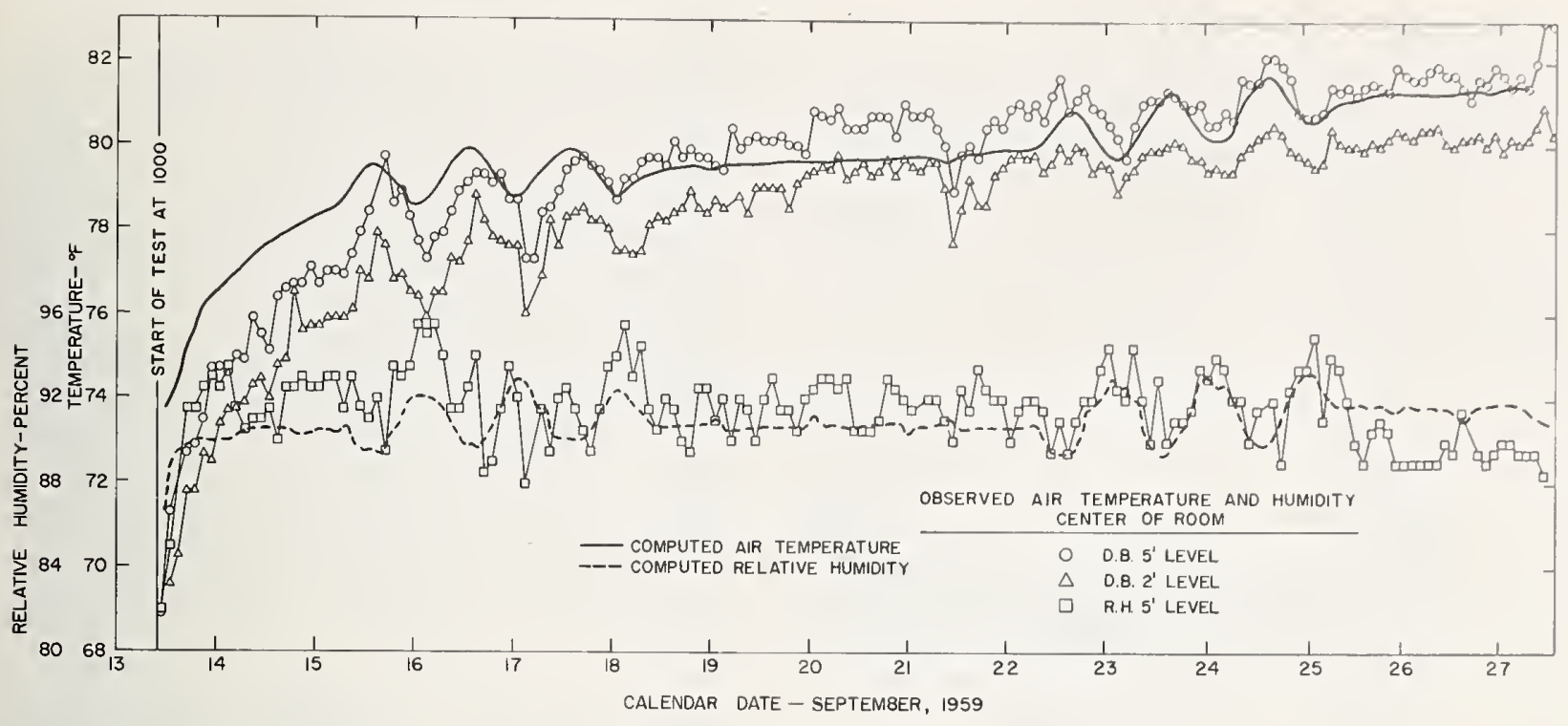

A comparison of the temperatures and humidities observed in an experimental family-size underground shelter during a simulated 2-week hot spell in Washington, D.C., with temperatures and humidities calculated by a finite-difference time-iteration solution of the 3-dimensional heat conduction equation using a digital computer.

studies of infiltration and its effects on heating loads. The portable katharometer has also been used to study air leakage into the insulated panels of refrigerated structures.

In 1950 , a theoretical and experimental program to evaluate and predict the heat transfer characteristics and the heating and cooling loads of underground chambers and structures was initiated in the Building Research Division. Completion of this work resulted in a design manual [128] for the Corps of Engineers that was used as the basis for design of several large underground shelters and communication centers built for and operated by the armed services for defense of the North American continent.

Some of the earliest work in this country on the thermal environment in underground fallout shelters was conducted in the Building Research Division, beginning in 1958. This work demonstrated that temperature and humidity conditions near the limit of human tolerance were likely to develop during summer occupancy of shelters in a significant part of the United States. The important parameters of climate, shelter design and operation, and site characteristics that affect thermal environment have been incorporated into computer programs [129] that can satisfactorily predict the resulting temperature and humidity conditions in shelters.

The information and experience gained in these early studies were used, through consultation and joint planning, to develop research programs in thermal environment in shelters in a number of universities and private research organizations. New techniques for analysis of earth temperatures [130], extreme weather conditions, and ventilation requirements [131] applicable to shelters have been developed by Kusuda and Achenbach for the Office of Civil De. fense. This information has been incorporated into design manuals, handbooks, and training course ma. terial for use by architects and engineers who design protective structures.

Test methods [132.134] were developed by Phillips and other investigators for the U.S. Department of Agriculture and vehicle manufacturers associations for measuring the cooling load of refrigerated warehouses and refrigerated trucks and trailers which take into account the effects of solar radiation on the exterior and air and moisture transfer into and through the insulated construction. The test methods for refrigerated trucks and trailers were adopted by the leading manufacturers' association for each type of vehicle, and commercial laboratories have been activated or are being commissioned to apply the test methods to the two kinds of vehicles. The laboratory and field studies on vehicles showed the significance of air and moisture leakage on cooling load and have been an influence in modifying designs to minimize these effects, both in the United States and internationally.

The parameters of effective distribution of chilled air inside refrigerated warehouses and vehicles have also been investigated and reported [135]. These find. ings have helped to promote vehicle design that provides a complete envelope of chilled air around the cargo in refrigerated vehicles and warehouses, thus assuring adequate protection of all parts of the product load from excessive temperature rise. The rate of air exchange that takes place when the service doors of a refrigerated rehicle are opened briefly for entering to remove cargo, as well as the effect of door openings on the cooling load, have been evaluated. Empirical formulae for calculation of air exchange and cooling load for short door openinge were developed [136].

\section{d. Architectural Acoustics}

Research and development work at the National 


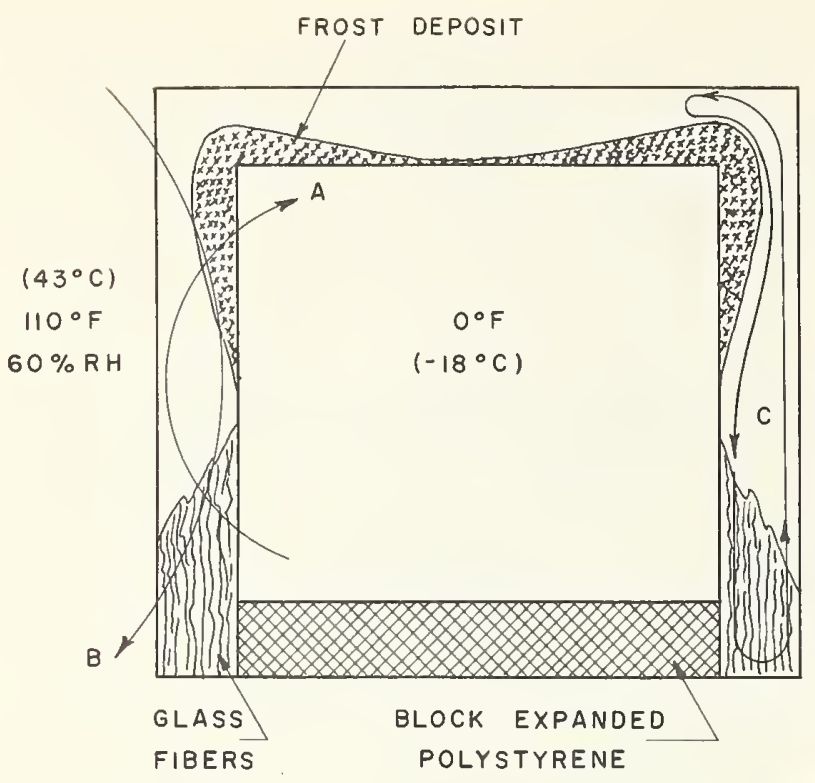

A diagrammatic vertical section of an insulated refrigerated structure showing the typical accumulation of frost in the in. sulated walls and roof caused by movement of moist air through cracks and openings under the influence of natural convection. Arrow $A$ indicates the direction of air movement between the interior space and the insulation space; arrow $B$ the direction of air movement between the exterior and the insulation space; and arrow $C$ the path of air circulation within the fibrous insulation.

Bureau of Standards in the field of acoustics was initiated in 1919 with the establishment of the Sound Section [140]. The early work of the section was devoted to research programs oriented toward military applications of accoustics. The first work in architectural acoustics was undertaken about a year later in response to numerous inquiries from governmental agencies. architects and builders regarding the soundinsulating properties of building materials and constructions. The increasing demands for such information and the wide scope of the problems involved necessitated the construction of the sound laboratory in the spring of 1922. Shortly thereafter, an intensive experimental investigation of the sound absorption and transmission properties of lime and gypsum plas. ters was undertaken at the joint request of the lime associations and gypsum industries.

Similar investigations by Chrisler and others [141-14.6] during the decade from 1925 to 1935 were extended to numerous types of building materials and constructions. Most of this early work and the information developed in more recent investigations are summarized in the widely distributed BMS Report 144. [147] and in NBS Monograph 77 [148]. These publications, which report the airborne and impact sound insulation ratings of more than 300 types of wall and floor structures, represent a comprehensive, authoritative and widely used compilation of acoustical performance data on building construction.

Berendt, Winzer, and Burroughs have recently completed an extensive technical investigation of major importance which deals with causes, alleviation, and control of noise problems in multifamily dwellings. This study, which was sponsored and published by the Federal Housing Administration, has culminated in the preparation of a "Noise Control Guide" [149] for the architect and builder. The Guide is considered by prominent individuals in the field of acoustics to be a major pioneering effort. The Guide contains the first recommended airborne and impact sound insulation criteria ever presented for use in this country. The compilation of specific sound insulation and fire performance ratings and the extensive illustrations of proper architectural acoustical detailing are also the first of their kind in this country.

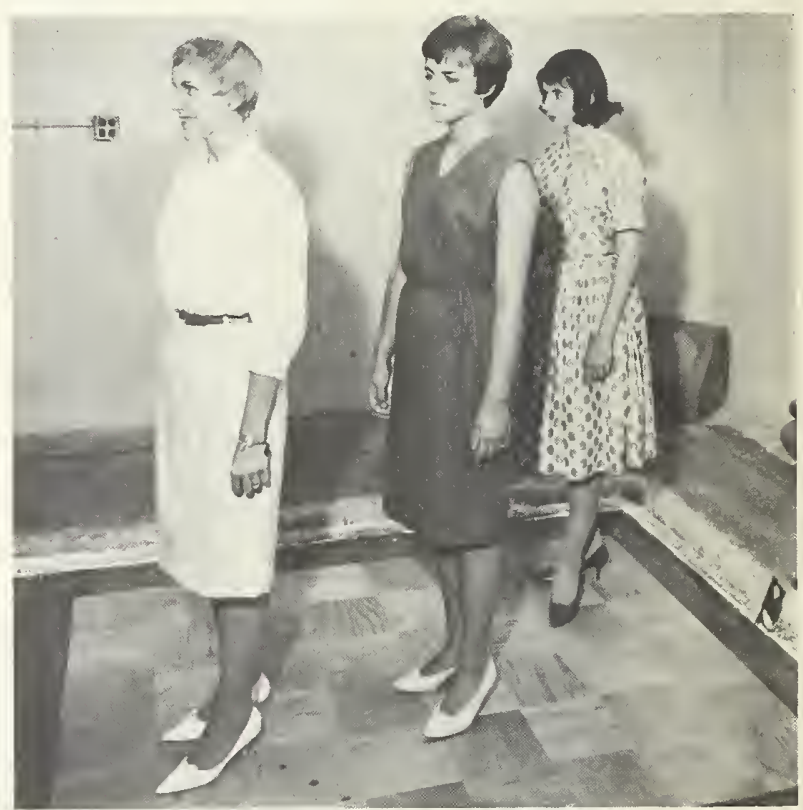

Measurement of the impact noise produced on coverings for concrete floors by footfalls. The sound transmitted to the room below was compared with that produced by a standard tapping machine used in laboratory tests.

Throughout the years the work in architectural acoustics has been guided by the results of theoretical and semiempirical investigations in the generation, transmission, and absorption of sound in buildings, structures, and materials. During this period, not only were new techniques of measurement developed, but improved acoustical instrumentation emerged which substantially advanced the state of the art. Theoretical work was begun in 1925 by Buckingham [150], whose classical paper formed the basis of all currently recognized national and international standard methods of measurement of sound transmission through partition walls. Subsequent theoretical and 
semi-empirical investigations [151-154] led to a better understanding of the transmission of sound through single and double walls in both laboratory and field installations.

Following completion of the large $15,000 \mathrm{ft}^{3}$ reverberation chamber in 1928, extensive theoretical and experimental investigations were undertaken to study the properties, characteristics, and behavior of diffuse and reverberant sound fields and the influence of such fields on the sound absorption and radiation efficiency of basic types of acoustical materials and of sound generators. Numerous research efforts [155-168] during the period from 1934 to 1965 greatly advanced the understanding and use of reverberant sound fields and improved substantially the accuracy and precision of acoustical measurements in such environments. From the very beginning, emphasis was placed on the development of new and improved test methods, calibration techniques, and acoustical instrumentation [169-173] by various members of the Sound Section.

Some of the effort of the Sound Section has always been directed toward noise problems of an applied nature such as room acoustics, noise control, and soundproofing of apartment buildings and airplane cabins. The staff was also actively engaged in serving as acoustical consultants to governmental agencies and in furnishing consultation, advice, assistance, and technical information on acoustics and noise problems to the building industry, industrial associations, educational institutions, national and international laboratories. architects, builders, and the public at large. These services covered an extremely broad spectrum of architectural acoustics dealing with residential, industrial, military, and community noise problems.

In support of the Bureau's mission and active interest in national and international standardization throughout this period, members of the Sound Section Staff have held the chairmanships and other positions of leadership of various acoustically oriented technical committees of the major standardization organizations and professional societies in this country and abroad. Currently, staff members are deeply involved in the acoustical standards work of organizations such as the United States of America Standards Institute, USASI; the International Standardization Organization, ISO; the American Society for Testing and Ma. terials, ASTM; the Acoustical Society of America, ASA; and the Audio Enginering Society, AES.

Much of this work is oriented toward developing new and improved methods of measuring the sound transmission and absorption of acoustical materials and building constructions; devising techniques for measuring the sound radiation from various types of equipment; developing more accurate methods for calibration of sound sensing devices such as microphones and audiometers; writing design and performance specifications for various types of acoustical in. struments; and standardizing acoustical terminology.

\section{e. Plumbing and Water Systems}

The National Bureau of Standards contributed sig. nificantly to the success of the work of the Plumbing Subcommittee of the U.S. Department of Commerce Building Code Committee initiated in 1921 by Secretary of Commerce Herbert Hoover. The contribution of the Bureau was largely in the field of original investigations of the hydraulics and pneumatics of plumbing systems and plumbing fixtures, planned and carried out under the able direction of the Plumbing Subcommittee, which was comprised of representatives from Government, industry, and professional engineering societies. The first Committee report issued in 1923 contained recommended minimum require. ments for plumbing in dwellings and similar buildings. This report was superseded in 1928 with another [174] based on further research results from multistory experimentation. Not only did this work estab. lish a precedent for reliance on objective data, but the format used in the Committee reports for presentation of recommended requirements, as well as the Committee's recommended requirements themselves, were utilized by numerous governmental bodies in develop. ing their own plumbing codes. Even today, many local plumbing codes reflect this early work.

Following the fatal and crippling epidemic of amoebic dysentery attributed to faulty plumbing on the occasion of the 1933-34 Chicago World's Fair, a considerable interest developed in measures designed to protect against the back flow or back siphonage of polluted liquids into potable water systems. As a part of the overall effort to achieve satisfactory sanitation as it related to plumbing, the National Bureau of Standards investigated the problems of cross connections and back siphonage, and studied the performance of various protective devices available or pro. posed for the purpose $[175,176]$. In addition, Bureau representatives became active on Subcommittee No. I of the American Standards Association A40 project on minimum requirements for plumbing, which included protective devices for potable water supplies in build. ings in its scope of interest. Two American Standards were later issued on such devices, based largely on Bureau work $[177,178]$.

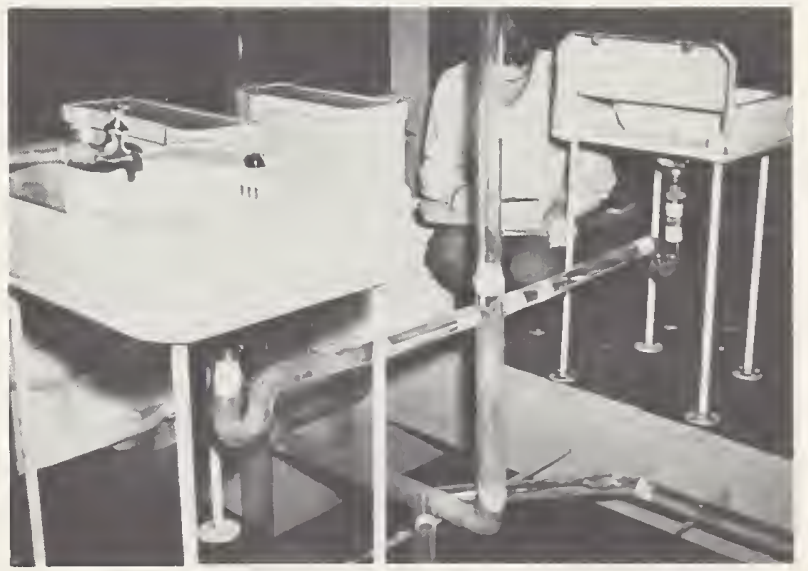

To aid in formulating a Uniform Plumbing Code, complete home plumbing drainage systems of transparent pipes and fittings were constructed in order that the flow phenomena could be observed and photographed. 
About the same time, Hunter and his associates carried out other investigations related to methods for estimating hydraulic loads on plumbing systems [179], methods for sizing water-distributing systems for buildings [180], strength of soldered joints for copper plumbing [181], and flow capacities of rainwater gutters [182]. The results of these investigations provided additional data needed by the American Standards Association Subcommittee in their project to develop an American Standard Plumbing Code and also responded to the needs of several Federal agencies concerned with plumbing systems.

After the research program on low-cost housing was initiated in 1937 an urgent need was expressed by agencies of the Federal government for a plumbing manual to guide the practice in Federal construction. The preparation of this manual [183] was carried out by the Bureau under the guidance of the Central Housing Committee and was issued in 1940. This manual was an extension of the earlier work performed in the twenties related to the needs of building and code officials, and has been widely used in the preparation of municipal and model plumbing codes as well as the American Standard National Plumbing Code [184].

lnvestigations in plumbing were interrupted during World War 11 because the hydraulic facilities of the Bureau were needed for other purposes. However, the Federal government relied heavily on previous Bureau work in the preparation of requirements for emergency plumbing standards [185]. The renewed emphasis on building construction following the war generated new demands for information on the performance of simplified plumbing constructions that might effect cost reductions. ln response to needs

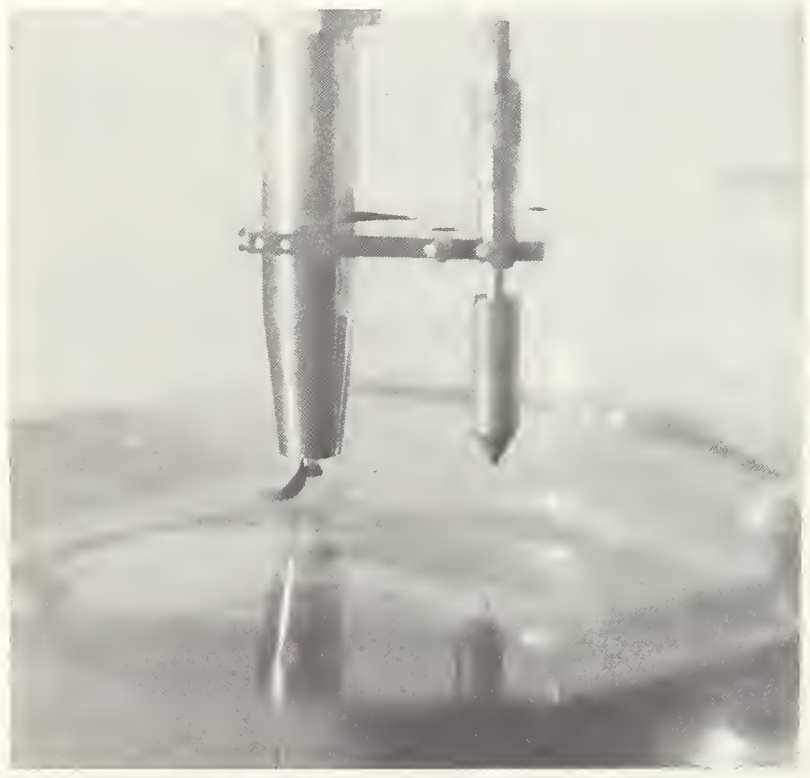

The parameters controlling backflow of water from a lavatory across an air gap into a faucet, illustrated in this figure, were studied to obtain critical values. Backflow can occur from a lavatory into an open faucet when unusual condi. tions produce a vacuum in the water system, if the faucet overhangs the rim of the lavatory improperly. expressed by the U.S. Department of Commerce, the Veterans' Administration, and various Federal housing agencies, French, Wyly, and Eaton investigated factors that affect self-siphonage of plumbing fixture traps, evaporation of fixture trap seals, fixture-unit load ratings, hydraulic performance of plumbing fix. tures and small-size drainage stacks, and frost closure of roof vents; and studied the performance of several forms of simplified venting for sanitary drainage systems [186-19]] during the decade following the war.

In recent years comprehensive technical investigations by $W_{y l y}$ and Eaton have been completed on the carrying capacities of soil, waste, and vent stacks $[192,193]$ the carrying capacities of horizontal drains [194], and the hydraulics of small-size lateral sanitary sewers [195]. These data have been reviewed by the USASI A40 Committee in the preparation of a currently proposed revision to the National Plumbing Code, ASA A40.8-1955.

A recent study of minimum venting systems for single-story residences [196] carried out for the National Association of Home Builders demonstrated the possibility of reducing the size and cost of these vents appreciably without deviating from present code requirements limiting variations in internal pressures in soil-waste-vent systems. The favorable results in the laboratory are now being explored in prototype field installations as a forerunner to future possible code modifications.

The research program of the National Bureau of Standards in plumbing has always been characterized by a high degree of collaboration with national codes and standards organizations and responsiveness to the needs of the construction agencies of the Federal government, and with the objective of introducing technical and statistical soundness into the design of plumbing systems. The plumbing research program has provided substantial and long-term national leadership, and the technical data developed through the years has had wide international recognition and usage.

\subsection{Materials and Composites}

a. Organic Materials and Composites

The earliest reference to work on organic building materials was a discussion of tests of paint appearing in the annual report of the Bureau for 1907. As early as 1909 the properties of linseed oil and turpentine were reported [197]. Outdoor exposure tests of paint were started in 1915. Of special interest among a number of reports on this subject are those on the painting of steel by Porter [198] and paints for exterior masonry by Sentil [199]. Seeking methods to accelerate the weathering of coatings, Walker and Hickson experimented with the carbon arc and water spray [200]. This important work led to the development of the commercial accelerated weathering devices that now have worldwide use.

An investigation of paints for use in traffic marking led to the development of an instrument [201] for measuring the abrasion resistance of these materials. More recently an apparatus [202] was developed by Roberts for measuring the abrasion resistance of coat- 


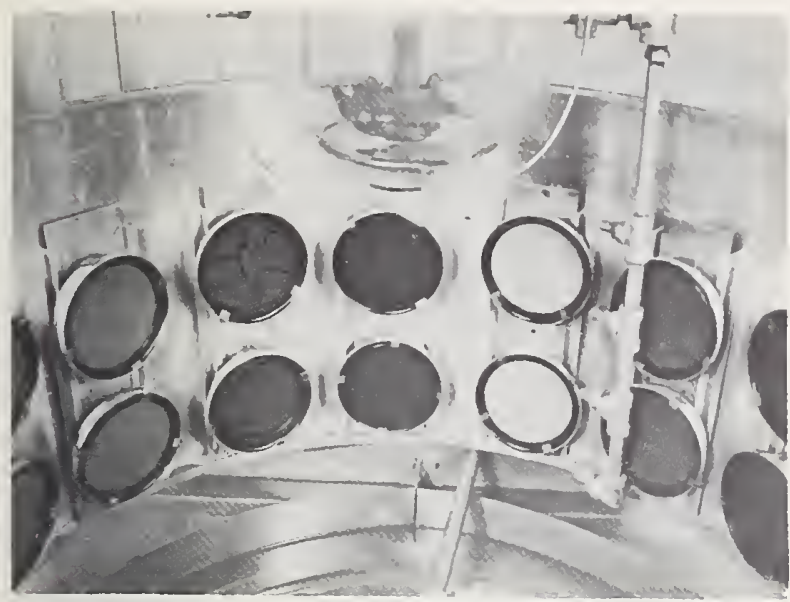

Specimens of organic protective coatings are mounted on the interior periphery of a carbon-arc weatherometer for study of accelerated weathering. The carbon arc, shown in the upper center, is a radiation source used to simulate solar radiation, and the spray nozzles at the right are used to simulate rain.
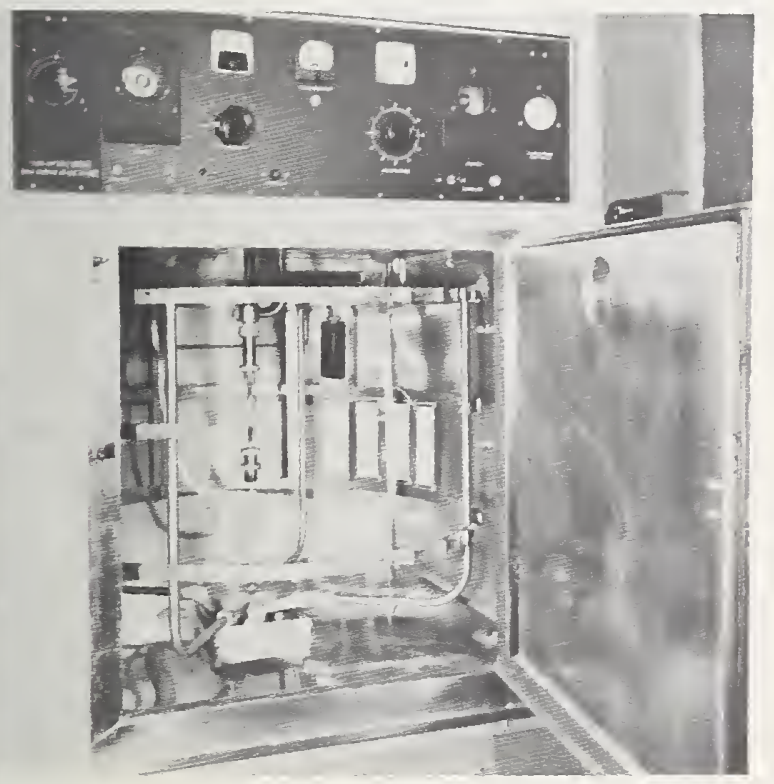

Panels of plastic materials are mounted on circular racks inside a xenon-arc weatherometer. The xenon arc, shown in the center, produces radiation in the ultraviolet region which closely resembles that of sunshine.

ings. The method measures the time required for a jet of fine aluminum oxide, propelled by carbon dioxide gas, to abrade through a coating to the substrate. The method has found wide acceptance in the organic coating industry and has been incorporated in Federal Test Method Standard No. 141.
A method for determining the dry hiding-power of paints [203] was developed by Howard, which later became the basis for a Federal Standard method of test for this property. Difficulties in the analysis of paint pioments and latex paints stimulated work on these problems. Simpler and more rapid methods have been developed quite recently for the determination of lead, zinc, and titanium [204, 205].

The development of methods of test and specifications for organic coatings has been a major program in building materials for several decades. Through chairmanship of the Technical Committee on Paint of the Federal Specifications Board in earlier years and with laboratory and field investigations, the Bureau has had the major responsibility for the development of all Federal Specifications concerning paint and related products. Although the elimination of Technical Committees of the Federal Specification Board has scattered the preparation of specifications among many agencies, the staff of the present Materials Durability and Analysis Section still contribute substantially to this work.

The development of methods of test for roof coatings and water-proofing was started as early as 1911. Specifications for prepared roofing were developed in 1919. The Asphalt Roofing Industry Bureau established a Research Associate Program at the Bureau in 1926 which continued until 1968. Their first Research Associate, O. C. Strieter, adapted the method for accelerated tests of organic coatings to asphalts [206], which with only slight modification is still in use today as ASTM Recommended Practice D529-62. Subsequent joint studies between the Bureau and this research associateship led to a number of significant contributions to the roofing industry and users of roofing products, including a hail resistance test and

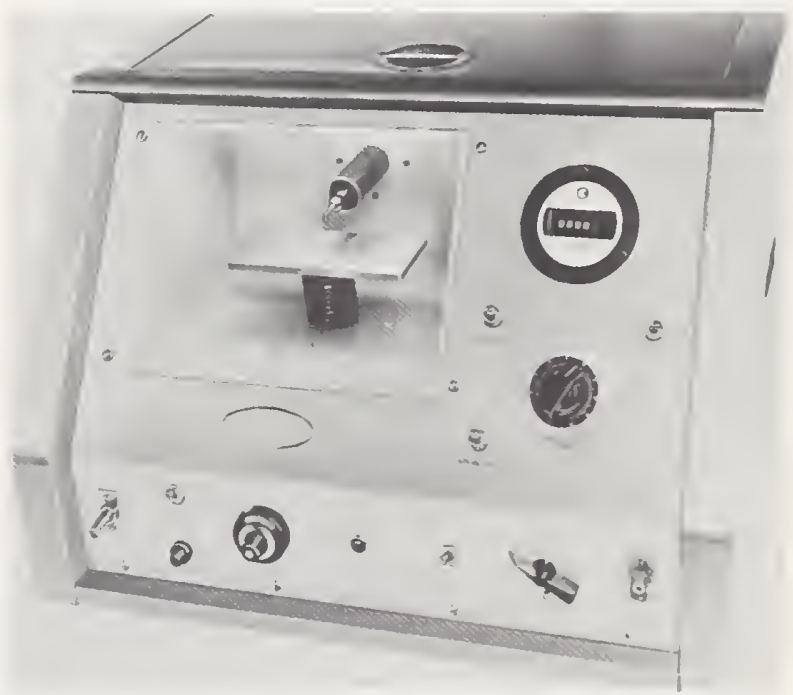

A jet abrader developed at NBS for measuring abrasion resistance of protective coatings. $A$ jet of fine aluminum oxide is projected by pressurized carbon dioxide from the fitting in the upper center of the instrument against the coated specimen below. The time required for the abrasive to penetrate the coating is read from the instrument in the upper right of the cabinet. 
techniques for evaluating new materials introduced into roofing products.

Significant progress has been made by Wright and Campbell in investigating the chemistry of photo. oxidation of coating-grade asphalts [207, 208]. Recent investigations showed that better methods could be developed than are presently used for the blowing of asphalts to coating-grade products [209, 210].

An intensive study of asphalt shingles by Snoke and Gallup [211] resulted in the first indication that mineral filler could be beneficial to the service life of the shingle. Later studies $[212,213]$ also revealed that the properties of the mineral filler were important to service life. A study of the problem of wind-resistance of asphalt shingles by Cullen led to the development of test methods for evaluating the techniques used for sealing the tabs [214]. This work provided the basis for the Guide Test Method for Wind Resistant Shingles of Underwriters' Laboratories, Inc.

A comprehensive field survey of roofing materials used in the United States was conducted over a period of several years. The results were published in several Building Materials and Structures reports and gave valuable information on the distribution of various roofing materials and their weathering qualities in various parts of the country. Laboratory investigation of the factors involved in premature failure of built-
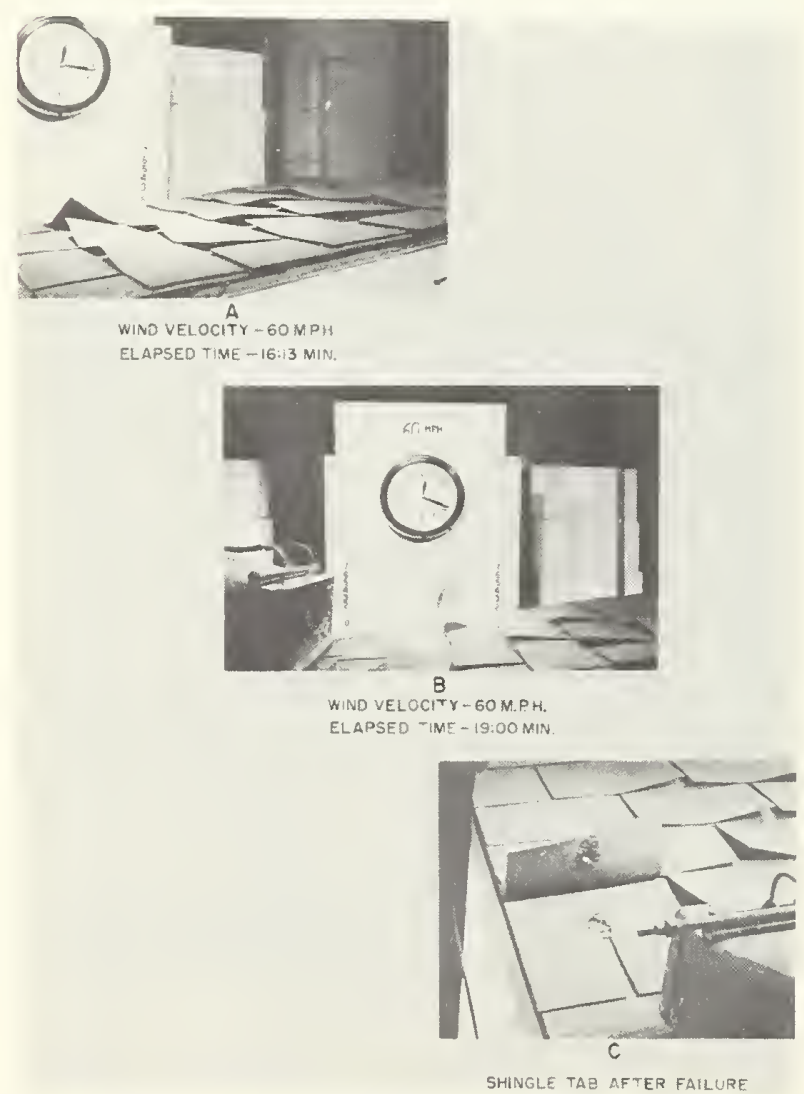

Storm test sequence showing failure of asphalt shingles sealed with plastic cement after exposure to a $60-\mathrm{mph}$ wind in a laboratory storm test machine. up roofs by Cullen $[215,216]$ has resulted in techniques that would eliminate many of these premature failures. This type of investigation is now being applied to other roof systems.

Technical investigations on a wide variety of flooring materials and floor coverings have been conducted over a period of more than three decades. One of the earliest investigations related to the wear of carpets. A machine was developed by Schiefer and Best [217] and used in an extensive investigation of the effect of quality of pile, density of pile, height of pile, type of pile anchorage and carpet underlays on the durability of carpets [218].

A device was also built by Kessler for the investigation of the wear resistance of natural stone flooring [219]. Wide variations were obtained in wear resistance even among materials of the same type. However, good correlation was obtained between field tests and laboratory results. Later an apparatus was developed for determining the relative wear resistance of concrete floors [220]. McBurney made a fundamental investigation of indentation of a plastic body such as asphalt tile and developed an apparatus and method [221] for evaluating this property. Later work by Sigler and Woodward extended identation and recovery measurements to many types of floor covering $[222,223]$. These measurements were also made on floor coverings after subjection to accelerated aging.

To help the Post Office Department in selection of floors for heavy use, a circular track, 10 feet in diameter, was built and two post office trucks pulled around the track with a wheel designed to produce a bumping and slipping action. Various floors were tested on this track by Emley and Hofer [224]. As part of the broad research program on low-cost housing initiated in 1937, this apparatus was modified to obtain performance data on all types of flooring and flooring adhesives. The results of these studies were published in four Building Materials and Structures Reports [225].

The specialized requirements for electrical conductance in floors for hospital operating rooms were investigated. A comprehensive investigation was made of various properties of these floors including the upper and lower limits of electrical conductance and the influence of maintenance methods on the proper-. ties of these floors [226].

Members of the staff of the Materials Durability and Analysis Section have been active on committees of the American Society for Testing and Materials concerned with paints, varnishes and lacquer; organic materials for roofing and waterproofing; plastics; skid resistance; and deterioration of nonmetallic materials; and with the committee on installation of ceramic tile of the USA Standards Institute. The members have not only engaged in extensive cooperative laboratory work, but have also provided the leadership for many task groups and committees.

\section{b. Inorganic Building Materials}

From its earliest days, the Bureau concerned itself with inorganic building materials. The Properties of 


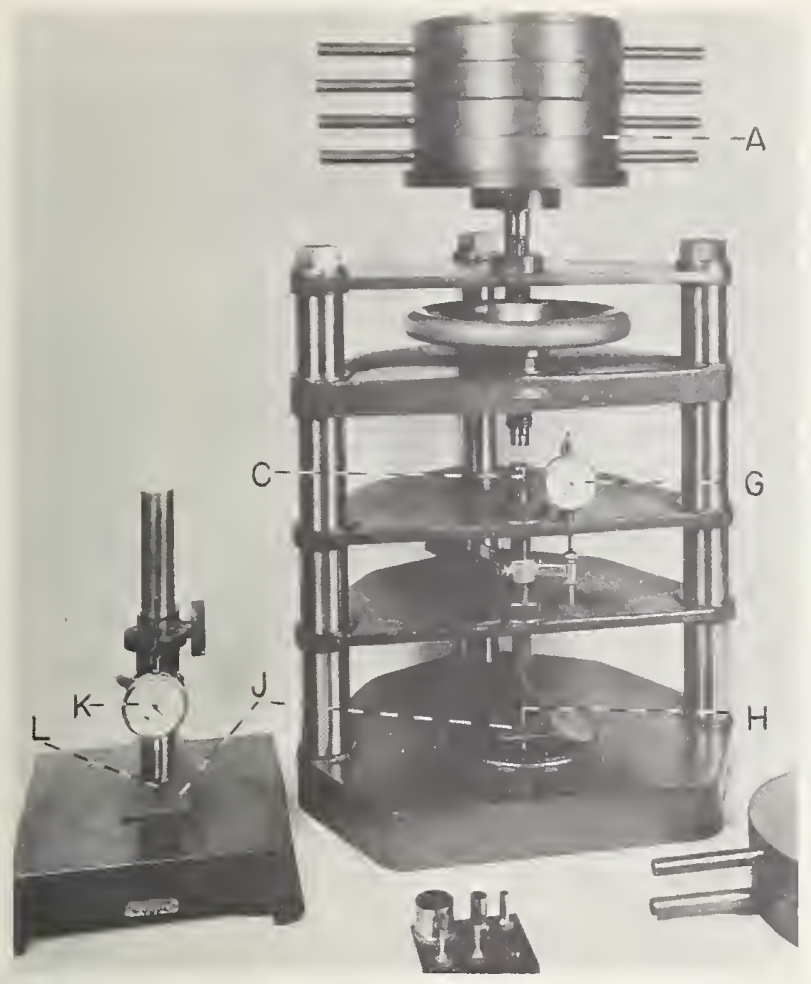

An apparatus used to measure the indentation and recovery of various types of floor coverings under loads simulating those caused by furniture or by walking over the surface. The indenting load $(A)$ is applied to the specimen $(J)$ through the plunger $(C)$ and the cylindrical indenting tool $(H)$. Micrometer $(G)$ indicates the idented thickness of the specimen, and micrometer $(K)$ and flat-ended foot $(L)$ indicate the original thickness of the specimen.

Materials Section, which was organized in 1904, tested cement for construction of the New Office Building for the House of Representatives in 1905, while the Technological Branch of the Geological Survey in St. Louis which was to become, in 1910, part of the National Bureau of Standards, was conducting work on ceramics, cement, and concrete. The earliest published work on lime was in 1911 and on gypsum in 1917. Work on inorganic building materials was pursued vigorously for over 50 years and resulted in about 300 publications on cement and concrete (unreinforced), and about 50 papers each on lime and gypsum.

\section{Cement and Concrete}

In the cement and concrete field, investigations were made on the constitution of hydraulic cements and clinker, the cement manufacturing process, the constitution and properties of hydrater cement, and the relations of these to the performance of concrete as evidenced both by laboratory tests and field observations.

In 1924 the Portland Cement Association established a research associate fellowship at the Bureau under the direction of R. H. Bogue. This work, together with the Bureau effort in the Sections on Concreting Materials. Chemistry of Mineral Products, and
Microscopic Constitution of Mineral Products, constituted a learling laboratory effort in this area for many years. The names of many prominent scientists who worked on cement chemistry and concrete at the Bureau will he recognized in the abbreviated list of publications cited. Several leading European chemists joined the staff for limited periods. The PCA Fellowship was terminated in 1960 and the Bureau effort in the Building Research Division was terminated in 1965.

\section{Cement Clinker}

In 1917 Bates and Klein [240] prepared, in the pure form, tricalcium silicate, the most important constituent of portland cement. This was followed by a systematic study of high temperature phase relationships of progressively more complex systems including the oxides of aluminum, iron, magnesium, sulphur, potassium and sodium [241-246]. The compounds found to be produced with pure materials at temperature equilibrium were characterized by optical and x-ray techniques, and compared with those observed in actual clinkers. Significant improvements in petrographic analysis through resin impregnation and etching of clinker sections were made by Insley and Ward [247-248], while Hansen and Harrington [249. $250]$, were perhaps the first to apply x-ray diffraction to identification of crystalline and glassy constituents. Sophisticated quenching furnaces were developed, along with differential thermal analyses furnaces, a thermogravimetric apparatus, and a small rotary laboratory kiln [251-253]. The structure of clinker was delineated as identification of various constituents became possible, while there was important work on the glass constituent, including its measurement and its dependence on heat treatment of the clinker [254257]. This work, together with that of others, removed cement manufacture from its strictly empirical base, and permitted the development of special cements for particular purposes; for example. low-heat cement for massive concrete construction. With an understanding of clinker chemistry, Bogue was able to develop a method for calculating the potential compound composition from the usual oxide analysis [258], thus facilitating the characterization of cement performance in cement specifications.

\section{Cement manufacture}

Knowledge of the phase relationships was of direct practical value in the manufacture of cements, not only from the standpoint of raw-material proportioning, but more importantly from that of the effect of particular ingredients on burning temperature and compound formation [259.260]. The rate of clinker cooling was found to affect setting time, dimensional stability, grindability, and strength, and this appeared to be related to glass formation and the crystalline form of the tricalcium silicate, magnesium oxide, and tricalcium aluminate [261].

\section{Cement Hydration}

Parallel with work on cement clinker were extensive studies on characterization of the compounds 
found, and the structure resulting, from the hydration of portland cement. Many compounds were synthesized from pure chemicals. usually by hydrothermal means at elevated temperatures [262-266]. Comparisons were made with those of cement hydration through the same identification methods utilized for clinker study. Chemical stabilities of the compounds were assessed by heat-of-solution measurements [267]. The principal compounds were studied separately in the pure form as early as 1917, as was the role of gypsum in retarding the set [240]. Infra-red spectra and nuclear magnetic resonance $[268,269]$ were used in the study of calcium silicates and water, respectively, in hydrating cement. Contributions were made on carbonation rates of setting cements under various conditions [270].

The structure of hydrated cement, as well as that of pure compounds, was observed using a powder and employing a vacuum technique in introducing water [271]. The techniques used permitted following the hydration progress with time. The development of gel was followed by means of surface area measurements using nitrogen and water vapor BET adsorption [272. $273]$. A reduction in surface area with time was dem. onstrated [274].

\section{Relation of Composition to Performance}

Much attention was given to the resistance of set cements to sulphates and the role of tricalcium aluminate in this deleterious reaction [275-278]. Precise measurements of heat of hydration of cement showed the relationship of heat release to compound composition and glass content $[279,280]$. Dimensional stability of set cement was related to periclase content [281].

Over the years attention was given to minor constituents in portland cement [247], and Blaine made statistical studies of the effect of minor constituents on laboratory-determined properties of 199 commercial cements and the concretes made with them, together with relationships between chemical and physical properties [282]. These results are expected to suggest fruitful directions for future research on the role of specific minor constituents in altering the structure and properties of the major cement com. pounds and thereby lead to improved cements.

\section{Other cements}

The properties of high early-strength cements, made possible by improved grinding facilities, were assessed both from the standpoint of strength at later ages [283] and $\mathrm{SO}_{3}$ requirements [284]. Other work dealt with high magnesia content [285], while a series of papers treated the physical properties and hydration process with high alumina cements [286, 287]. A continuous survey was made of properties of masonry cements $[288,289]$.

\section{Concrete Aggregates}

Work on concrete aggregates included extensive investigations of the alkali-aggregate reaction [290.
292], and measurement of the expansion developed [293]. A number of aspects of aggregate durability were treated, including accurate determination of the coefficients of thermal expansion of many types of aggregates [294], the internal surface area of others [295], and the resistance to freezing and thawing in a variety of accelerated tests $[296,297]$.

\section{Concrete Admixtures}

Recognition of the possibility of modifying the properties of concrete by the addition of small quantities of ingredients in addition to the usual cement, sand, gravel, and water resulted in evaluative work and research starting in 1910 and continuing intermittently until the present. Dampproofing [298], air entraining [299], and accelerating admixtures [300] received the most attention, not only with regard to their effects on properties of concrete, but on the mechanism of the reactions. The Calcium Chloride Association supported a research fellowship at the Bureau related to this program for about 30 years, prior to its termination in 1968.

\section{Concrete}

Early work on measurement of the important property of workability of concrete [301] was supplemented later by studies on consolidation by vibration [302]. The first work on high pressure steam curing, the process now used so widely in manufacture of concrete block and pipe, was reported in 1910 [303], while perhaps the most comprehensive investigation to date on electrolysis in concrete was published in 1915 [304].

Measurement of the important concrete property of strength was given due attention. In 1915 Wig et al. [305] reported results of 20,000 tests, involving 240 sands and 60 coarse aggregates. Their discussion of factors affecting strength listed 17 conclusions, covering all factors involved, which are still valid after 50 years of further investigation. Tucker contributed a group of classical papers on the statistical treatment of fracture of brittle materials [306-308], while Kaplan applied the Griffith crack theory to concrete [309]. There were developed perhaps the first dependable tensile strength measurement [310], one of the earliest measurements of dynamic modulus [311] (a non-destructive strength test), and an apparatus for assessing abrasion resistance of concrete surfaces [220].

Throughout the entire period, the staff was concerned with durability aspects of concrete. In 1912 the Bureau started its first studies on the corrosion of cement [275]. A branch laboratory was established in Atlantic City in the very early days to observe the effects of sulphates in sea water on concrete, while the alkali attack on concrete brick, pipe, drain tile, and roads in the far west was investigated in a joint effort of the Washington laboratory and the San Francisco branch laboratory [312]. Later work on the chemical nature of the attack has been mentioned 


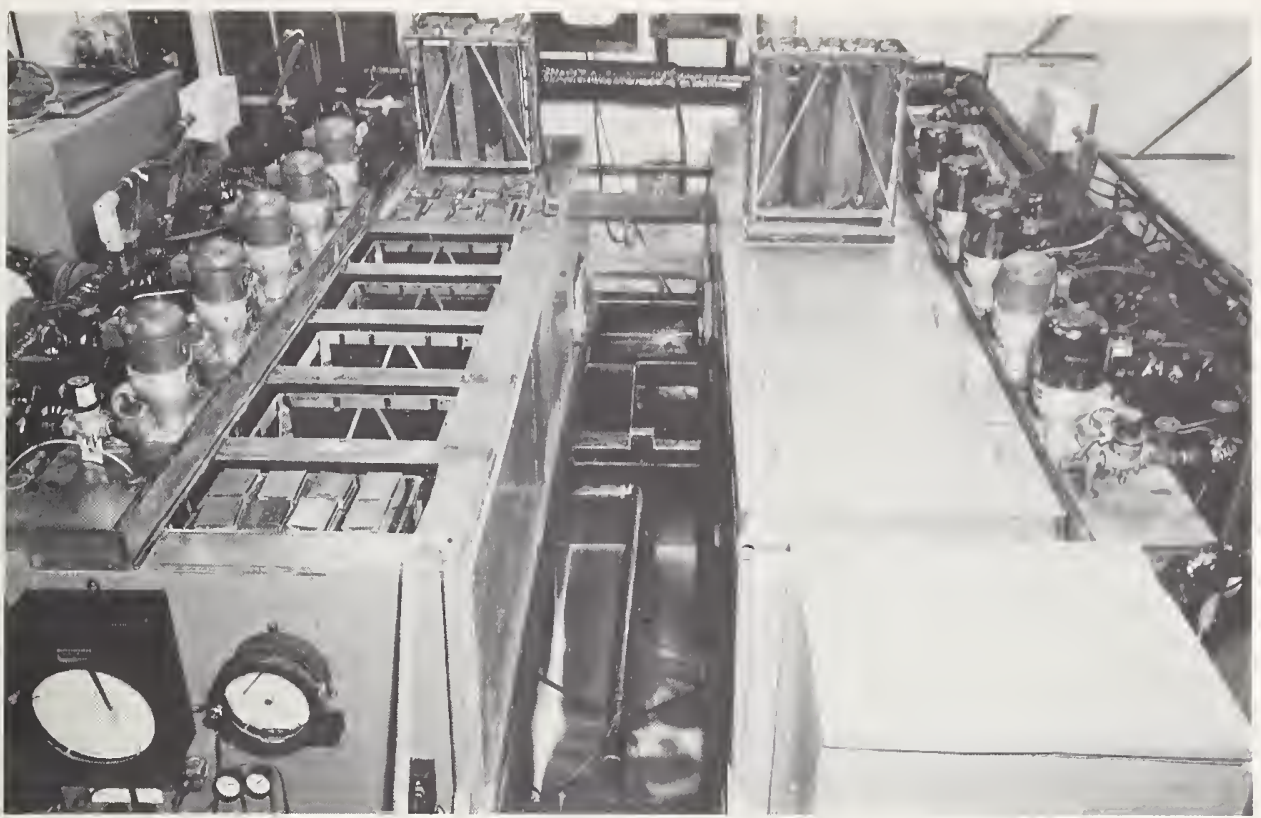

\begin{abstract}
An automatic apparatus designed to compare four ASTM test methods employed to investigate the resistance of concrete specimens to repetitive cycles of freezing and thawing. Shown in the photograph are five 35-gal and one 110-gal specimen treatment tank on each side of the center aisle. Each tank was equipped with a stirring device, an immersion heater and a temperature controller. The concrete specimens were supported in racks so that the racks in all tanks could be withdrawn simultaneously by an overhead hoist. The heating and cooling equipment for condition. ing the brine and the air for the several test procedures was located on the level beneath that shown here.
\end{abstract}

above. Interest in the deterioration caused by freezing and thawing led to early development of laboratory freezing and thawing equipment [313], to be followed later by a highly sophisticated versatile apparatus capable of simultaneously comparing the four ASTM accelerated tests as applied to concretes, with various aggregates, degrees of saturation, and entrained air content [297.314]. In the meantime, a pioneering study [296] by Valore of volume change in mortar specimens during freezing and thawing cycles added greatly to the understanding of this disruptive force.

\section{Cement Testing and Test Methods}

Starting in 1903 and continuing through 1965, the Bureau operated an acceptance testing service for the construction agencies of the Federal Government. Cement was tested for most of the important Federal concrete constructions in the United States, including the large dams of the Bureau of Reclamation and the Corps of Engineers, important dry docks, military airfields, navigation locks, etc. The annual volume of testing involved up to 18 million barrels of cement. Until about 1933, the testing was carried out by specific congressional appropriation to the National Bureau of Standards. After that time it was performed on a reimbursable basis. Laboratories were maintained not only in Washington, D.C., but at one time or another at Northampton and Allentown, Pa.; Hudson, N.Y.; Pittsburgh; St. Louis; Duluth; Kansas City; Denver; Houston; Seattle; and at San Francisco, Permanente, Riverside, and San Diego, California. The work on cement testing made necessary, and possible, a continued effort on test procedures and participation in the activities of the ASTM work on portland cement. It involved responsibility for Federal specifications for cementing materials.

Contributions to the chemical test methods were many, the chemical testing for many years being per. formed in the Chemistry Division under the direction of recognized authorities. Test methods developed or improved included those on $\mathrm{Na}_{2} \mathrm{O}, \mathrm{K}_{2} \mathrm{O}, \mathrm{SrO}$, by flame plotometer and carbon are [315-317], $\mathrm{SiO}_{2}$ [318], $\mathrm{SO}_{3}$ [319], sulfide sulphur [320], $\mathrm{TiO}_{2}$ [321], $\mathrm{MgO}$ [322], free lime [323], and general chemical analysis by $\mathrm{x}$-ray fluorescence [324]. Standard chemical analysis samples were developed and are available to the industry. These are in current demand to calibrate $\mathrm{x}$-ray fluorescence and atomic absorption equipment used for rapid cement analysis. The early Bureau literature refers frequently to papers on the fineness determination, first by sieving [325], and then as cements became finer, to the development of a sedimentation method for measurement of surface area [326] and an air permeability method [327], all of which were adopted for specification use. the latter throughout the world. Since 1935 an NBS standard cement sample, now in its 12 th release, has been arailable for calibration of the 325 sieve, the Wagner turbidimeter, and the Blaine fineness meter. There was a good deal of early work on setting time of cements [328], investigation of the variables in the autoclave soundness test [329], evaluation of various factors in the strength test [330], and derelopment of the test 
for bleeding [331]. In addition, the Bureau participated in virtually all of the many ASTM Committee C-I cooperative test programs over many years.

\section{Reference Laboratories}

In 1929, the Cement Reference Laboratory was established as a joint project between the. National Bureau of Standards and the cement industry, acting through ASTM [332]. Test equipment and procedures employed in cement testing laboratories throughout the country are inspected at two-year intervals. Refer. ence samples are issued so each laboratory can assess its own performance. The technique of issuing reference samples in pairs was developed in the Statistical Engineering Section [333] and first applied to the cement program [334]. It identifies test methods which require modification either in procedure or description. The reference sample program is also a useful tool in establishing interlaboratory precision data and is used to assess the effect of selected test variables by altering the directions issued to half of the participants. Information obtained both in the inspection and sample programs on deficiencies in test procedures is furnished to the standards-writing technical committees and thereby furnishes an important feedback function.

The CCRL effort was gradually expanded to include concrete tests, and its success led to the establishment of a similar program for state highway laboratories in the fields of asphalt, soils, and concrete aggregates.

\section{Lime}

The level of work on lime was considerably lower than that on cements, but publications appeared regularly from 1911 to 1950, with limited work after that time. As with cement, tests were developed for lime, such as fineness [335], water retention [336], and setting time [337]; and the results related to the properties of cement-lime mortars [338] and plasters [339]. The best known test, which forms the basis of the ASTM requirement for consistency, is the Emley plasticimeter [340].

A good deal of work was directed to the analysis of lime [341, 342], with a very important contribution on the determination of unhydrated magnesia content in hydrated dolomitic lime. Wells demon. strated that delayed hydration of magnesia, with its attendant expansion, was responsible for many delayed white-coat plaster failures [343]. An autoclave test was developed to predict the potential for expansion [344]. Later it was demonstrated that some of the expansion in masonry could be attributed to expansion of the lime constituent in the mortar.

\section{Gypsum}

Work on gypsum paralleled that on lime. Tests were developed or investigated for setting time [345], and fineness [346]. There were studies of bond of gypsum plaster [347] to tile, the problem of efflorescence [348], and the properties of lime-gypsum

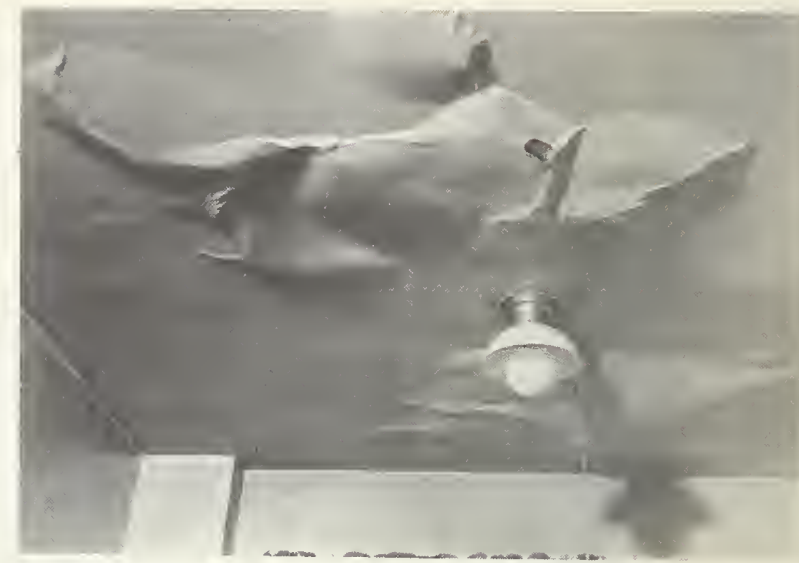

Investigation of white-coat plaster has revealed how to avoid bulging and failure, such as shown here, caused by slow hydration and expansion of the magnesium in dolomitic limes.

mixtures [349]. The volume change upon setting was measured [350, 351], as was the effect of high temperature [352].

\section{Contributions to Private Technical Organizations}

During the entire history of activity of the Bureau in inorganic building materials, the staff has participated in the technical and administrative work of organizations such as the American Concrete Institute, the American Society for Testing and Materials, the USA Standards Institute, and the Highway Research Board. On the ACI at least five staff members have served as President, nine have served on the Board of Directors, and a number have served as technical committee chairmen. In ASTM, two have been elected as President and four on the Board of Directors. Four technical committees were organized and first chaired by Bureau personnel; viz., C-2 on Magnesium Oxychloride and Magnesium Oxysulfate Cements, C.11 on Gypsum, C-15 on Manufactured Masonry Units, and C-17 on Asbestos-Cement Products. In all, eleven staff members have been chairmen of those ASTM Committees listed above and C-1 on Cement, C-7 on Lime, C-8 on Refractories, C-9 on Concrete and Concrete Aggregates, and C-12 on Masonry Mortars. Four of the staff headed Highway Research Board technical committees.

\section{c. Ceramic and Metallic Building Materials}

Work on both ceramics and metals was initiated at the National Bureau of Standards in 1911. The early work on ceramics consisted principally of investigating the properties of bricks and of clays and, for metals, proof testing to determine if parts purchased by the Government met specifications.

A Ceramics Division was organized in 1918. Some of the initial studies on building materials were con. cerned with the strength and absorption properties of hollow tile and terra cotta for architectural applica. tions. Other early work on ceramics was related to strength measurements and to freezing and thawing 
effects on brick and tile. Terra cotta continued to receive emphasis in the Division because of its rather extensive use during this period for building decoration.

An Enameled Metals Section was formed in 1919. Knowledge in this area was limited and what little was known about the enameling process was considered proprietary. Technological papers by Staley, Shaw, and Danielson [353.355] issued in the period 1919-1925 were important contributions and served to stimulate a rapid expansion of porcelain enamel for household appliances and, later, for outdoor signs and architectural panels. Research in these early years was directed for the most part toward the effect of composition on properties. A classic study conducted by Harrison [356] on the rheological properties of porcelain enamel slurries remains an important reference study for investigators working on any type of suspension that exhibits non-Newtonian flow.

Research in metallurgy at the Bureau during these early years was outstanding. Under the direction of Dr. Burgess, who later became the Bureau's Director. the Metallurgy Division made important contributions [357-359] that went far towards placing metals tech. nology on a firm scientific foundation.

Corrosion of metals received some attention during the decade between 1920 and 1930. The weathering characteristics of art bronze were investigated. In 1922, the first underground corrosion studies were initiated. These studies, which have continued with only little interruption since their inception, have supplied a large amount of much needed information to the building industry on the corrosion behavior of materials in various types of soils $[360,361]$.

During the period 1932 to 1947 the principal contributions of the National Bureau of Standards to the

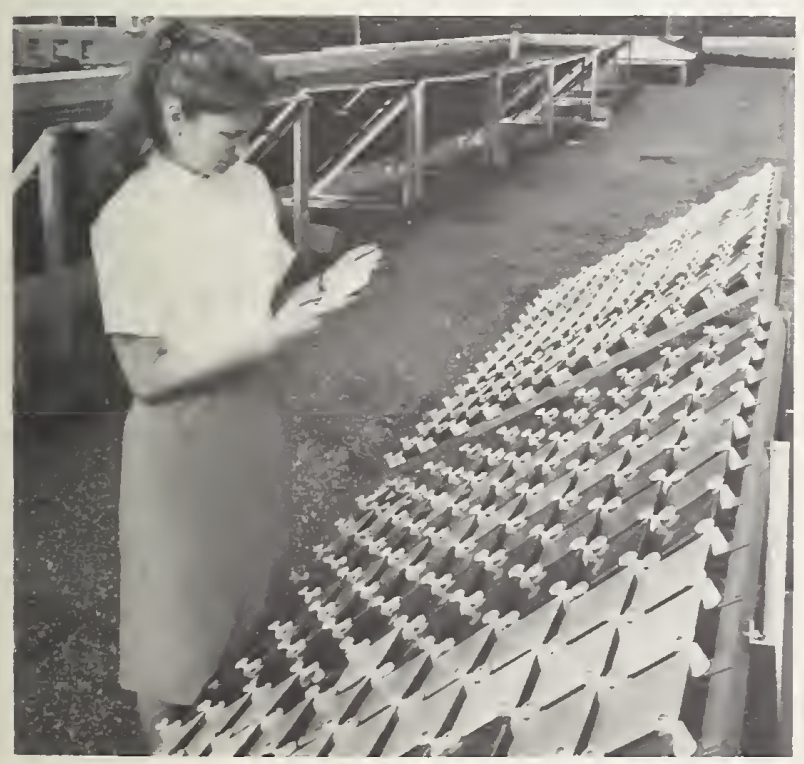

Exposing porcelain enamels on aluminum to determine durability is part of a current program to develop standard test procedures for porcelain properties such as weather resistance, alkali resistance, and ease of cleaning. building industry in the field of metals and ceramics were (a) development of standard test procedures, and (b) investigation of deterioration of these materials in various types of service. Investigations of weather resistance of porcelain enamels for architectural use were initiated in 1939. Results of these studies [362-364] have played an important role in today's large-scale use of architectural porcelain, since the studies led to test procedures that promoted the selection of only the most durable compositions.

The Porcelain Enamel Institute initiated its Research Associateship at the National Bureau of Standards in 1939, and this activity has operated continu. ously up to the present time. The principal objective of this industry-supported program has been the de. velopment of standard test procedures. Nore than one-half of the current ASTM tests for porcelain enamels originated from the work of this Associateship in conjunction with the former Enameled Metals Section. Part 13 of the ASTM Book of Standards [365], which includes those standards pertaining to all ceramic materials, lists 19 Standard Test Methods for Porcelain Enamels. Those Standard Test Methods for porcelain enamels dealing with abrasion resistance. acid resistance, adherence, color stability, flatness of panels, image gloss, reflectance, reflectivity and coefficient of scatter. specular gloss and torsion resistance were based principally on research carried out in the Enameled Metals Section.

Other accomplishments during the period 1932 to 1947 that furthered the use of ceramics and metals in buildings included (a) studies of moisture expansion in ceramic whiteware and its relationship to delayed crazing of wall tile [366], (b) the war-time development of high-temperature protective coatings and the subsequent use of these coatings for gas stoves and radiant heaters [367], and (c) the development of a large number of standard test procedures for both metals and ceramics.

The period immediately following World War II was one in which a great deal of research was carried forward for other Government agencies. In general, the research of this type on metals and ceramics had very little, if any, relationship to buildings. However, beginning in the late 1950 's, emphasis again shifted to use of ceramics and metals as building materials. Program areas included (a) development of standard tests. (b) exposure-site testing of selected materials [368]. (c) laboratory studies of atmospheric corrosion [369], and (d) development of performance criteria for specific products.

\subsection{Codes, Standards, and Specifications}

The Congressional act establishing the National Bureau of Standards authorized it to cooperate with other Government agencies and with private organizations in the development of standard practices for use in codes and specifications.

Within five vears after the Bureau was created other agencies of the Federal Government recognized the Bureau's ability to determine by test whether materials and supplies met purchase specifications, and also 
recognized the economic benefit of such tests. The early doubling and redoubling of the testing program at the Bureau produced demands from many industries for standard test procedures and specifications. As a part of this pattern, building materials and structural systems came under intensive study in the first two decades of the Bureau's operations. The growth in industrial technology accelerated rapidly during this same period. Entirely new industries were formed, and established industries were expanded along new lines. The maintenance of communication among these burgeoning and divergent industries, each tending to develop its own scientific and manufacturing language, necessitated and spurred a parallel standards development activity. Trade associations, professional societies, governmental agencies, including the Bureau, were enlarging their standards activities. Standards of practice, standards of performance, standard specifications and safety codes were needed, and the Bureau endeavored to meet these needs in many different fields. One of the original Bureau staff members. E. B. Rosa, initiated the study of the hazards of electrical practice in 1913, as a result of a directive enacted by Congress, an effort which later resulted in the $\mathrm{Na}$ tional Electric Safety Code. The early editions of this Code were developed by the Bureau, although it later became a project of the American Standards Association and the USA Standards Institute, with the Bureau acting as sponsor.

During the early years of the twentieth century the mushrooming growth in standards activities by many organizations produced overlapping standards committees, with resulting duplications of effort and conflicting requirements. Sponsoring organizations, each promoting its own standards effort, vied with one another for the public use of their standards. P. G. Agnew of the Bureau staff was disturbed over this competitive type of approach to the formation of standards, since a standard was considered to be an agreement among interested parties. Accordingly, Agnew left the Bureau in 1918 and together with about 15 industry executives representing the country's leading engineering societies-American Society of Civil Engineers, American Institute of Mining Engineers. American Society of Mechanical Engineers, American Institute of Electrical Engineers, and the American Society for Testing and Materials-brought about the formation of the American Engineering Standards Committee. Three agencies of the Federal Government - the War Department, Navy Department. and the Department of Commerce-also participated in this founding effort. S. W. Stratton, E. B. Rosa. and G. K. Burgess were officially named by the Secretary of Commerce to represent the Bureau on the American Engineering Standards Committee. This Committee was the forerunner of the American Standards Association, which was reorganized into the United States of America Standards Institute in 1966.

Building codes, being primarily concerned with safety, came in for an increasing amount of Bureau attention. Requirements for safe construction practices were being developed unilaterally by many different groups across the country. Lacking a single central control and without a commonly accepted background of basic scientific principles, the codes appearing on the national scene seemed to be drifting further apart in performance requirements and material specifications. The correction of this divergent trend was one of the purposes for which Secretary Hoover appointed the Building Code Committee in 1921, consisting of seven outstanding architects and engineers.

G. N. Thompson of the Building and Housing Division of the Bureau was appointed Secretary to this Committee. Through Thompson, the Committee had access to the scientific and engineering staff and equipment of the National Bureau of Standards, and these resources were used to develop technical information that would answer many of the questions raised during the Committee's deliberations. Such was the process used in developing the technical basis for a series of reports, known as Building and Housing Reports, issued by the Building Code Committee between 1921 and 1933. These reports covered such subjects as the construction of small dwellings, plumbing requirements, minimum live load requirements for buildings of several occupancies, masonry wall requirements, allowable stresses on materials, and a uniform arrangement for building codes. During this same era the Bureau prepared more than 200 Federal Specifications which were circulated to industry for comment and modified in conference and consultation through liaison with the American Engineering Standards Committee. A large number of these specifications covered building materials and components, such as paint, varnish, cement, lime, asphalt, built-up roofing, glazing, etc.

In 1933, as a result of an economy program in the Federal Government, the American Standards Association established a Building Code Correlating Committee to take over the work of the Building Code Committee of the U.S. Department of Commerce. In the ensuing years technical questions that arose in the ASA Sectional Committees continued to form the basis of many scientific investigations at the Bureau. Thompson was chairman of the Building Code Correlating Committee for many years and also of the Construction Standards Board which succeeded it.

The Bureau provided leadership in many important construction standards activities by directly sponsoring the following American Standards: the National Electric Safety Code (ASA C2); the Safety Code for Elevators (ASA A17); Building Code Requirements for Minimum Design Loads in Buildings and other Structures (ASA A58); and Building Code Requirements for Masonry (ASA A41). In addition, staff members participated actively in the development of other American Standards in the field of building construction, including the National Electrical Code (ASA Cl), the Safety Code for Building Construction (ASA A10); Building Code Requirements for Fire Protection and Fire Resistance (ASA A51); and the Safety Code for Mechanical Refrigeration (ASA B9).

When the American Standards Association decided to incorporate in 1947, the U.S. Department of Commerce felt obliged to withdraw as a member body 


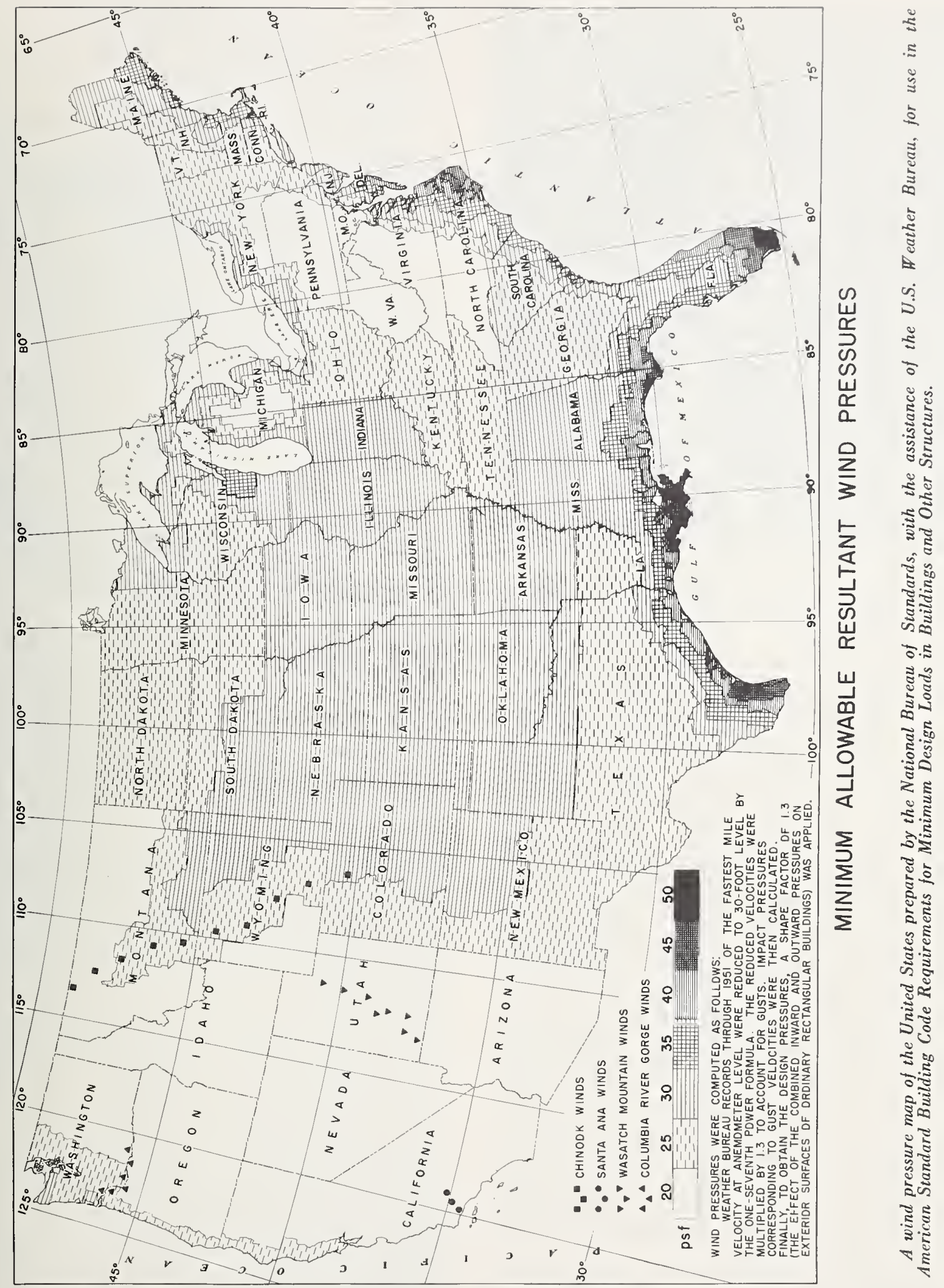

because it was considered inappropriate for a Federal agency to hold membership in an incorporated association without statutory authorization. This action brought an end to an era of Bureau leadership in national building standards activities that had extended over a period of nearly thirty years. The fact that E. C. Crittenden, Associate Director of the National Bureau of Standards, was Chairman of the 


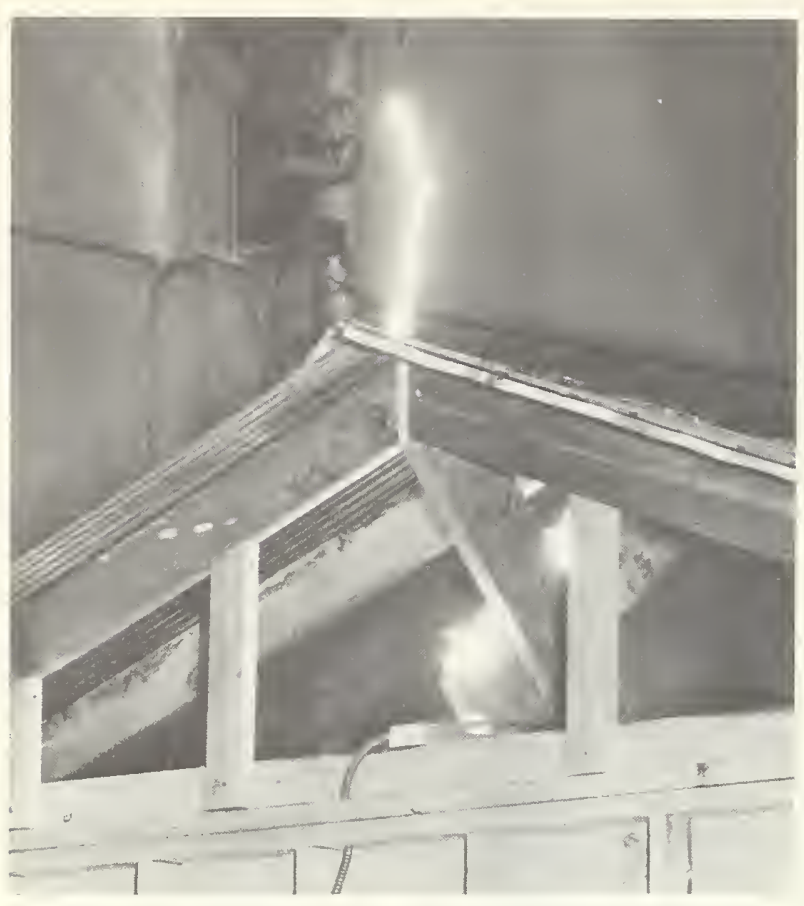

The lightning hazards of ungrounded metallic roofing, siding, and reflective insulation were investigated using high voltage discharges to typical simplified building constructions.

Standards Council at the time the Bureau terminated its membership in the American Standards Association is indicative of the type and extent of the leadership role that had been exercised up to this point. It was not until 1952 that Bureau personnel resumed participation in Standards Council meetings. and then only on an "observer" basis.

In the period from 1947 to 1960 , the staff of the Building Research Division concentrated its attention on the properties of building materials, structures, equipment, and facilities. Staff members continued to participate as individual members of various committees of the American Standards Association and to furnish technical information developed at the Bureau to these and other standards-writing committees, but leadership and coordination in national standards by Bureau personnel was deemphasized.

In the last few years a reversal in this trend has brought widespread recognition of the need for greatly increased collaboration between the Federal Government and the building industry in revision of building codes and standards to permit and promote the use of new materials and methods in building construction. Under the leadership of A. Allen Bates during the period 1962 to 1967, the Building Research Division again increased its activity in building codes and standards, and this increased participation has continued and grown since 1967.

\section{Current Programs and Objectives}

A number of forces have brought about gradual change in recent years in the objectives of the Build. ing Research Division and the means for carrying them out. Some of the principal influences in this change are as follows:

a. Increased emphasis at the national level on the application of scientific and technical methods to major civilian industrial activities.

b. Reorganization of the Bureau into Institutes.

c. Industry development of new materials and systems with potential use in building construction.

d. Long-range planning within the Division.

e. Move to new laboratory facilities.

f. Application of computer science to technical analysis, design, and performance of buildings and building systems.

g. Emphasis on the performance concept in evaluation of building components and systems.

The changes in emphasis and in the laboratory research and development programs have been gradual and are still in progress. The nature of these changes will be described briefly and some examples of current laboratory work will be presented as illustrations.

\subsection{Organizational Change}

During the last few years it became evident at the national level that space science and advanced military research had produced sophisticated technology that could have significant application to major segments of civilian industrial activities. It was also evident that the full potential for scientific spin-off into civilian activities was not being realized because adequate scientific resources of men, materials, leadership, and planning were not being allocated to important industries such as building construction, transportation, and textiles. One of the steps taken by the Department of Commerce to stimulate greater application of scientific methods to some of these industries was to reorganize the National Bureau of Standards in 1964 into three Institutes: namely, the Institute for Basic Standards, the Institute for Materials Research, and the Institute for Applied Technology. The Building Research Division and two other existing technical divisions were placed in the Institute for Applied Technology, and several new units were created to centralize the Bureau's assistance to the nation's industries through laboratory research and development, and systems analysis.

Since 1964 the structure of the Building Research Division has been altered to emphasize the principal functional characteristics of buildings; namely, structural strength, fire resistance, durability, and environmental effectiveness; and to develop and apply the systems engineering process to building design and construction. Furthermore, the routine testing of cement and concrete for the construction agencies of the Federal government was transferred to the Corps of Engineers, and laboratory research in the chemistry and physics of cement and concrete was greatly dimin. ished. The administrative structure also recognizes that the useful output of the Division to the building industry and to the nation is in the form of advanced tech. nical information and test methods that can be used by other organizations in the preparation and promulgation of standards, codes, and specifications. Con- 


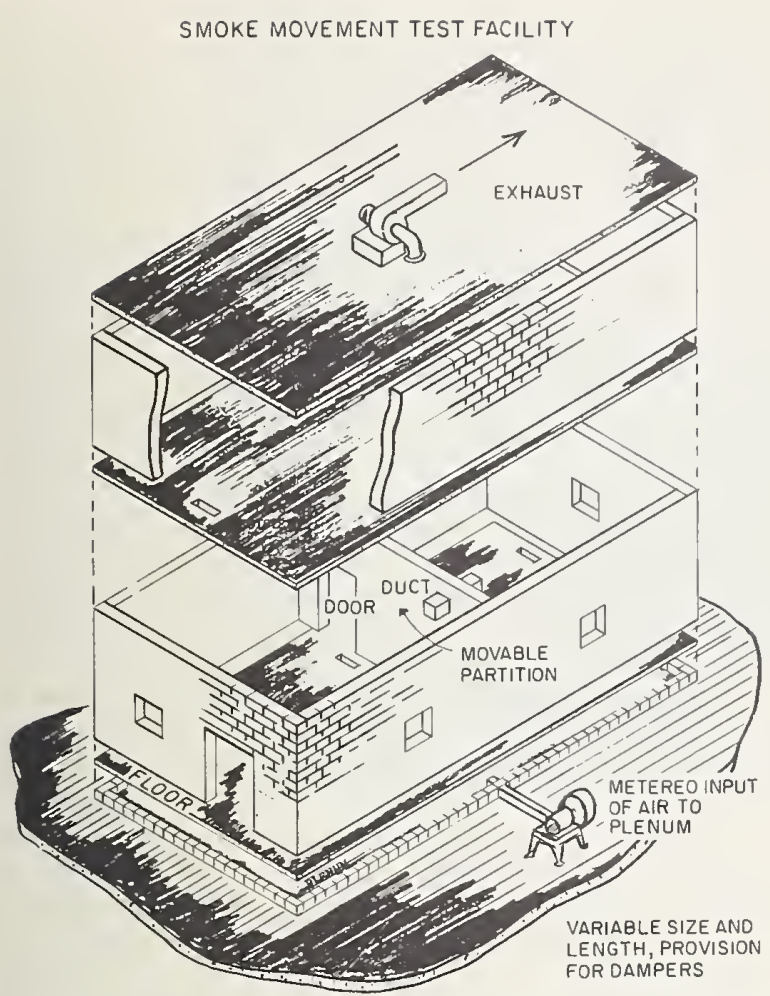

This two-story test facility of brick was designed to permit the study of the spread of smoke and fire both horizontally and vertically under various conditions of ventilation and air flow pattern. The facility has a ventilated plenum under the first floor, floor register openings through the first and second floors, an interior partition and several window openings on the first floor, and an exhaust blower in the second floor ceiling to permit a variety of air flow patterns to be sim. ulated.

currently, the Division, along with the rest of the Federal government, has adopted the program planning and budgeting system (PPB) conceived and first implemented in the Department of Defense. This system is characterized by a functional relationship in mission from the smallest Bureau subdivision to the Departmental mission, by program-planning five years in advance, and by analysis of the cost-benefits of all programs that are in progress or newly implemented. The categorization of the Division program into the eight subelements described earlier in this bulletin is a part of this programming and budgeting system.

\subsection{Occupation of New Facilities}

Laboratories for building research became available at the new headquarters of the National Bureau of Standards at Gaithersburg late in 1966. The occupation of these facilities broadened the scope and capability of some parts of the building research program, notably those in structures and thermal environment, whereas some other important programs have fewer facilities at the new site than existed at the Washington laboratories; viz. fire research, architectural acoustics, and plumbing.

The Structures laboratory at Gaithersburg utilizes not only testing machines but the modern concept of a heavily reinforced "tie-down" floor together with sophisticated hydraulic actuators as a loading system instead of the usual array of testing machines. 'The test floor, which is independent of the building frame, consists of heavily reinforced concrete, six feet in thickness, containing an imbcrlded grid of steel I-beams to resist lateral thrust. The main section of the test floor is approximately $50 \mathrm{ft}$ square and has a $20 \cdot \mathrm{x}$ 25 - $\mathrm{ft}$ extension on one side for testing long beams. The structure under test, whether a beam, slab, frame, or other configuration, is either anchored to the test floor directly or supported by heavy steel members which are anchored to the test floor at selected points. The hydraulic loading system is capable of applying either a fixed or a cyclic load which can be programmed with respect to magnitude, amplitude, and frequency.

The testing machine laboratory contains six testing machines for compression, torsion, and universal testing, and a laboratory for application of high-level sustained loads to concrete and masonry specimens with automatic equipment for monitoring and recording deformation of the specimens.

The environmental facilities at Gaithersburg comprise thirteen special purpose environmental chambers ranging from one to three stories in height. The largest of these will accommodate a full-size house as a test specimen. Other rooms provide environments for study of thermal conductivity in an underground laboratory at constant temperature; for studies of air condi. tioning systems, heating systems, refrigerators and freezers, refrigerated warehouses and vehicles, and air cleaners: and for investigation of heat, air and moisture transfer phenomena in building elements. These special purpose laboratories incorporate temperature and relative humidity control in various ranges from -50 to $150^{\circ} \mathrm{F}$ and 15 to 85 percent, respectively.

New large-scale facilities for studying the fire endurance of walls, floors, and columns and for investigating the growth, spread, and extinguishment of fire, were not included in the initial construction program at Gaithersburg. Likewise. sound transmission laboratories and hydraulic facilities for full-scale plumbing research have not been constructed at the new site, Limited programs in fire research continue to be carried out at the Washington site, while planning for new laboratories at Gaithersburg is in progress.

\subsection{Changes in Program Emphasis}

The building industry has always used a very wide range of materials for the construction of buildings; e.g., from natural materials such as rammed earth for walls to cable-supported roofs of sophisticated curvature. However, in recent years manufacturers have developed a large number and wide variety of new materials and new combinations of organic, inorganic, and metallic materials for use in buildings. Quite often these new products cannot be evaluated adequately by existing test methods. Likewise the gradual growth in factory-prefabricated components as a substitute for field assembly of components has 


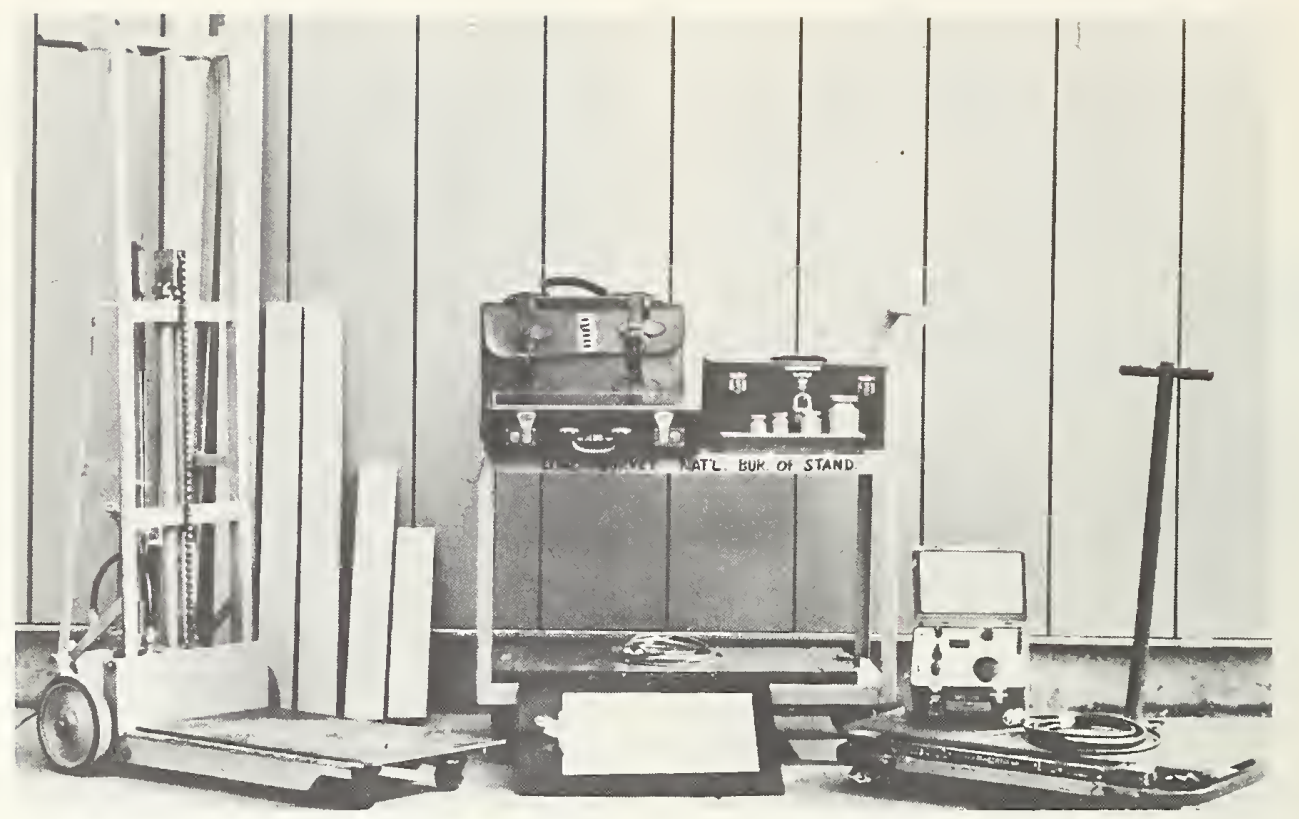

Two types of commercial desk handlers, an electronic load platform, and other equipment and supplies used in evaluation of live floor loads and fire loads in modern office buildings. This equipment was used to determine the weights and approximate horizontal locations of all items in each room of several buildings. The amount and location of combustibles in each room was also determined in two categories: "movable contents" and "interior finish." A computer program was developed for tabulation of data, statistical analysis of the information, and preparation of graphical relationship between the measured loads and the characteristics and usage of the structures.

created a strong demand for new evaluative procedures. Thus the competition in the market place between new products and those of conventional design with a long experience record emphasizes the need to describe the requirements of the user in performance-type language rather than by specifying particular classes of materials. dimensions, arrangements of components, or physical and chemical composition of the materials.

The rapid growth in the use of computers in building design has also stimulated efforts to evaluate building systems in performance terms, because computer methods permit analysis of a larger number of design variables, the study of more complex designs, and a more rapid and economical comparison of alternate designs than was possible by earlier techniques.

Thus the need to evaluate materials and systems of widely different physical and engineering properties for a given application, and the more sophisticated analytical methods made possible by computer technology have stimulated the manufacturer, the designer, and the user to look toward performance requirements as a desired evaluation technique. The application of the performance concept has in turn revealed the inadequacy of some of the existing test methods and indicated the need for new technical data on materials and systems.

Industralized prefabrication of building components, and efforts to identify performance requirements for them and for integrated structural and environmental systems, have also led to research on test methods for more complex components of building than heretofore.

\subsection{Current Research and Development Programs}

In the last two years the research program in structures has emphasized the acquisition of new field data on the live loads occurring in buildings of various occupancies, the development of new design data and test procedures for the engineering properties of structural masonry, and research on the interaction between different elements of framed structures.

A pilot study of live floor loads and fire loads in two large office buildings has been completed. Relatively inexpensive equipment for rapid weighing of building contracts was developed. The furniture, equipment, and interior fabrics of the various rooms were categorized with respect to location and combustibility, to furnish new data on fire loading of buildings. Data code and logging forms were devised and a statistically oriented computer program was prepared for establishing correlations and probabilities and for direct graphical representation of the significant results from the field data. The results [31] of this pilot study will be used as a basis for statis. tical sampling of the rooms in additional buildings of similar occupancy under the sponsorship of the American Iron and Steel Institute, and have already been used in carrying out load surveys in post office buildings.

A group of studies on structural masonry systems is in progress. Work leading to a new test procedure for determining the racking strength of masonry systems has been carried out in which an apparatus capable of simultaneously applying edge loads and racking loads 
to large masonry wall specimens was developed. The transverse or flexural resistance of unreinforced masonry walls to wind loads and other horizontal forces has been investigated for a variety of materials, including brick, block with crushed stone aggregate, split block, and lightweight concrete units. The investigation included specimens bonded with conventional and high-bond-strength mortars. The effect of edge load on flexural strength of masonry systems utilizing highstrength mortars has been reported [32] and a computer program for calculating the strength of walls under the combined action of edge and transverse loading was developed. An apparatus has been designed for studying the inelastic and time-dependent response of high-strength concrete to high-level sustained loads. Laboratory investigations to develop engineering data on creep at these high loads are in progress.

Evaluation of the strength of buildings and their behavior under load is made complex by the interaction between the various elements in composite systems and the transfer of stress at the connections between prefabricated components. A research investigation is in progress for studying the effect of shear-stud spacing on the strength and behavior of composite beams comprised of concrete slabs and structural steel beams connected by welded shear studs. This study is planned to provide new design information on composite flexural members in buildings. In another study, the behavior of precast concrete continuous beam-tocolumn connections, both reinforced and prestressed, is being investigated. The continuous beam-to-column connections were designed to represent typical field conditions including the effects of axial loads in the beams. An important objective in this study is to develop a method of test for structural connections in prefabricated structures.

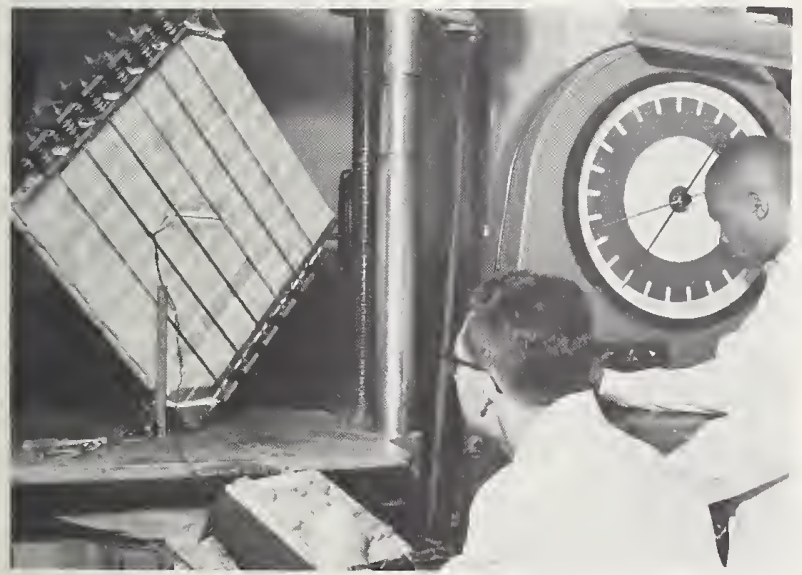

A simplified test procedure for studying the racking failure of masonry walls was developed using quarter-scale models of concrete masonry units. The racking loads were applied diagonally to the masonry wall in a compressive testing machine while a system of spring-loaded yokes simulated normal ver. tical load along the top edge of the wall. Racking failures were obtained in the models which were quite similar to those observed in prototype walls. It was found that relatively small boundary forces had a measurable effect on the racking strength of the models.

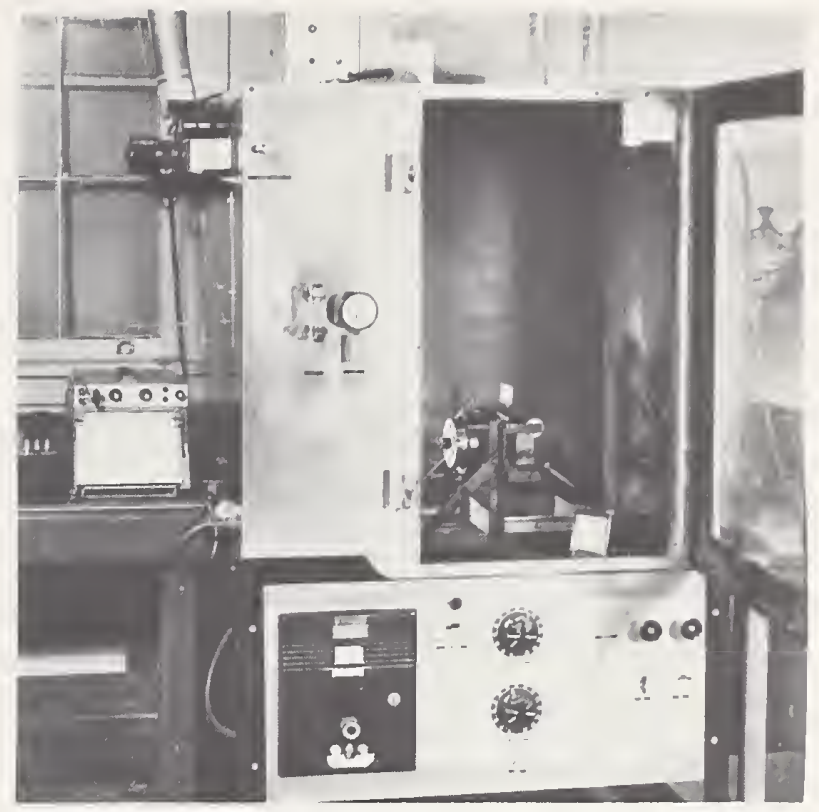

A smoke test chamber developed at the Bureau to study the obscuration effects of smoke produced during either flaming or smoldering exposure of materials. Small specimens of fabrics, sheet materials, or laminates of known surface area are $i g$ nited and burned in the chamber and the smoke accumulates without significant decrease in oxygen content. The progres. sive attenuation of a light beam passed vertically through the smoke aerosol is measured by a photometer. Smoke is reported in terms of specific optical density over a unit length of path within a chamber of unit volume per unit surface area of the specimen.

Current fire research is centered around studies of the flammability of fabrics and plastic films, the detection and analysis of toxic decomposition compounds in fire gases, inhibiting agents for control of fires, the fundamental mechanisms in flame spread, and experimental and theoretical investigations of the air movement in rooms caused by an incipient fire. The growing recognition that the obscuration and toxic effects of smoke constitute a major hazard to life during the early stages of many fires, even before the danger of high temperatures is critical, has led to increased research on the generation, composition, movement, and detection of combustion gases and smoke.

A test method and apparatus for measuring the amount of smoke produced by smoldering and flaming combustion of materials and for evaluating the obscuration effect of the smoke has been developed recently, and many common building materials have been evaluated in this apparatus [71]. The convection pattern for the air and combustion gases produced in a room during the initial stages of a localized incipient fire within the room has been investigated [72] as a basis for the development of early fire detection and suppression techniques. The characteristics of the gas flow pattern have also been studied photographically and described with mathematical models for computer analysis [73].

An investigation was completed of dwelling unit doors as barriers to fire and smoke. This preliminary 
investigation [74] showed that conventional wood panel doors served as effective fire barriers for only a few minutes and that none of the usual edgetreatments for doors was very effective in controlling the transmission of smoke. Recommendations were included in the report for measurement of radiation flux from all doors during test, for a standard method for the measurement of smoke transmission around the edges of doors, and for better standardization of furnace pressures to control the gas leakage around doors during test. The need for development of improved methods to reduce smoke transmission around doors was also emphasized.

A survey has been completed of methods for analyzing the toxic combustion products from burning cellulosic and plastic materials, including gas chromatography, colorimetric detector tubes, infrared absorption, specific ion electrodes, and classical wet chemistry procedures. Determinations [75] have been made employing one or more of these measurement techniques, of the optical density of the smoke and the maximum concentration of various toxic combustion gases from burning a large selection of materials typically applied as interior finishes in commercial aircraft, for use by the Federal Aviation Administration in a broader study of hazardous combustible characteristics of cabin materials. A closely related study is being carried out to determine the nature of the final degradation products of fire extinguishing agents after exposure to diffusion flames as a means of clarifying the mechanism by which inhibition is effected in combustible materials.

Active programs in environmental engineering during recent years are related to the characteristics and parameters of building materials and components that influence the interior thermal environment, to the equipment and systems that generate and distribute energy for heating and cooling buildings, to the hydraulic systems that provide potable water and sanitary drainage, and to selected interactions between these major systems. A nationwide survey of the various computer programs for calculating the heating and cooling loads of buildings has been completed for publication [137]. This investigation revealed that the identification and input of data on the physical parameters of the building, the weather, and the usage was the most time-consuming part of the computer calculation process. The feasibility of storing all of the handbook data in a large-memory computer was investigated, as well as a system which employs optical scanning of carefully designed data input sheets. The improvements in load calculation methodology have been coordinated with a task group of the American Society of Heating, Refrigerating and Air-Conditioning Engineers as a part of an overall effort to develop a computer program for calculating the characteristics of temperature and humidity in an occupied building under the dynamic operating conditions of outdoor weather, energy usage and distribution, and occupant density and activity. A related study employs a modelling technique for analyzing the complex convection pattern inside a room bounded by different combinations of heated and cooled surfaces. A flow visualiza- tion method [138] employing photography to evaluate the velocity and direction of air currents in small enclosures has been developed. A model that will permit study of air motion in full-sized rooms is under construction and a mathematical model has been developed for computer prediction of the experimental findings.

An experimental apparatus for investigating the basic mechanisms of simultaneous transfer of heat, moisture, and air through building constructions with or without internal cavities has been constructed. Long-term studies of wall constructions employing fibrous insulation and foamed plastic insulation have been carried out to explore the relative importance of diffusion and convection as transport processes for movement of water vapor through openings and through fibrous and other materials, and to study methods of measuring moisture accumulation inside of building elements.

Investigation of the factors affecting the thermal environment in underground fallout shelters has continued. An analysis [139] of the frequency and duration of periods of summer weather with high dry-bulb temperature and high dewpoint temperatures was completed for six cities. illustrative of different climatic areas of the country. The effect of simultaneous occurrences of high temperature and high humidity on the environment in underground shelters was evaluated as a basis for selection of the minimum design ventilation rates to be used in various climatic regions. These pilot studies have been used by others as a pattern for an analysis of the environmental conditions likely to occur in fallout shelters throughout the country on a probability basis, and to

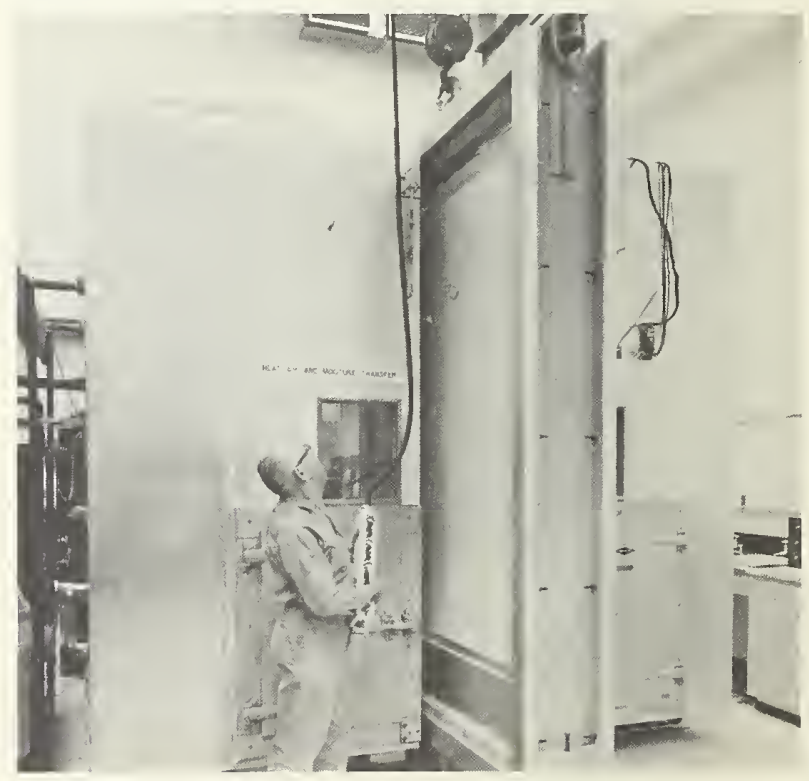

An apparatus for studying air, moisture, and heat transfer through full-scale exterior wall constructions was composed of two environmentally-controlled chambers, open on their facing sides, capable of being closed with an airtight seal against a steel support frame for the wall specimen to be tested. A wall specimen is being moved into the apparatus by an over. head crane in this photograph. 
prepare design criteria for ventilation systems for shelters. A comparison of the digital computer simulation of environment with observed conditions during tests of seven different shelters in various climates was prepared for the Office of Civil Defense. A comprehensive set of analytical heat transfer solutions and finite difference calculations was completed to show the effect of various climatic, occupancy, and construction parameters on the temperature conditions during short occupancy periods.

Improvements in measurement techniques for air conditioning calorimetry have been studied in continuing programs. The performance of square-edged orifices as air mixers has been reported [117] and good application techniques and probable errors in the use of thermocouples, thermistors, and thermometers for measuring the temperature of moving air in isothermal and nonisothermal surroundings have been described [118].

Work continues on the development of test apparatus and procedures for accurate measurement of the thermal conductivity of insulations, metals, and alloys, and to develop data on selected materials to be used as thermal conductivity reference standards in other laboratories. Work of primary importance was carried out on the thermal conductivity and electrical resistivity of thermocouple-grade platinum in the temperature range from 100 to $900^{\circ} \mathrm{C}$. This investigation [91] improved the accuracy in measurement of the thermal conductivity of platinum and by correlating the results obtained by the heat-flow method with those obtained when heating the specimen by passing an electric current through the specimen, through the Lorenz number, it made possible the use of a relatively simple electrical resistivity measurement for determining the thermal conductivity of platinum. Data on the thermal conductivity, electrical resistivity, and Lorenz number of Armco iron, often used as a reference material, also have been published [92], as well as data [93] on the thermal conductivity of four commercial heat-resistant alloys in the temperature range from -150 to $700{ }^{\circ} \mathrm{C}$. Analytical formulations were developed for numerical evaluation of thermal radiation characteristics of cylindrical and conical cavities to facilitate analysis of the results obtained in the thermal conductivity experiments.

A recently completed study of domestic drainage systems sought to identify the important physical characteristics and usage parameters that affect the accumulation of greasy deposits associated with kitchen drains. Measurements were made of temperature gradients, hydraulic resistance, fluid density, viscosity, fat content, weight, and longitudinal center of gravity of waste accumulations in drain systems representing the widest range of materials likely to be used.

The objectives of current investigations of the dura. bility of building materials and components are to evaluate the deterioration caused by interaction between the elements of the weather and externally exposed parts of a building, and to a lesser degree the interaction between the user of the building and the building components with which he comes in contact, such as floor and interior wall surfaces. Evaluation of deterioration is alternatively made under natural conditions of exposure or simulated exposure as in a weathering machine, an abrasion aparatus, or some other device designed for a particular purpose.

An additional objective is to obtain correlation between deterioration under natural conditions of outdoor exposure and accelerated simulated exposure in a laboratory apparatus, so the latter procedure can more reliably and expeditiously be used to determine durability of materials.

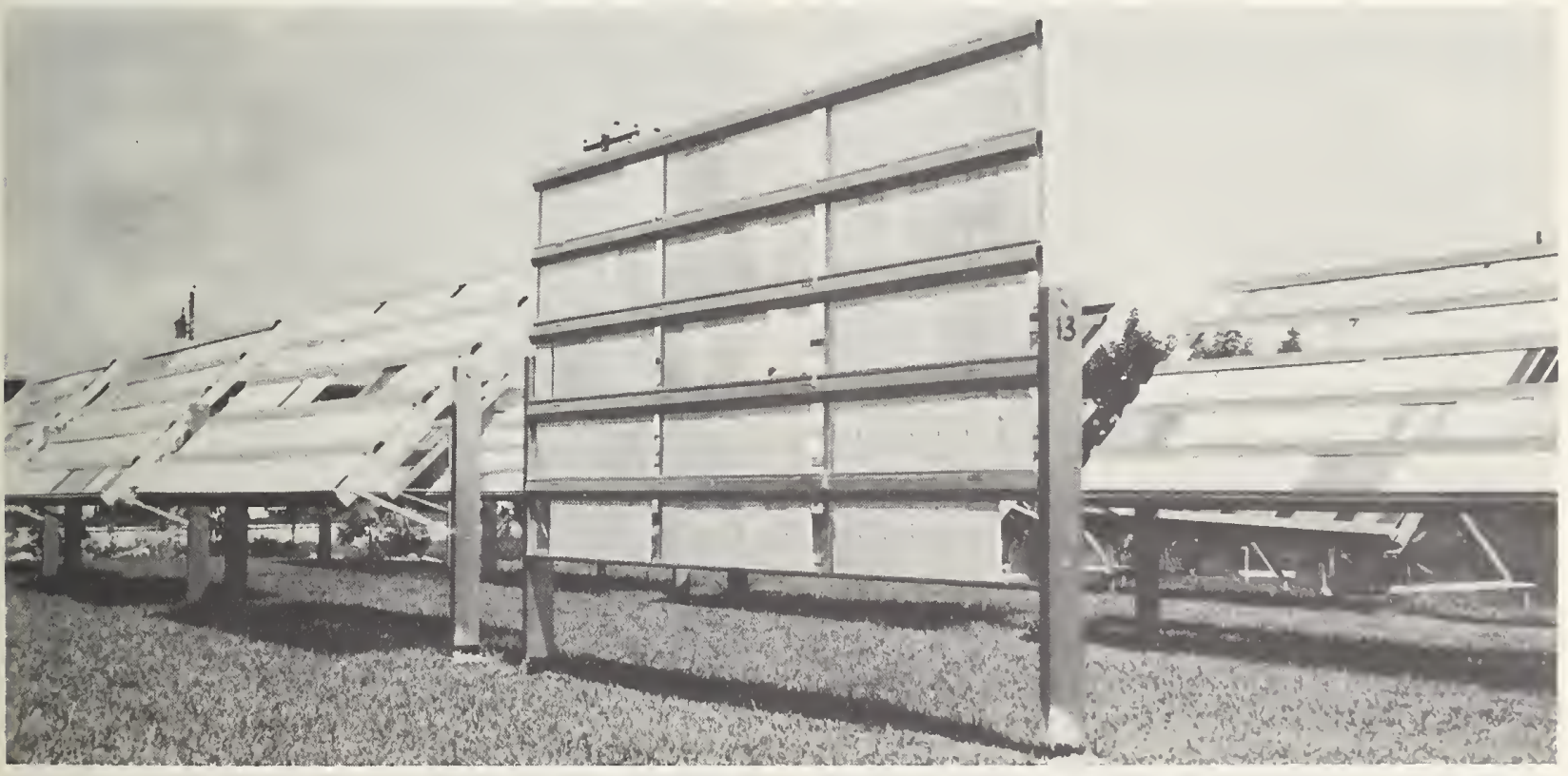

Material exposure racks at a Florida test station. These racks allow exposure of the test specimens to different quantities of solar radiation by changing the angle of exposure. 
Six exposure sites have recently been established at locations representing a variety of North American climatic conditions from arctic to semitropical, from dry to humid, and from industrial to rural, to enhance the study of the interaction between weather variables and the deterioration of building materials.

New efforts have recently been initiated to identify and measure the elements of outdoor environment that significantly affect deterioration or degradation of building materials. Of particular interest is the selection or development of instruments for measuring the amount of radiant energy received in the ultraviolet region of the spectrum, which is a predominant cause of chemical degradation of some materials. Another important weather parameter being explored is the frequency and duration of surface wetness caused by the surface temperature attaining the dewpoint temperature in conjunction with exposure to air pollutants such as the oxides of nitrogen and sulfur. It has been found that the optical properties and surface roughness of a material significantly affect the formation of dew because of their effect on energy exchange. A closely related effort is the development of an environmental test chamber [369] to simulate and accelerate outdoor corrosive conditions of metals when sulfur dioxide is a contaminant in the atmosphere. The correlation between natural exposure and accelerated laboratory exposure is being explored by testing selected specimens of zinc-coated, aluminumcoated, and aluminum-silicon-coated steel in this chamber and at the Gaithersburg outdoor exposure site while monitoring carefully the environmental conditions in both instances. New studies are also being undertaken to measure under simulated service conditions the chemical and physical changes which occur in plastic sheets and paint films when exposed to atmospheres contaminated with sulfur dioxide and ozone while being irradiated with a xenon lamp. Another correlation being investigated is the weatherability of porcelain-enameled metal in outdoor exposure and the indications of discontinuities in the enameling revealed by a high-voltage probe moved over the surface.

A comprehensive laboratory study of the engineering properties of built-up roof membranes, combined with an extensive field investigation of failures in similar membranes, identified the more important parameters involved in failures of these roofing systems. The results of the study showed that failures due to thermal shock were related to certain physical properties of bituminous built-up membranes such as breaking load in tension. modulus of elasticity, and the coefficient of linear expansion. A thermal-shock resistance factor [227] was derived from the laboratory data on these physical properties and the values of this factor were correlated with the observed performance of similar materials in service. Values of the thermal-shock resistance factor were reported for commonly used built-up membranes for the temperature range likely to occur in the United States. This approach tends to bridge the gap between laboratory measurement of engineering properties of built-up roofing membranes and the in-service behavior with respect to thermal stress failure. In a related study [228], newly-developed analytical colorimetric methods and gas chromatography were used to measure peroxide, carbonyl, and carboxyl formation during photo-oxidation of asphalt films.

A hail-resistance test was developed under the Research Associate program of the Asphalt Roofing Industry Bureau [229]. This test was developed primarily for roofing, but is applicable to all building systems. The damage to various roofing systems has been evaluated under the impact of hail stones typical of those encountered in various parts of the country. This research associate program has also constructed a small-scale flame spread apparatus for roofing specimens, and explored the correlation between the results obtained in this apparatus and the larger apparatus of Underwriters' Laboratories.

Both laboratory and field studies are in progress on floor coverings and flooring systems. The labora. tory effort comprises a study of the bonding of various floor coverings to a concrete subfloor, and the effect of concrete curing agents on this bond. Included in this study are resilient floor coverings such as linoleum and asphalt and vinyl tile; seamless, monolithic surfacings; and textile floor coverings. The field evaluations [230] were conducted on new flooring systems at military installations where heavy wear and rough usage occur, such as barracks and mess hall kitchens. The results of these studies are being used to revise military and Federal specifications and ASTM and product standards for floor coverings, substituting performance requirements for material requirements wherever possible.

Major programs in the development of test methods and specification requirements for protective coating systems are in progress. The research falls into three broad categories: (a) development of new and im. proved methods of chemical analysis; (b) develop. ment of new and improved physical methods of tests, and (c) formulation of criteria that are reliable indicators of the performance of coatings in service. Some of the published technical data [231,232] and test methods $[233,234]$ have been incorporated in ASTM Standards and Federal $[235,236]$ or Military speci-

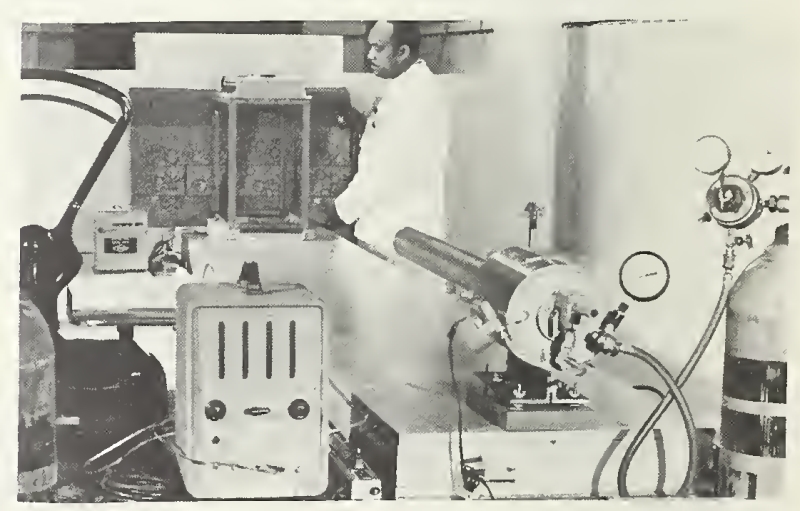

An apparatus for studying the hail resistance of roof constructions. The apparatus consisted of a compressed air gun for launching the hailstones, a timer for determining their velocity, and a target area for positioning the test specimen. 
fications. A manual [237] presenting practical information on the properties, selection, and use of organic coatings and a discussion of basic principles in a number of areas related to composition and application of these coatings was issued recently. In a related development for the military services, most of the source material for a protective paint manual was provided to a contractor preparing the manual, and the manuscript has been reviewed progressively as the various portions were prepared. These publications represent comprehensive and authoritative guides to the architect, engineer, maintenance superintendent, procurement officer, and others responsible for the proper selection and application of paints and other organic coatings.

Laboratory and field studies of single and multicomponent elastomeric joint sealants for building construction have been in progress for several years. Recently a new, accelerated laboratory test procedure has been developed which predicts 20-year performance of sealants in active joints between masonry. metal, and glass panels as used in modern building design. For test purposes, an electronically controlled machine was developed to automatically compress and extend sealants at a specific rate and number of cycles at high and low temperatures, respectively. The idea of compressing the sealant beyond its nominal width is unique in specification requirements. The machine has been widely accepted by the sealant industry. The performance requirements developed in the sealant program have been incorporated into three Federal Specifications which are being used by state, municipal, and private procurement authorities $[238,239]$.

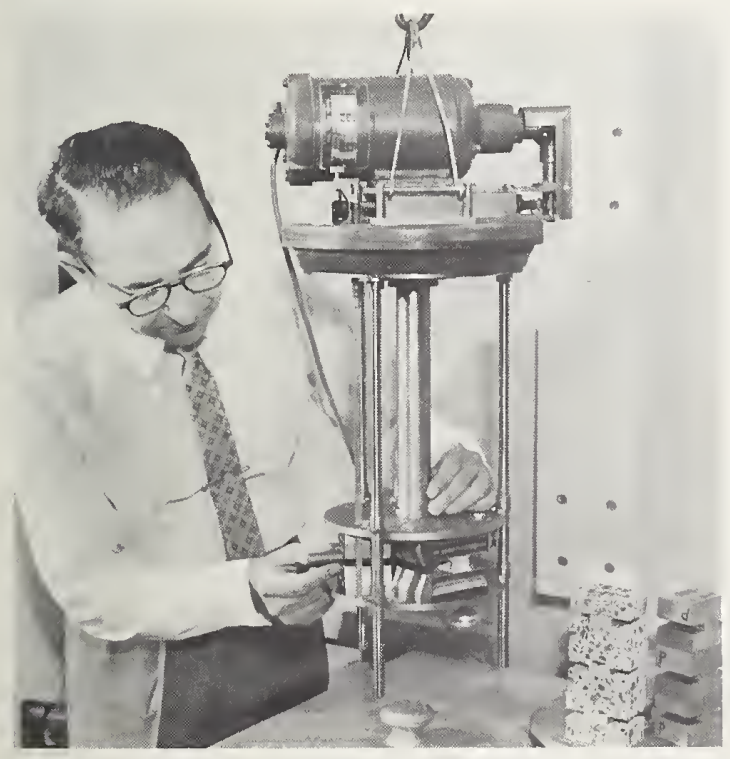

After being subjected to heating, soaking, and freezing exposures in the laboratory, elastomeric joint sealants for building construction are tested for adhesion and cohesion in this machine, to help predict the 20-year performance of these materials in buildings. Elongated sealant specimens with ply. wood substrates are shown being removed from the stainless steel grips in the machine. At the right are sealant specimens between lightweight aggregate and conventional concrete substrates prepared for test.
A numher of studies have been carried out in the current program of the Building Research Division in which critcria for some component or subsystem of a building have been developed on a broad interdisciplinary base. Some of these studies have been completed and others are still in progress. In most instances the performance concept has been applied to the development of the criteria, in which the adequacy of the component for the needs of the user was the central objective of the evaluative procerlure rather than measurement of any specific set of physical, chemical, or engineering properties. In each case the appearance in the market of a new combination of materials or a new solution to a users' need has been the stimulus for seeking evaluative procedures that were responsive to important performance requirements, but were not based specifically on the properties of the conventional products or systems of the past. Several of these studies are described in the following paragraphs to illustrate their nature.

An investigation [370] of the performance characteristics of sanitary plumhing fixtures was carried out. with the emphasis of the laboratory studies directed principally toward bathtuls. This study was hrought about by the introduction into the market of glass. fiber-reinforced plastic bathtubs in competition with the conventional enameled steel and cast iron models, and in consequence of the recognized difference in the physical, chemical, and engineering properties of the new product as compared to the metal bathtubs. Many existing test methods were evaluated, and several new or modified tests were developed. before test procedures were recommended for evaluation of sixteen characteristics covering structural, mechanical, thermal, and chemical performance of both the new and conventional fixtures. This investigation illustrated rather clearly the difficulties encountered in developing performance tests for evaluating the acceptance level of properties like slip resistance, scratch resistance, and cleanability for a product made of several materials having widely different properties.

An investigation was recently completed for the Federal Housing Administration to develop performance criteria for exterior wall systems for residential construction. This study encompassed a variety of characteristics related to structural adequacy. fire safety, environmental effectiveness, and durability and deterioration. New test methods were developed for visual obscuration effects of smoke, air and moisture transfer, deflections caused by temperature and moisture effects, impact resistance, and several strength properties. New criteria were prepared for all of the strength properties and associated deformations, and new criteria were suggested for surface flammability of walls, maximum air penetration, and maximum temperature difference between room air and wall sur. face. Criteria for the effects of weathering on color change, washability, chalking, erosion, peeling, and cracking were recommender as well as criteria relative to impact and abrasion resistance. The investigation did not produce enough information on a number of characteristics related to fire, deterioration, dynamic heat and moisture exchange, and physiological com- 


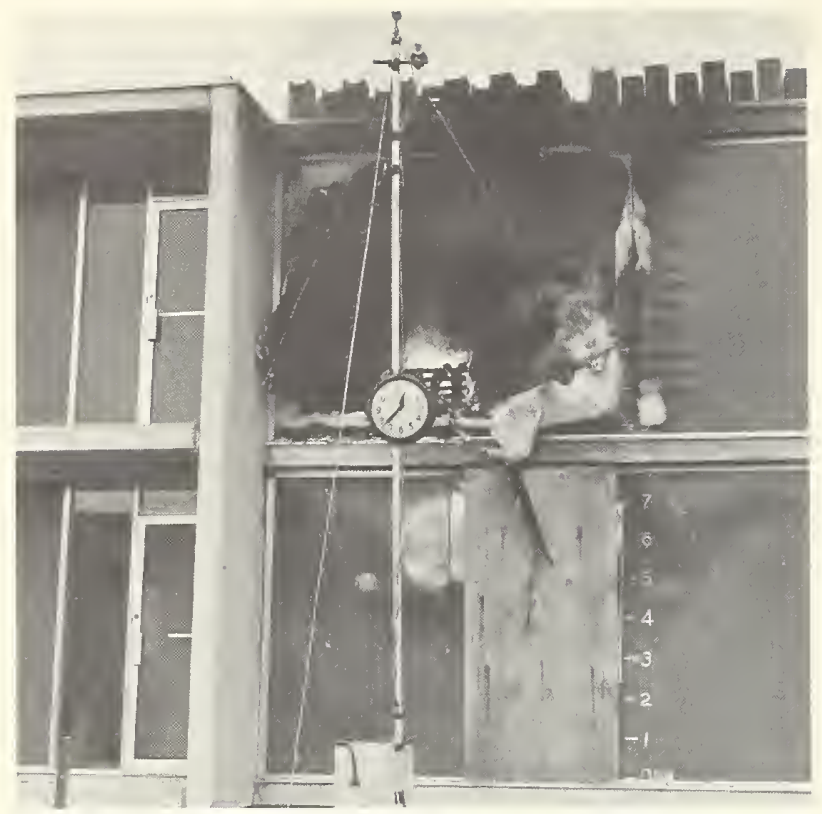

Active burning stage of an experimental test building representative of current building practice and architectural in. novations. The concrete block on the roof of the building represented the design structural load, and a wood crib inside the building provided the combustible contents for this field burnout test.

fort to permit rational selection of performance requirements.

A study was made of the performance characteristics of demountable, panel-type refrigerators insulated with polyurethane foam for their applicability to field use for storage of frozen or fresh food in military applications. The investigations covered (a) the strength of bond between the insulation and its protective metal skins. (b) the strength of the panels under compression and racking loads. (c) the heat transfer properties of the insulation, (d) the effects of internal cargo and racking forces on the air infiltration and cooling load of the assembled refrigerator, (e) the resistance of the sandwich panels to puncture and flexure, and (f) the comparison of several modifications in construction materials and processes. The results of this investigation caused the sponsor to shift his procurement from constructions using glass fiber as the insulation to a sandwich-type panel construction in which the insulation is bonded to the surface materials.

In the last few years the nationally-recognized need for the development of building codes and standards to keep pace with innovations in materials, design. assembly and construction, and the obvious urgency in rehabilitating or replacing major sections of our large cities, has caused the Building Research Division to increase its activity in building codes and standards. This increased activity has been characterized by renewed participation in joint efforts of the model building code groups, by acceptance of new leadership responsibilities as a member or sponsor of standards committees and organizations, and by collaboration with representatives from the building in- dustry and with standards-generating organizations in proposed reorganization of the nation's codes and standards system.

In May 1968 a National Conference of States on Building Codes and Standards was approved, and the National Bureau of Standards agreed to provide the secretariat for this Conference through the Building Research Division. The objectives of this Conference are: to foster cooperation among State construction and regulatory officials in developing uniform administrative procedures, requirements, and nomenclature; to develop State programs for the introduction of innovations in building materials, construction systems, and building practices; to participate in the activities of nationally recognized standards-generating organizations; to encourage comprehensive training and educational programs; and to utilize technical information developed at the National Bureau of Standards related to performance requirements and measurement techniques. As sponsor of this Conference, the Building Research Division conducts a national forum of the States for discussion, evaluation, and improvement of State laws, regulations, test methods, standards and inspection procedures that comprise the building regulatory controls of the States and their political subdivisions. and as a source of new technical information on innovative building components and sytems.

The Building Research Division participated actively in the reorganization of the American Standards Association into the USA Standards Institute. Staff members cooperated in the development of the new procedures of the USA Standards Institute and are actively participating in the Construction Standards Board, the Safety Standards Board, and the Heating, Air-Conditioning, and Refrigeration Standards Board. Administrative sponsorship or cosponsorship of seven USA Standards Committees is furnished by the Building Research Division in behalf of the National Bureau of Standards.

Contributions to the development of national standards in Colombia, South America, were made through seminars conducted there in the fields of building codes, modular coordination, electric, and elevator codes. Assistance was also furnished in the coordination of the standards effort in several cities in Colombia, designed to facilitate the formulation of a uniform building code.

The Building Systems Section was created early in 1967 to provide a focus for study of the performance requirements for buildings in a more interrelated frame of reference than consideration of the strength, safety. durability, and environmental effectiveness of the major components as independent objectives and to introduce economic considerations and the behavioral and social sciences into the evaluation process. A phased project was undertaken to apply the systems engineering process to the design and construction of office buildings of the type currently specified by the Public Buildings Service. The needs of Federal office-space users have been studied and a set of performance requirements [371] has been prepared based on these needs. A performance specification, 
based on these prformance requirements, has been completed, and revised after receipt of comments from representatives of industry and other Federal agencies. The specification is currently being enlarged to include vertical as well as horizontal structural components, the core system, and the complete heating, air conditioning, and ventilating system.

A plan for applying the systems engineering process to the building construction program of the Post Office Department was prepared. This program was designed to introduce new methodologies, organizational structures, and contractual procedures into the building construction process to accelerate completion of buildings; and to carry out long-range research to make the total network of postal buildings better serve the overall objective of mail distribution.

\section{Future Objectives}

Some of the major considerations heralding change in the building industry and the planned response of the Building Research Division are the following:

(a) The need to increase the inventory of new buildings of all kinds in the near future;

(b) The need to rehabilitate or replace large sections of the core areas of major cities;

(c) The need to lower the unit cost of commercial and residential building construction;

(d) The trend toward the industrialization of the building process;

(e) The application of computer technology to the design, analysis, construction, and testing of buildings.

The latter two items in the above list can probably be considered as a part of the cause of change in the building industry as well as a part of the methodology for meeting the national building needs. Certainly efforts have been made by various materials manufacturers to prefabricate and industrialize building components on a limited scale for two decades or more. However, this process has not advanced as rapidly or as far in the United States as in some European countries. The application of computers to building is only about five years old, but is accelerating greatly at the present time.

It is widely believed by public officials, urban technologists, manufacturers, research organizations, and others, though not universally accepted by all interests, that the urgent need for more building construction and for lower building costs can only be met by industrialization of the building process. However. there are a great many technological, regulatory, administrative, management, labor, and fiscal problems in attaining the benefits of industrialization. Of this total spectrum of problems, the Building Research Division is best able to contribute to solutions of the technological problems and to overcoming the regulatory obstacles involved in the codes and standards system as applied to building construction.

In this context, greater emphasis has been placed on the following program objectives of the Building Research Division since J. R. Wright assumed leader- ship of the Division in July 1967:

(1) Developing the potential of the performance concept for describing the functional requirements of buildings and building components;

(2) Development of an adequate compendium of supporting performance test methods, mathematical models, and computer programs;

(3) Assisting in the promulgation of performance standards, and the administrative and laboratory systems for accelerating the acceptance of innovations in building construction;

(4) Broadening the disciplinary scope of the research programs of the Division;

(5) Increasing research and technological support to Federal agencies engaged in building con. struction;

(6) Collaboration with municipalities, States, national codes and standards organizations, and Federal agencies in the unification of building requirements;

(7) Promoting the exchange of information and technological proficiency between the scientific and engineering personnel of the Division and the professionals in the building industry.

\subsection{Performance Requirements and Standards}

The research and development activities of manufacturers are producing an ever-increasing flow of new materials, products, prefabricated components, and systems for buildings that cannot be adequately evaluated by existing test methods. The present inventory of performance-type test methods falls far short of meeting the needs for evaluating these innovations, and, in fact, the potential for describing the perform-

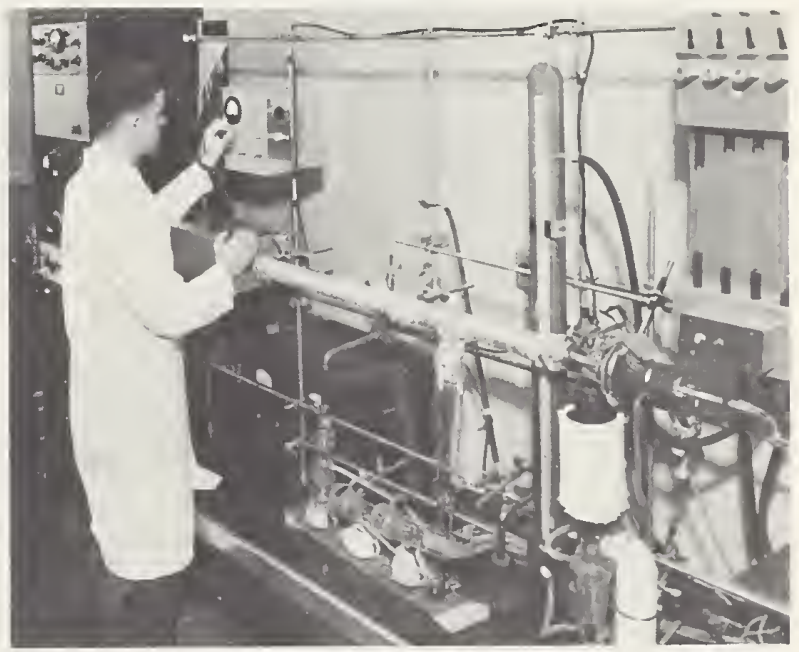

A new type of time-of-fight spectrometer was built to study" electron capture behavior as a mechanism of fire extinguish. ment by chemical inhibitors. The apparatus consists of an ion source at the right, a long drift tube in the center, a collector shielding box at the left, and auxiliary electronic equipment. It is used to analyze a simple mass spectrum in a stream of ions by measuring the time required for the ions of different masses to traverse the drift tube under the influence of opposing radio frequency fields at the entrance and exit of the drift tube. 
ance requirements for many building subsystems has not been adequately explored. Furthermore, when widely different materials or subsystems are proposed for the same application, the requirements by which they are evaluated must be first stated in broad, qualitative terms. Such statements of qualitative user requirements often involve psychophysical reactions of the occupant as well as the physical and engineering properties. Thus the delineation of performance requirements and the test methods for measuring performance require a broad disciplinary capability on the part of a research laboratory.

A detailed and comprehensive examination has been undertaken by the Building Research Division of the potential for preparing performance requirements for residential buildings and all the subsystems for residences; an inventory of presently-available performance standards and tests for measuring the performance has been prepared; an estimate of the research and development resources needed to provide the test procedures and standards not now available has been made; and, based on anticipated cost-benefits, the priorities for undertaking various portions of the performance standards development have been suggested. Future phases of this program will be com- prised of test development and the incorporation of the performance tests into national standards and into construction practice. The program of test development will include studies of not only complex fullscale building systems, but also scale models, mathematical models, and the use of computer technology for system analysis.

An initial study of the structural performance of a full-scale house section of new design was recently completed, in which a two-room section of the first floor was loaded with the design dead load, floor load, and wind load of a three-story structure. This investigation evaluated the stresses and deflection of an in. tegrated portion of a complete structure, and provided a pattern for future study of other complete structural systems for buildings. The Building Research Division has the facilities for similar investigations of the environmental characteristics of complete buildings by installing them in the new environmental facilities, where exterior temperature and humidity can be controlled over the full summer and winter range.

A similar approach will be made in evaluating the integrated systems offered by the building industry to satisfy the needs of the Public Buildings Service for office space. In this case the Division will either

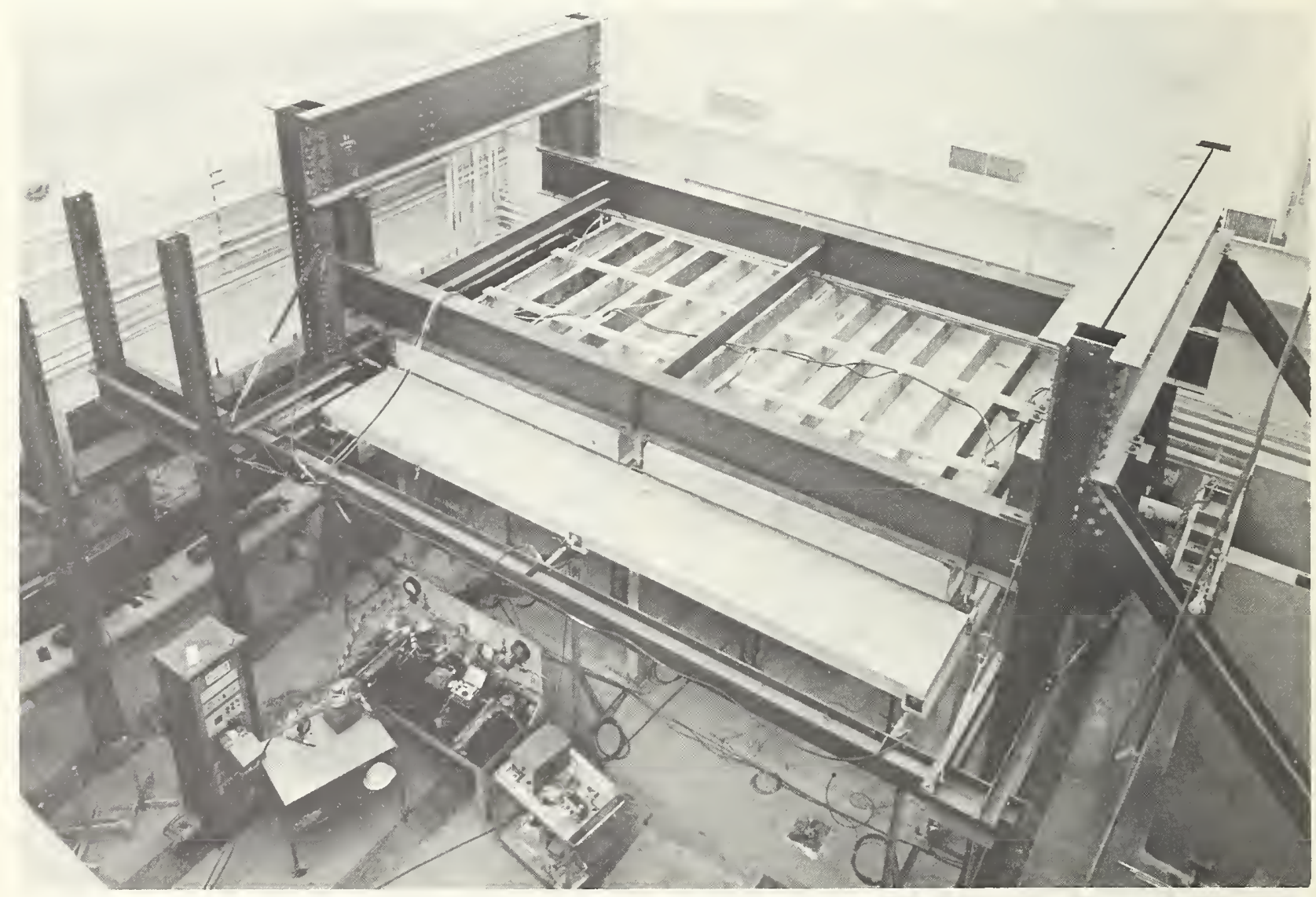

Performance tests of a full-scale subsection of a modular building system were made using a structural test floor and hydraulic loading system. The heavy steel members constituted a reaction frame for applying loads to various parts of the building. Hydraulic rams applied simulated wind loads in a horizontal direction on one side and one end of the structure, and vertical loads on the columns to simulate the loads created by the upper floor levels of a complete building. Vertical live loads on the top slab of the specimen were simulated by air bags confined between the slab and the reaction frame. These were inflated to produce a uniformly distributed load on the slab. The equipment in the foreground controlled the loading and recorded the loads and the deflections of various elements of the structure. 
monitor the tests conducted by industry or perform the tests to evaluate interior wall systems and integrated floor-ceiling constructions designed to satisfy a performance specification prepared by the Division, based on user needs and employing the systems engineering process in its preparation.

\subsection{Broadening of the Disciplinary Scope}

Consideration of the performance requirements for buildings from the user's point of view quickly reveals that the occupant is more responsive to such factors as space arrangements, natural and artificial illumination, noise and vibration control, air purity, the thermal environment, and the convenience and effectiveness of the service systems than he is to the more basic characteristics of strength, safety, and health, because he cannot evaluate the adequacy of these latter characteristics directly with his senses. Contemporary liv. ing in the city has also made building occupants conscious of the need for control of air purity, mechanical noise and vibration, illumination, thermal environment. and location and arrangement of building services.

In order to respond to this broader concept of performance requirements, the Building Research Division has created a Sensory Environment Branch which will be responsible for studies of building systems that determine and control the thermal, aural, and visual environment in buildings; advanced studies of the thermophysical properties of materials; the systems and equipment that transport energy, fuel, waste, water, persons, and materials in buildings; and the subjective response of the building occupant to the physical stimuli received from the building through his sensory system. This latter objective will involve the development of experimental techniques and data collection in the behavioral and social sciences and in architecture.

Other new areas of research in which investigations are already initiated or for which facilities are currently being developed are:

(a) field measurement of the wind forces on build. ings and the resulting stresses and deflections in the structure;

(b) field surveys of live floor loads and fire loads in buildings of different types of occupancy;

(c) the response of complex structural systems to dynamic and vibration loading;

(d) the use of a mobile laboratory to make realtime studies in the field of the growth and severity of fires, the development and movement of combustion gases, and the structural behavior of buildings during and after planned fires:

(e) the use of a mobile acoustical laboratory to study the attenuation of outdoor noise obtained by selected building constructions, the transmission of interior noise from room to room and floor to floor. and the response of the building occupants to noise of different types and intensity ;

(f) the use of the reverberation room and anechoic chamber in the new Sound Laboratories at Gaithersburg to study the acoustical properties of

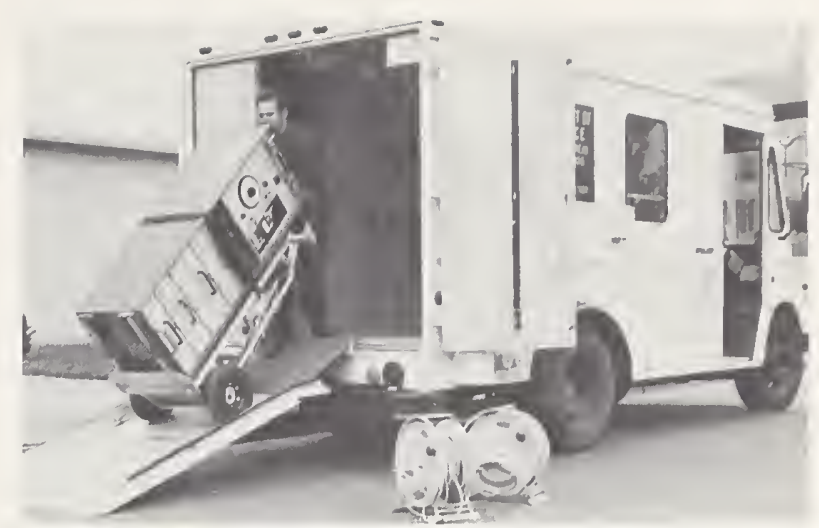

A mobile acoustical laboratory recently acquired to obtain acoustical performance data on building systems and materials under field conditions. The loudspeakers, microphones, accel. rometers, amplifiers, analyzers, and tape recorders installed in the vehicle will be useful for measuring levels of outside noise entering a building, flanking transmission paths of noise, sound absorptive properties of materials, impact-generated noise transmission, and in development of field test methods for accoustical performance. When necessary, complete mea. surement systems can be removed from the vehicle, as shown in the photograph, and located in a building under study.

different types of building elements;

(g) the development of cost analysis and cost synthesis procedures to assess carefully the cumula. tive cost of building construction on a continuous basis as construction progresses; and

(h) the enlargement of the scope of the Research Associate program to include industry $\cdot$ sponsored research programs on smoke movement in buildings, heat transfer in building components, and systems engineering in building design.

\subsection{Technological Support to Federal Agencies}

The Building Research Division has for many years provided new scientific and technical information on building materials and components to the agencies of the Defense Department. This information has been used regularly to revise and improve specifications and other procurement documents of these agencies. Likewise, research programs have been carried out for the Federal Housing Administration on an intermittent basis for about three decades, to develop information and criteria to be incorporated in their Minimum Property Standards. Currently, a planned effort is being made to enlarge the scope of this technological support to the agencies of the Federal Government. The problems of the Federal Government in designing, constructing, and operating buildings; and in the purchase of materials and services, are viewed as similar to those encountered in private construction. Since the inventory of Federal buildings as a whole is a small but significant part of the total private inventory, any improvements that can be made in the performance of Federal buildings or in the building process may result in multiplied benefits by application to private construction of similar types of structures.

In the field of housing, the Building Research Divi- 
sion expects to collaborate with the Department of Housing and Urban Development in incorporating the most recent available technical data into requirements for housing, in converting requirements to a performance basis wherever possible, in devising test procedures for innovative designs of building systems and components to reveal their suitability for current highpriority programs, and in conducting research programs in selected disciplines where the cost-saving potential of better design data appears most favorable.

The Division is assisting the Post Office Department in its large-scale post office construction program by research on the structural design of ceiling supports for equipment, studies of floor loading in post offices, and the analysis of air cleaning systems and equipment. The assistance also includes application of computer tchnology to heating and cooling load calculations, to analysis of weather data, and to the storage and retrieval of data on the location and interrelation of architectural features and the components of the various service systems in post office buildings.

In addition to the application of the systems engineering process to the design of interior partitions and floor-ceiling constructions of office buildings for the Public Buildings Service, the Division is undertaking a study of the functional arrangement of space and furniture in offices for this agency, and of the special architectural features needed in buildings for mental health patients for the National Institute of Mental Health. The performance requirements for floor coverings for hospitals are also being investigated for the Public Health Service, in relation to qualities of wear, soiling, sound absorption. and rolling friction.

\subsection{Professional Liaison and Information Exchange}

Several new methods and procedures have been initiated for accelerating the flow of technical results from Division research programs and other sources to the building industry and Federal building agencies. and for broader cooperation between the professionals

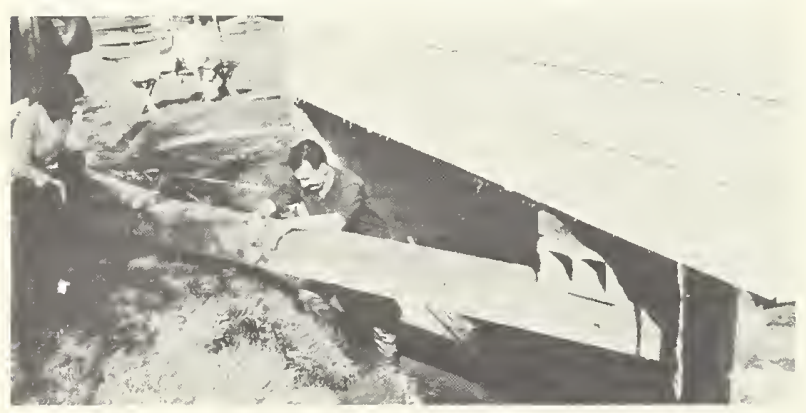

A flood in Fairbanks, Alaska in August 1967 caused extensive damage in hundreds of homes by washing out and dislocating foundations and soaking the structure and furnishings up to midheight of the first story. A visiting team of NBS engineers made recommendations that facilitated drying of the homes for early rehabilitation with a minimum removal of water-soaked building materials. in the building industry and the Building Research Division in educational and research activities.

The first of a series of conferences on Man and His Shelter was held at the National Bureau of Standards in 1968. The theme of the first conference was the Performance of Buildings: Concept and Measurement. The staff of the Division presented the results of research programs to develop performance requirements and test procedures for innovative structural systems for low-income housing, exterior wall systems for houses, sanitary plumbing fixtures, floor coverings in hospitals, and the application of the systems engineering process. Also presented was a summary of the meaning of the performance concept and the various expressions used to relate it to user requirements, testing, acceptance criteria, codes, standards, and specifications. Some of the new programs of the Department of Housing and Urban Development for stimulating experimental housing, and innovations in design, construction, financing, and user participation were described by government and private participants in these programs. The con. cept of the new town was illustrated by a member of the design team for one of these developments. This conference served to bring together more than two hundred persons representing the manufacturers of materials and building components, architects, engineers, urban planners, and research personnel from industry, government, and academic institutions.

The publications of the Building Research Division are cataloged and classified in convenient form for distribution to visiting technical groups and to inquirers by mail. The Building Science Series of technical reports was initiated to provide a specific and easily identified publication medium for reporting technical information developed principally by the Building Research Division to the design, manufacturing, and construction segments of the building industry, and to public and private officials concerned with building codes, standards, and specifications. Because some of this research information is reported in highly technical language and style, a professional writer will present selected reports in a form more suitable for application to building construction and practice.

Emphasis is being placed on expansion of the Research Associate program, because these research projects develop technical information of immediate interest and utility to industry. The program provides a good atmosphere for the exchange of laboratory expertise between industry and Division personnel, and broadens the scope of technical investigations in progress at any given time with a minimum cost and minimum duplication of industry and government effort. The Research Associate program brings industry personnel to the National Bureau of Standards for specified periods of time, where they have access to scientific effort in many disciplines. Efforts are being made to send Division personnel to selected industry organizations for similar periods of training and technical participation. 


\subsection{New Facilities}

The long-range planning of the Division for a research program that is responsive to the evolving needs of the building industry has identified a number of areas in which the laboratory facilities now available at Gaithersburg are inadequate. The lack of large-scale furnaces for fire tests, sound transmission chambers for architectural acoustics, and plumbing research facilities has already been mentioned. Detailed descriptions of the research programs and the required new facilities for carrying them out have been prepared in the areas of plumbing, fire research, architectural acoustics, the investigation of the effects of climatic exposure on full-scale building components, and large-scale dynamic têsting of complex structural systems. Several years will elapse before these high-priority facilities are constructed and equipped for use. In the meantime, the research pro-

\section{References}

\subsection{Structures}

[1] Humphrey, R. L., and Losse, L. H., The Strength of Reinforced Concrete Beams (first series, Tech. Pap. BS $1(1910-1912)$ T2.

[2] Bragg, J. C., Compressive Strength of Large Brick Piers, Tech. Pap. BS 11 (1918-1919) T111.

[3] Stang, A. H., Parsons, D. E., and McBurney, J. W., Compressive strength of clay brick walls, BS J. Research 3, 507 (1929) RP108.

[4] BOCA Basic Building Code, Bldg. Offic. Conf. Amer., Inc. (1960).

[5] National Building Code, Nat. Board of Fire Underwriters (1955).

[6] Southern Standard Building Code, Southern Bldg. Code Congr. (1965).

[7] Uniform Building Code, Intern. Conf. of Bldg. Offic. (1964).

[8] Final report of the special committee on steel columns and struts, ASCE Trans. 83 (1919-1920).

[9] Basquin, O. H., Tangent Modulus and the Strength of Steel Columns in Tests, Tech. Pap. BS 18, 381 (192425) T263.

[10] Tuckerman, L. B., and Stang, A. H., Tests of Large Columns with H-Shaped Sections, Tech. Pap. BS 21, 1 (1926-27) T328.

[11] Stang, A. H., and Greenspan, Martin, Perforated cover plates for steel columns: Summary of compressive properties, J. Research NBS 40, 347 (1948) RP1880.

[12] Jakkula, A. A., and Stephenson, Henson K., Steel Columns, A Summary and Appraisal of Past Works, Bull. No. 91, A. and M. College of Texas (1947).

[13] Palmer, L. A., and Hall, I. V., Durability and strength of bond between mortar and brick, BS J. Research 6, 473 (1931) NBS RP290.

[14] McBurney, John W., and Richmond, Joseph C., Strength Absorption and Resistance to Laboratory Freezing and Thawing of Building Bricks Produced in the United States, NBS Building Materials and Structures Report 60 (1940).

[15] Standard Methods for Conducting Strength Tests of Panels for Building Construction, ASTM Designation E72.61.

[16] Whittemore, H. L. and Stang, A. H., Methods of Determining the Structural Properties of Low Cost House Constructions, NBS Building Materials and Structures Report 2 (1938).

[17] Fishburn, Cyrus C., Watstein, David, and Parsons, D. E., Water Permeability of Masonry Walls, NBS Building Materials and Structures Report 7 (1938). gram of the Division will be developed and expanded in the directions already indicated, or modified as new circumstances arise, to better adapt the physical and functional characteristics of buildings to the essential needs of the user and to stimulate all segments of the building industry toward worthwhile innovation.

The contributions of many former and present members of the staff of the Building Research Division and the Sound Section to the historical portiors of this report are gratefully acknowledged: R. D. Berendt, B. E. Foster, C. T. Mahaffey, D. G. Moore, A. F. Robertson, H. E. Robinson, W. W. Walton, D. Watstein, and R. S. Wyly. Extensive use was made of the Annual Reports of the Bureau and R. C. Cochrane's Measures for Progress-A History of the National Bureau of Standards in corroborating the dates of initiation of various programs and other events.

[18] Kessler, D. W., Physical and Chemical Tests on Commercial Marbles of the United States, Tech. Pap. BS 12 (1919) T123.

[19] Clark, A. P., Bond of concrete reinforcing bars, J. Research NBS 43, 565 (1949) RP2050.

[20] Standard Specifications for Minimum Requirements for the Deformation of Deformed Reinforcing Bars for Concrete Reinforcement, ASTM Designation A205-65.

[21] Clark, Arthur P., Cracking in reinforced concrete flexural members, J. Amer. Concrete Inst. 27 No. 8 $851.862(1956)$.

[22] Chi, Michael, and Kirstein, A. F., Flexural cracks in reinforced concrete beams, J. Amer. Concrete Inst., 29, No. $10,865.878$ (1958).

[23] Mathey, R. G., and Watstein, David, Effect of tensile properties of reinforcement on the flexural charac. teristics of beams, J. Amer. Concrete Inst., 31, No. 12, 1253-1273 (1960.

[24] Mathey, R. G., and Watstein, David, Investigation of bond in beam and pullout specimens with high-yieldstrength deformed bars, J. Amer. Concrete Inst., 32, No. 9, 1071-1090 (1961).

[25] Mathey, R. G., and Watstein, David, Shear strength of beams without web reinforcement containing deformed bars of different yield strengths, J. Amer. Concrete Inst., 60, No. 2, 183-207 (1963).

[26] Reichard, T. W., Creep and Drying Shrinkage of Lightweight and Normal-Weight Concretes, Nat. Bur. Stand. (U.S. Monogr. 74, 30 pages (1964).

[27] Minimum Requirements for Thin-Section Precast Concrete Construction, ACI Standard 525-63.

[28] Dunham, John W., Brekke, Guttorm N., and Thompson, George N., Live Loads on Floors in Buildings, NBS Building Materials and Structures Report 133, (1952).

[29] Brekke, Guttorm N., Wind Pressures in Various Areas of the United States, NBS Building Materials and Structures Report 152 (1959).

[30] Minimum Design Loads in Buildings and Other Structures, American Standard A 58.1.

[31] Bryson, J. O., and Gross, D., Techniques for the Survey and Evaluation of Live Floor Loads and Fire Loads in Modern Office Buildings, Nat. Bur. Stand. (U.S.), Bldg. Sci. Ser. 16, 32 pages (Dec. 1969).

[32] Grenley, D. G., Cattaneo, L. E., Pfrang, E. O., The effect of edge load on the flexural strength of clay masonry systems utilizing high-bond mortars, Proc. Intern. Conf. on Masonry Structural Systems; Austin, Texas (1967).

\subsection{Fire Research}

[33] Ingberg, S. H., Griffin H. K., Robinson, W. C., and Wilson, R. E., Fire Tests of Building Columns, Tech. Pap. BS 15, 1 (1921) T184. 
[34] Hull, W. A., A Comparison of the Heat-insulating Properties of Some of the Materials Used in Fire. resistive Construction, Tech. Pap. BS 12, (1919) T130.

[35] Hull, W. A., and Ingberg, S. H., Fire Resistance of Concrete Columns, Tech. Pap. BS 18, 635 (1924-25) T272.

[36] Ingberg, S. H.. Fire Tests of Brick Walls, NBS Building Materials and Structures Report, 143 (1954).

[37] Ingberg, S. H., The fire resistance of gypsum partitions, Proc. Am. Soc. Testing Mater. 25, 299 (1925).

[38] Ingberg, S. H., and Foster, H. D., Fire resistance of hollow load-bearing wall tile, BS J. Research 2, 1 (1929) RP37.

[39] Mitchell, N. D., Fire tests of columns protected with gypsum, BS J. Research 10, 737 (1933) RP563.

[40] Brown, C. R., Fire tests of treated and untreated wood partitions, J. Res. NBS 20, 217 (1938) RP1076.

[41] Sale, P. D., Compression tests of structural steel at elevated temperatures, J. Res. NBS 13, 713 (1934) RP741.

[42] Ingberg, S. H., and Sale, P. D., Compressive strength and deformation of structural steel and cast iron shapes at temperatures up to $950{ }^{\circ} \mathrm{C}$, Proc. Am. Soc. Testing Mater. 26, 33 (1926).

[43] Fire tests of office occupancies, Quart. Natl. Fire Pro. tect. Assoc. 20, 243 (1927).

[44] Ingberg, S. H., Tests of the severity of fires, Quart. Natl. Fire Protect. Assoc., 22, 43 (1928).

[45] Fire test of brick joisted buildings, Quart. Natl. Fire Protect. Assoc. 22, 62 (1928)

[46] Mitchell, N.D., Tests of theater proscenium curtains, BS J. Research 11, 491 (1933) RP603.

[47] Fire Resistance Classifications of Building Constructions, NBS Building Materials and Structures Report, 92 (1942).

[48] Brown, C. R., Determination of the Ignition Tempera* tures of Solid Materials, PhD. Thesis, Catholic Univ. of America, Washington, D.C. (1934).

[49] Setchkin, N. P., A method and apparatus for determining the ignition characteristics of plastics, J. Res. NBS 43, 591 (1949) RP2052.

[50] Setchkin, N. P., Self-ignition temperatures of combustible liquids. J. Research NBS 53, 49 (1954) RP2516.

[51] Standard Method of Test for Determining the Non. combustibility of Elementary Materials, ASTM Designation E136-65.

[52] Ingberg, S. H., When may spontaneous ignition occur, Fire Engrg. 83, 357 (1930).

[53] Obold, W. L., Hoftheins, F. M., Ingberg, S. H., and James, L. H., Heating and Ignition Tests with Jute, Natl. Fire Protect. Assoc. Mono. (1934).

[54] Mitchell, N. D., New light on self ignition, Quart. Natl. Fire Protect. Assoc. 45, 165 (1951).

[55] Raskin, W. H., and Robertson, A. F., An adiabatic apparatus for the study of self-heating of poorly conducting materials, Review of Scientific Instruments 25, [6], 541-544 (1954).

[56] Gross, D., and Robertson, A. F., Self-ignition temperatures of materials from kinetic-reaction data, J. Res. NBS 61, 413 (1958) RP2909.

[57] Mitchell, N. D., Fire hazard tests with masonry chimneys, Quart. Natl. Fire Protect. Assoc. 43, 117 (1949).

[58] Robertson, A. F., Gross, D., and Loftus, J. J., A method for measuring surface flammability of materials using a radiant energy source, Proc. Am. Soc. Testing Mater. 56,1437 (1956)

[59] Gross, D., and Loftus, J. J., Flame spread properties of building finish materials, ASTM Bull. 230 (1958)

[60] Gross, D., and Loftus, J. J., Surface flammability of fire retardant and conventional paint assemblies, Fire Res. Abstr. and Rev. 3, [3], 151-158 (1961).

[61] Robertson, A. F., Surface Flammability Measurements by the Radiant-panel Method, ASTM Spec. Tech. Publ. 344 (1962) ; also ASTM Proc. 62, 33-46 (1962).

[62] Gross, D., and Loftus, J. J., Surface flame propagation on cellulosic materials exposed to thermal radiation, J. Res. Nat. Bur. Stand. (U.S.) 67C (Eng. and Instr.) No. 3, 251 (July-Sept. 1963).
[63] McCamy, C. S., and Lee, T. G., Fire extinguishment by means of dry powder, Sixth Int. Symp. on Combustion, Combust. Inst. (1956).

[64] Lee, T. G., and Robertson, A. F., Effectiveness of Some Powdered Materials in Extinguishing Hydrocarbon Fires, Nat. Acad. Sci.-Nat. Res. Council Publ. 786 (1961).

[65] Creitz, E. C., Inhibition of diffusion flames by methyl bromide and trifluoromethyl bromide applied to the fuel and oxygen sides of the reaction zone, J. Res. Nat. Bur. Stand. (U.S.) 65A (Phys. and Chem.) No. 4, 389 (July-Aug. 1961).

[66] Lee, T. G., Electron attachment coefficients of some hydrocarbon flame inhibitors, J. of Phys. Chem. 67, 360 (1963).

[67] Halpern, Carl, Effect of methyl bromide additions on the flame speed of methane, J. Res. Nat. Bur. Stand. (U.S.) $67 \mathrm{~A}$ (Phys. and Chem.) No. 1, 71 (Jan.-Feb. 1963).

[68] Setchkin, N. P., and Ingberg, S. H., Test criterion for an incombustible material, Proc. Am. Soc. Testing Mater 35, 866 (1945).

[69] Loftus, J. J., Gross, D., and Robertson, A. F., Potential heat-a method for measuring the heat release of materials in building fires, Proc. Am. Soc. Testing Mater. 61, (1961).

[70] Ingberg, S. H., Dunham, J. W., and Thompson, J. P. Combustible Contents in Buildings, NBS Building Materials and Structures Report 149 (1957).

[71] Gross, D., Loftus, J. J., and Robertson, A. F., A Method for Measuring Smoke from Burning Materials, ASTM Spec. Tech. Publ. 422, 166-204 (1967).

[72] Torrance, K. E., Orloff, L., and Rockett, J. A., Experiments on natural convection in enclosures with localized heating from below, J. Fluid Mech., 36, Pt. 1, 2131 (1969).

[73] Torrance, K. E., and Rockett, J. A., Numerical study of natural convection in an enclosure with localized heating from below-Creeping flow to the onset of laminar instability, J. Fluid Mech., 36, Pt. 1, 33-54, (1969).

[74] Shoub, H., and Gross, D., Doors as Barriers to Fire and Smoke, Nat. Bur. Stand. (U.S.) Bldg. Sci. Ser. 3, 10 pages (March 1966).

[75] Gross, D., Loftus, J. J., Lee, T. G., and Gray, V. E., Smoke and Gas Produced by Burning Aircraft Finish Materials, Nat. Bur. Stand. (U.S.) Bldg. Sci. Ser. 18, 27 pages (Feb. 1969)

\subsection{Heat and Moisture Transfer}

[76] Dickinson, H. C., and Van Dusen, M. S., The Testing of Thermal Insulators, J. Am. Soc. Refrig, Engr., 3, No. 2, 5-25 (1916).

[77] Method of Test for Thermal Conductivity of Materials by Means of the Guarded Hot-plate, ASTM Designation $\mathrm{C}-177$.

[78] Robinson, H. E., and Watson, T. W., Interlaboratory Comparison of Thermal Conductivity Determinations with Guarded Hot Plates, Am. Soc. Testing Mater. Spec. Tech. Publ. 119 (1951).

[79] ASHRAE Handbook of Fundamentals, 429-434 (Am. Soc. of Heating, Refrig. and Air-cond. Engrs., 1967).

[80] Watson, T. W., and Robinson, H. E., Thermal conductivity of some commercial iron-nickel alloys, ASME J. of Heat Transfer, 83C, No. 4, 403-408 (1961).

[81] Robinson, H. E., The conductive disk method of measuring the thermal conductivity of insulations, Suppl. to Bull. of International Inst. of Refrig., Annexe 19621, 43-50 (1962).

[82] Flynn, D. R., A radial flow apparatus for determining the thermal conductivity of loose fill insulations to high temperatures, J. Res. Nat. Bur. Stand. (U.S.) $67 \mathrm{C}$ (Eng. and Instr.), No. 2, 129-137 (Apr.-June 1963).

[83] Peavy, B. A., Steady state heat conduction in an exposed exterior column of rectangular cross section, J. Res. Nat. Bur. Stand. (U.S.) 69C (Eng. and Instr.), No. 2, 145-151 (Apr.-June 1965). 
[84] Robinson, H. E., Powlitch, F. J., and Dill, R. S., The Thermal Insulating Value of Airspaces, Housing Research Paper No. 32 (U.S. Housing and Home Finance Agency), 1-32, U.S. Govt. Printing Office (1954).

[85] Robinson, H. E., Cosgrove, L. A., and Powell, F. J., Thermal Resistance of Airspaces and Fibrous Insulations Bounded by Reflective Surfaces, NBS Building Materials and Structures Report 151 (1957).

[86] Powell, F. J., and Robinson, H. E., Measurement of Effect of Moisture on Heat Transfer Through Insulated Flat-roof Constructions, Am. Soc. Testing Mater., Spec. Tech. Publ. 312 (1961).

[87] Woolley, H. W., Moisture Condensation in Building Walls, NBS Building Materials and Structures Report 63 (1940).

[88] Dill, R. S., and Cottony, H. V., Laboratory Investigation of Condensation in Wall Specimens, NBS Building Materials and Structures Report, 106 (1946).

[89] Dill, R. S., Robinson, W. C., and Robinson, H. E., Measurement of Heat Losses from Slab Floors, NBS Building Materials and Structures Report, 103 (1945).

[90] Martin, H. R., Achenbach, P. R., and Dill, R. S., Effect of Edge Insulation upon Temperature and Condensation on Concrete-slab Floors, NBS Building Materials and Structures Report, 138 (1953).

[91] Flynn, D. R., and O'Hagan, M. E., Measurements of the thermal conductivity and electrical resistivity of platinum from 100 to $900{ }^{\circ} \mathrm{C}$, J. Res. Nat. Bur. Stand. (U.S.) 71C (Eng. and Instr.), 258 (Oct.-Dec. 1967).

[92] Watson, T. W., Flynn, D. R., and Robinson, H. E., Thermal conductivity and electrical resistivity of Armco Iron, J. Res. Nat. Bur. Stand. (U.S.) 71C (Eng. and Instr.), 285 (Oct.-Dec. 1967).

[93] Watson, T. W., and Flynn, D. R., Thermal conductiv. ity of four heat-resistant alloys, Trans. Metallurgy Soc. of American Institute of Metallurgic Engineers, 242, 844-846, 1967.

\subsection{Mechanical Systems}

[94] Weaver, E. R., Eiseman, J. H., and Shawn, G. B., A Method for Testing Gas Appliances to Determine their Safety from Producing Carbon Monoxide, Tech. Pap. BS 20, 125 (1925) T304.

[95] Eiseman, J. H., Smith, F. A., and Merritt, C. J., The effect of altitude on the limits of safe operation of gas appliances, BS J. Research 10, 619 (1933) RP553.

[96] Voight, C. Q., Fire hazard of domestic heating installations, BS J. Research 11, 353 (1933) RP596.

[97] Dryden, H. L., Stutz, W. F., and Heald R. H., Some comparative tests of 16 -in. roof ventilators. ASHRAE J. 27 (1921).

[98] Dill, R. S., and Achenbach, P. R., Effect of Soot on the Rating of an Oil.fired Boiler, NBS Building Materials and Structures Report 54 (1940).

[99] Dill, R. S., and Achenbach, P. R., Performance of a Coal-fired Boiler Converted to Oil, NBS Building Materials and Structures Report 111 (1948).

[100] Automatic Mechanical Draft Oil Burners Designed for Domestic Installations, Com. Stand. 75 (1939).

[101] Gas Floor Furnaces (Gravity Circulating Type), Com. Stand. 99 (1942).

[102] Warm-air Furnaces Equipped with Vaporizing Pot-type Oil Burners, Com. Stand. 104 (1946).

[103] Solid.fuel-burning Forced-air Furnaces, Com. Stand. 109 (1944)

[104] Testing and Rating Convectors, Com. Stand. 140 (1948).

[105] Dill, R. S., A Test Method for Air Filters, ASHVE Trans. 44, 379 (1938).

[106] AFI Dust Spot Test Code, Air Filter Inst. (1960).

[107] Dill, R. S., Achenbach, P. R., and Duck, J. T., Observed performance of some experimental chimneys, ASHVE Trans. 48, 351 (1942).

[108] Achenbach, P. R., and Cole, S. D., Performance of fourteen masonry chimneys under steady state condi- tions, ASHVE Trans. 55, 129 (1949).

[109] Guide, Am. Soc. Heating and Ventilating Engrs. (1944).

[110] Underground Heat Distribution Systems, Fed. Constr. Counc. Tech. Rep. 30R-64, NAS-NRC (1964).

[111] Evaluation of Components for Underground Hcat Distribution Systems, Fed. Constr. Counc. Tech. Rep. 39, NAS.NRC (1960).

[112] Achenbach, P. R., and Phillips, C. W., Mcasurcments of drinking water usage from electric water coolcrs, Refrigerating Engineering 37, (Dec. 1954).

[113] Achenbach, P. R., Davis, J. C., and Smith, W. T., Analysis of Electric Energy Usage in Air Force Houses Equipped with Air-to-air Heat Pumps, Nat. Bur. Stand. (U.S.) Monogr. 5134 pages (July 1962).

[114] Davis, J. C., and Achenbach, P. R., Performance characteristics of split-type residential air-to-air heat pumps, Suppl. Bull. Intern. Inst. Refrigeration Annexe 1962-1, 349-355 (1962).

[115] Achenbach, P. R., Phillips, C. W., and Smith, W. T., Heating performance of air-to-air heat pumps at two Air Force housing projects, ASHRAE Trans. 70, 375 (1964)

[116]Faison, T. K., Davis, J. C., and Achenbach, P. R., A test apparatus for the study of forced air-mixing devices, J. Res. Nat. Bur. Stand. (U.S.) 70C, (Eng. and Instr.), No. 1, 25-31, (Jan.-March 1966).

[117] Faison, T. K., Davis, J. C., and Achenbach, P. R., Performance of Square-edged Orifices and Orifice-Target Combinations as Air Mixers, Nat. Bur. Stand. (U.S.) Building Science Series 12 (1967).

[118] Davis, J. C., Faison, T. K., and Achenbach, P. R., Errors in temperature measurement of moving air under isothermal conditions using thermocouples, thermistors, and thermometers, ASHRAE Trans. 73, Pt. 1 (1967).

[119] Davis, J. C., and Achenbach, P. R., An investigation of psychrometric measurement techniques in air-conditioning calorimetry. Humidity and Moisture: Mea. surement and Control in Science and Industry, Vol. 2, Applications, 303-313 (Reinhold Publ. Corp. New York, N.Y., 1965).

[120] Achenbach, P. R., and Davis, J. C., Condensate collection as a measuring technique for studying the cooling capacity of air.conditioning units, Proc. XI Intern. Congr. Refrig., Munich, Germany, 1963; also, Progress in Refrigeration Science and Technology, II, 1281-1286 (Pergamon Press, Inc., New York, N.Y. 1963).

[121] Standards Measurements Guide-Temperature Measurements Section, ASHRAE Stand. 41 (1966).

[122] Test Procedures to Determine Suitability of Ducts for Use in Residential Warm Air Heating and Air-condi. tioning Systems, Fed. Hous. Adm. Tech. Studies Publ. 954 (1965).

\subsection{Thermal Environment in Structures}

[123] Dill, R. S., and Achenbach, P. R., Temperature Distribution in a Test Bungalow with Various Heating Devices, NBS Building Materials and Structures Report 108 (1947).

[124] Achenbach, P. R., Temperatures in a Test Bungalow with some Radiant and Jacketed Space Heaters NBS Building Materials and Structures Report 114 (1949).

[125] Achenbach, P. R., and Tierney, E. M., A Study of a Baseboard Convector Heating System in a Test Bung. alow, NBS Building Materials and Structures Report 115 (1949)

[126] Coblentz, C. W., and Achenbach, P. R., Field measurements of air infiltration in ten electrically heated houses, ASHRAE Trans. 69, 358-363 (1963).

[127] Coblentz, C. W., and Achenbach, P. R., Design and performance of a portable infiltration meter, ASHRAE Trans. 63 (1957).

[128] Manual on Heating and Air Conditioning of Underground Installations, U.S. Corps of Engrs. EM 1110, $345-450$. 
[129] Kusuda, T., and Achenbach, P. R., Numerical analysis of the thermal environment of occupied underground space with finite cover using a digital computer, ASH. RAE Trans. 69, 439 (1963).

[130] Kusuda, T., and Achenbach, P. R., Earth temperatures and thermal diffusivity at selected stations in the United States, ASHRAE Trans. 71, 61 (1965).

[131] Kusuda, T., and Achenbach, P. R., Outdoor air psychrometric criteria for summer ventilation of protective shelters, ASHRAE Trans. 71, 76 (1965).

[132] Achenbach, P. R., and Phillips, C. W., Heat sink method for measuring the cooling load of refrigerated structures, Proc. X Intern. Congr. Refrig., Copenhagen, II, 272 (1959).

[133] Phillips, C. W., Goddard, W. F., Achenbach, P. R., Johnson, H. D., and Penney, R. W., A Rating Method for Refrigerated Trailer Bodies Hauling Perishable Food, USDA Marketing Res. Rep. 443 (1960).

[134] Phillips, C. W., and Penney, R. W., Development of a Method for Testing and Rating Refrigerated Truck Bodies, USDA Tech. Bull. 1376 (1967).

[135] Achenbach, P. R., Chilled air distribution in refrig. erated trailers, Suppl. Bull. Intern. Inst. Refrig., Annexe 1961-2, 9-25 (1961).

[136] Penney, R. W., Phillips, C. W., Refrigeration Requirements for Truck Bodies-Effects of Door Usage, USDA Tech. Bull. 1375 (1967) .

[137] Mulroy, W. J., Kusuda, T., and Phillips, C. W., Sur. vey of digital computer programs for heating and cool. ing load calculations. SICCAP 2, No. 2, 4-8 (1968).

[138] Barber, E., and Kusuda, T., A photographic method for studying natural convection in rectangular enclosures with the use of metaldehyde. (in preparation).

[139] Kusuda, T., and Achenbach, P. R., Coincident sum. mer weather characteristics of six selected cities in the United States, ASHRAE J. 8, No. 11 (1966.)

\subsection{Architectural Acoustics}

[140] Chrisler, V. L., Acoustical work of the National Bureau of Standards, J. Acoust, Soc. Am. 7, 79 (1935).

[141] Eckhardt, E. A., and Chrisler, V. L., The sound insulating properties of partition walls (chiefly lath and plaster), Am. Arch. 128, 405 (1925).

[142] Eckhardt, E. A., and Chrisler, V. L.. Transmission and absorption of sound by some building materials, BS Sci. Pap. 21, 37 (1926) S526.

[143] Chrisler, V. L. Transmission of sound through building materials, BS Sci. Paper. S 22, 227 (1927) S552.

[144] Chrisler, V. L., and Snyder, W. F., Transmission of sound through wall and floor structures, BS J. Research 2, 541 (1929) RP48.

[145] Chrisler, V. L., Measurement of sound transmission, J. Acoust., Soc. Am. 1, 175 (1930).

[146] Chrisler, V. L., and Snyder, W. F., Recent sound transmission measurements at the National Bureau of Standards, J. Research NBS 14, 749 (1935) RP800.

[147] Sound Insulation of Wall and Floor Construction, NBS Building Materials and Structures Report 144 (1955).

[148] Berendt, R. D., and Winzer, G. E., Sound Insulation of Wall, Floor, and Door Constructions, Nat. Bur. Stand. (U.S.) Monogr. 77, 49 pages (Feb. 1964): (also Consolidated Suppl. to NBS Building Materials and Structures Report 144 above).

[149] Berendt, R. D., Winzer, G. E., and Burroughs, C. B., A Guide to Airborne, Impact and Structure-Borne Noise Control in Multifamily Dwellings, FHA-HUD, TS 24 (1967).

[150] Buckingham, Edgar, Theory and interpretation of experiments on the transmission of sound through parti. tion walls, BS Sci. Pap. 20, 193 (1925) S506.

[151] London, A., Methods for determining sound transmission loss in the field, J. Research NBS 26, 419 (1941) RP1388.

[152] London, Albert, Transmission of reverberant sound through single walls, J. Research NBS 42605 (1949) RP1998; also the Phys. Soc. (1948) Symp. of the
Acoustic Group, Noise and sound transmission, 194 (1949).

[153] London, Albert, Transmission of reverberant sound through double walls, J. Research NBS 44, 77 (1949) RP2058. Also J. Acoust. Soc. Am. 22, 270 (1950).

[154] Waterhouse, Richard V., Transmission of reverberant sound through walls, Acustica 4, 290 (1954) (Proc. First Intern. Congr. Acoust. 1953).

[155] Chrisler, V. L., Dependence of sound absorption upon area and distribution of absorbent material, BS J. Research 13, 169 ([1934]) RP700.

[156] Chrisler, V. L., Effect of paint on the sound absorption of acoustic materials, J. Research NBS 24, 547 (1940) RP1298.

[157] Cook, R. K., and Chrzanowski, Peter, Absorption and scattering by sound absorbent cylinders, J. Research NBS 36, 393 (1946) RP1709; also J. Acoust. Soc. Am. 17, 315 (1946).

[158] Sound Absorption Coefficients of the More Common Acoustic Materials, Letter Circular NBS LC 870 (1947).

[159] Cook, Richard K., and Chrzanowski, Peter, Absorption by sound-absorbent spheres, J. Research NBS 42, 219 (1949) RP 1963; also J. Acoust. Soc. Am. 21, 167 (1949).

[160] Cook, R. K., Waterhouse, R. V., Berendt, R. D., Edelman, Seymour and Thompson, M. C., Jr., Measurement of correlation coefficients in reverberant sound fields, J. Acoust. Soc. Am. 27, 1072 (1955).

[161] Cook, R. K., Absorption of sound by patches of absorbent materials, J. Acoust. Soc. Am. 29, 324 (1957).

[162] Cook, R. K., Sound absorption by areas of finite size, Proc. Third Intern. Congr. Acoust. (1959).

[163] Waterhouse, R. V., Interference patterns in reverberant sound fields, J. Acoust. Soc. Am. 27, 247 (1955).

[164] Waterhouse, R. V., Output of a sound source in a reverberation chamber and other reflecting environments, J. Acoust. Soc. Am. 30, 4 (1958).

[165] Waterhouse, R. V., and Berendt, R. D., Reverberation chamber study of the sound power output of subsonic air jets, J. Acoust. Soc. Am. 30114 (1958).

[166] Waterhouse, R. V., Radiation impedance of a source near reflectors, J. Acoust. Soc. Am. 351144 (1963).

[167] Waterhouse, R. V., Interference patterns in reverber. ant sound fields II, J. Acoust. Soc. Am. 37, 424 (1965).

[168] Daniel, Eric D., On the dependence of absorption coefficients upon the area of the absorbent material, J. Acoust. Soc. Am. 35, 571 (1963).

[169] Chrisler, V.: L., The measurement of sound absorption by oscillograph records, J. Acoust. Soc. Am. 1, 418 (1930).

[170] Snyder, W. F., An automatic reverberation meter for the measurement of sound absorption, BS J. Research 9, 47 (1932) RP 457.

[171] Cook, R. K., Absolute pressure calibration of microphones, J. Research NBS 25, 489 (1940) RP1341; also, abbrev. in J. Acoust. Soc. Am. 12, 415 (1941).

[172] Waterhouse, Richard V., and Cook, R. K., New method of recording the sound transmission loss of walls as a continuous function of frequency, J. Acoust. Soc. Am. 27, 967 (1955).

[173] Berendt, Raymond D., and Schmidt, Henry A., Jr., A portable impedance tube, J. Acoust. Soc. Am. 35, 1049 (1963).

\subsection{Plumbing and Water Systems}

[174] Recommended Minimum Requirements for Plumbing in Dwellings and Similar Buildings, NBS Building and Housing Pub. BH13 (1928).

[175] Hunter, R. B., Golden, G. E., and Eaton, H. N., Crossconnections in plumbing systems, J. Research NBS 20, 479 (1938) RP1086.

[176] Golden, G. E., and Hunter, R. B., Backflow prevention in over-rim water supplies, NBS Building Materials and Structures Report 28 (1939). 
[177] Air Gaps in Plumbing Systems, Am. Stand. A40.4 (1942).

[178] Backflow Preventers in Plumbing Systems, Am. Stand. A40.6 (1943)

[179] Hunter, R. B. Methods of Estimating Loads in Plumbing Systems, NBS Building Materials and Structures Report 65 (1940).

[180] Hunter, R. B., Water-distributing Systems for Buildings, NBS Building Materials and Structures Report 79 (1941).

[181] Maupin, A. R., and Swanger, W. H., Strength of Softsoldered Joints in Copper Tubing, NBS Building Matcrials and Structures Report 58 (1940).

[182] Beij, K. H., Flow in roof gutters, BS J. Research 12 , 193 (1934) RP644.

[183] Plumbing Manual, NBS Building Materials and Structures Report 66 (1940).

[184] National Plumbing Code, Am. Stand. A40.8 (1955)

[185] Emergency Plumbing Standards for Defense Housing, Division of Defense Housing Coordination, Executive Office of the President (1942).

[186] French, J. L., Stack Venting of Plumbing Fixtures, NBS Building Materials and Structures Report 118 (1950).

[187] French, J. L., Eaton, H. N., and Wyly, R. S., Wet Venting of Plumbing Fixtures, NBS Building Materials and Structures Report 119 (1950).

[188] French, J. L., and Eaton, H. N., Self-siphonage of Fixture Traps, NBS Building Materials and Structures Report 126 (1951).

[189] Housing Research Paper 15, Housing \& Home Finance Agency (1951).

[190] Housing Research Paper 31, Housing and Home Finance Agency (1954).

[191] Eaton, H. N., and Wyly, R. S., Frost Closure of Roof Vents in Plumbing Systems, NBS Building Materials and Structures Report 142 (1954).

[192] Wyly, R. S., and Eaton, H. N., Capacities of Plumb. ing Stacks in Buildings, NBS Building Materials and Structures Report 132 (1952).

[193] Wyly, R. S., and Eaton, H. N., Capacities of Stacks in Sanitary Drainage Systems for Buildings, Nat. Bur. Stand. (U.S.) Monogr. 31, 52 pages (July 1961).

[194] Wyly, R. S., Investigation of Hydraulics of Horizontal Drains in Plumbing Systems, Nat. Bur. Stand. (U.S.) Monogr. 86, 38 pages (Dec. 1964).

[195] Small-size Pipe for Sanitary Lateral Sewers, Nat. Acad. Sci.-Nat. Res. Council Publ. 507 (1957).

[196] Beausoliel, R. W., and Wyly, R. S., Minimum Venting for Plumbing Systems, Nat. Bur. Stand. (U.S.) Tech. News Bull. 50, No. 5, 75-77 (1969).

\subsection{Organic Materials and Composites}

[197] Bearce, H. W., The Density and Thermal Expansion of Linseed Oil and Turpentine, Bur. Stand. Tech. Pap. BS 1 (1912) T9.

[198] Porter, W. C., Painting Steel, NBS Building Materials and Structures Report 102 (1944).

[199] Sentil, C., Paints for Exterior Masonry Walls, NBS Building Materials nad Structures Report 110 (1947).

[200] Walker, P. H., and Hickson, E. F., Accelerated tests of organic protective coatings, BS J. Research 1, 1 (1928) RP1.

[201] Hickson, E. F., Some properties and tests of traffic or zone paints, J. Research NBS 19, 21 (1937) RP1007.

[202] Roberts, A. G., Improved NBS Abrasive Jet Method for Measuring Abrasion Resistance of Coatings, Am. Soc. Testing Mater. Bull. 244, 48-51 (1960).

[203] Howard, P. T., A Method of Preparing Paint Films for Determining Their Dry Contrast Ratio, Natl. Paint, Varnish and Lacquer Assoc. Sci. Sec. Circ. 695 (1944).
[204] Berger, H. W., and Cadoff, B. C., The polarographic analysis of white lead and zinc oxide in white paint pigments, J. Paint Tech. Eng. Official Digest 37, No. 480, 35-42 (1965).

[205] Berger, H. W., and Cadoff, B. C., Polarographic analysis of titanium (IV) - EDTA complexcs: Application to paint pigments, J. Paint Tech. Eng. Official Digcst 37 No. 480 (1965); also J. Res. Nat. Bur. Stand (U.S.) 69C (Eng. and Instr.), No. 1, 67-70 (1964).

[206] Stricter, O. C., Accelerated tests of asphalts, BS J. Research 5, 247 (1930) RP197.

[207] Campbell, P. G., and Wright, J. R., Infrarcd spectra of asphalt-Some aspects of the changes caused by photooxidation, J. Res. Nat. Bur. Stand. (U.S.), 68C, (Eng, and Instr.), No. 2, 115-123 (1964)

[208] Wright, J. R., Campbell, P. G., and Fridinger, T. L., The effect of carbon-arc intensity on asphalt oxidation, J. Appl. Chem. 14, 30-35 (1964).

[209] Wright, J. R., and Campbell, P. G., Photooxidation of asphalts in the presence of ozone, J. Res. Nat. Bur. Stand. (U.S.), 68C, No. 4, 297-304 (1964).

[210] Campbell, P. G., and Wright, J. R., Oxidation of asphalt flux with oxides of nitrogen, Ind. \& Eng. Chem. Prod. Res. and Develop. 4, 121-128 (1965).

[211] Snoke, H. R., and Gallup, B. E., Accelerated weathering tests of mineral-surfaced asphalt shingles, J. Research NBS 18, 669 (1937) RP1002.

| 212| Strieter, O. C., Weathering tests on filled coating asphalts, J. Research NBS 20, 159 (1938) RP1073.

[213] Greenfeld, S. H., Effect of Mineral Additives on the Durability of Coating Grade Roofing Asphalts, NBS Building Materials and Structures Report 147 (1951).

[214] Cullen, W. C., Wind resistance of asphalt shingle roofing, Bldg. Res. Inst., New Bldg. Res. (Fall 1960); also Nat. Acad. Sci.-Nat. Res. Counc., 33-42 (1961).

[215] Cullen, W. C., Solar Heating, Radiative Cooling, and Thermal Movement-their Effects on Built-up Roofing Nat. Bur. Stand. (U.S.) Tech. Note 231, 33 pages (April 1964).

[216] Cullen, W. C., Effects of Thermal Shrinkage on Builtup Roofing, Nat. Bur. Stand. (U.S.), Monogr. 89, 6 pages (March 1965).

[217] Schiefer, H. F., and Best, A. S., Carpet wear testing machine, BS J. Research 6, 927-936 (1931) RP315.

[218] Schiefer, H. F., and Cleveland, R. S., Wear of carpets, BS J. Research 12, 155-166 (1934) RP640.

[219] Kessler, D. W., Wear resistance of natural stone flooring, BS J. Research 11, 635-648 (1933) RP612.

[220] Schuman, L. and Tucker, J., Jr., A portable apparatus for determining the relative wear resistance of concrete floors, J. Research NBS 23, 549-570 (1939) RP1252.

[221] McBurney, J. W., Indentation of asphalt tile, Proc. Am. Soc. Testing Mater. 34, Part II (1934).

[222] Sigler, P. A., and Woodward, M. B., Indentation and Recovery of Low-Cost Floor Coverings, NBS Building Materials and Structures Report 14 (1939).

[223] Sigler, P. A., and Woodward, M. B., Indentation Characteristics of Floor Coverings, NBS Building Materials and Structures Report 73 (1941).

[224] Emley, W. E., and Hofer, C. E., Test of floor coverings for postoffice workrooms, J. Research NBS 19, 567570 (1937) RP1046.

[225] Performance Test of Floor Covernings for Use in Lowcost Housing, Parts 1, 2, 3, and 4, NBS Building Materials and Structures Reports 34 (1940); 43 $(1940) ; 68$ (1941); 80 (1942).

[226] Boone, T. H., Hermach, F. L., MacArthur, E. L., and McAuliff, R. C., Conductive Flooring for Hospital Operating Rooms, Nat. Bur. Stand. (U.S.) Monogr. 11. 16 pages $(1960)$.

[227] Cullen, W. C., and Boone, T. H., A Thermal Shock Resistance Factor for Bituminous Built-up Roofiing Membranes. Roofing, Siding and Insulation 44, Pt. I, No. 11 (1967) ; 44, Pt. II, No. 12 (1967).

[228] Campbell, P. G., and Wright, J. R., Oxidation products in an oxygen-blown Kuwait asphalt. Indus. \& 
Eng. Chem., Product Res. Development 5, No. 4 (1966).

[229] Greenfeld, S. H., Hail resistance of roofing products, Nat. Bur. Stand. (U.S.), Bldg. Sci. Ser. 23, 9 pages (Aug, 1969).

[230] Wolfe, Winthrop C., Field study of floor coverings, Flooring, (Nov, 1968).

[231] Post, M. A., Determination of bound styrene in in. soluble emulsion polymerised styrene-butadiene copolymers, J. Appl. Chem., 17, (July 1967).

[232] Post, M. A., Qualitative and quantitative determination of emulsion-polymerised binders in latex paints, J. Appl. Chem. 17 (Nov. 1967).

[233] Berger, H. W., The determination of mercury in latex paints and paint films mercury fungicides. J. Paint Tech. 38, No. 498 (1966).

[234] Berger, H. W., The estimation of molecular weights of vinyl acetate copolymers in latex paints. J. Fed. Soc. Paint Tech. 39, No. 508 (1967).

[235] Federal Specification TT-P-97c,-Paint, Styrene-butadiene Solvent Type, White (for exterior masonry).

[236] Federal Specification TT-P-29g,-Paint, Latex Base, Interior, Flat, White and Tints.

[237] Roberts. A. G., Organic Coatings-Properties, Selection, and Use, Nat. Bur. Stand. (U.S.), Bldg. Sci. Ser. 7, 187 pages (Feb. 1968).

[238] Federal Specification T'T-S,00227d Sealing Compound: Elastomeric Type. Two Component.

[239] Federal Specification TT-S-00230b Sealing. Compound; Elastomeric Type, Single Component.

\subsection{Inorganic Materials}

[240] Bates, P. H., and Klein, A. A., Properties of the Calcium Silicates and Calcium Aluminate Occurring in Normal Portland Cement, Tech. Pap. BS 8 (1917) T78.

[241] Brownmiller, L. T., and Bogue, R. H., The System $\mathrm{CaO}-\mathrm{Na}_{2} \mathrm{O}-\mathrm{Al}_{-} \mathrm{O}_{i}$, BS J. Research \&, 289 (1932) RP414.

[242] Hansen, W. C., Dyckerhoff W., Ashton, F. W., and Bogue, R. H. Studies on the system $\mathrm{CaO}-\mathrm{Al}_{2} \mathrm{O}_{3}-\mathrm{SiO}_{2}$ : The composition of $8 \mathrm{CaO}+\mathrm{Al}_{2} \mathrm{O}_{3}+2 \mathrm{SiO}_{2}$. J. Phys. Chem. 31 607, (1927), William \& Wilkins Co., Balti. more, Md.; also Rock Products (Tradepress Publishing Corp., 309 W. Jackson Blvd., Chicago, Ill.) 30, (1927).

[243] McMurdie, H. F., and Insley, H., Studies of the quaternary system $\mathrm{CaQ}-\mathrm{MgO}-2 \mathrm{CaO} \cdot \mathrm{SiO}_{2}-5 \mathrm{CaO} \cdot 3 \mathrm{Al}_{2} \mathrm{O}_{3}, \mathrm{~J}$. Research NBS $16,467^{\circ}$ (1936) RP884.

[244] Taylor, William C., The system $2 \mathrm{CaO} \bullet \mathrm{SiO}_{2}-\mathrm{K}_{2} \mathrm{O} \bullet$ $\mathrm{CaO} \bullet \mathrm{SiO}_{2}$ and other phase equilibria studies involving potash, J. Research NBS 27 (1941) RP1421.

[245] Greene, Kenneth T., and Bogue, R. H., Phase equilibrium relations in a portion of the system $\mathrm{Na}_{2} \mathrm{O}-\mathrm{CaO}_{-}$ $\mathrm{Al}_{2} \mathrm{O}_{3}-\mathrm{SiO}_{2}$, J. Research NBS 36 (1946) RP1699.

[246] Newkirk, Terry F., and Thwaite, R. D., Pseudoter. nary system calcium oxide-monocalcium aluminate $\left(\mathrm{CaO} \cdot \mathrm{Al}_{2} \mathrm{O}_{3}\right)$ dicalcium ferrite $\left(2 \mathrm{CaO} \cdot \mathrm{Fe}_{2} \mathrm{O}_{3}\right)$. J. Research NBS 61 (1958) RP2900.

[247] Insley, H., and McMurdie, H. F., Minor constituents in Portland cement clinker, J. Research NBS 20, 173 (1938) RP1074.

[248] Ward, George W., Effect of heat treatment and cooling rate on the microscopic structure of portland cement clinker, J. Research NBS 26, 49 (1941) RP1358.

[249] Harrington, E. A., X-ray diffraction measurements on some of the pure compounds concerned in the study of portland cement. Am. J. Sci., 13, 467 (1927).

[250] Hansen, W. C., Further studies on portland cement compounds by the X-ray diffraction method. J. Am. Ceram. Soc. 11, 68 (1928).

[251] Mauer, F. A., An analytical balance for recording rapid changes in weight, Rev. Scien. Instr. 25, 598 (1954).

[252] Ordway, F., New techniques for new approaches to cement chemistry. Ceramic Age 52, 28 (1951).
[253] Bogue, R. H., Chemistry of Portland Cement, 2nd Ed., 319-321 (Reinhold Publ. Corp., New York, 1955),

[254] Insley, Herbert, Structural characteristics of some con. stituents of portland cement clinker, J. Research NBS 17, 353 (1936) RP917.

[255] Taylor, W. C., Nature of prismatic dark interstitial material in portland cement clinker, J. Research NBS 30, (1943) RP1536.

[256] Insley, H., The nature of the glass in portland cement clinker, J. Research NBS 25, 295 (1940) RP1324.

[257] Lerch, Wm., and Brownmiller, L. T., Method for approximating the glass content of portland cement clinker, J. Research NBS 18, 609 (1937) RP997.

[258] Bogue, R. H., Calculation of compounds in portland cement, Ind. \& Chem. Eng. (Anal. Ed.) 1, 192 (1929).

[259] Hansen, W. C., Influence of magnesia, ferric oxide, and soda upon the temperature of liquid formation in certain portland cement mixtures. BS J. Research 4, 55 (1930) RP132.

[260] Bates, P. H., The application of the fundamental knowledge of portland cement to its manufacture and use, J. Franklin Inst. (Franklin Inst., 20th \& Parkway, Phila, Pa.) 193289 (1922)

[261] Lerch, William, and Taylor, W. C., Some effects of heat treatment on portland cement clinker, PCA Fel. lowship Paper 33, July 1937; Concrete M.S., 45, 199 (July.Aug., 1937).

[262] Flint, E. P., and Wells, L. S., Study of the system $\mathrm{CaO}-\mathrm{SiO}_{2}-\mathrm{H}_{2} \mathrm{O}$ at $30{ }^{\circ} \mathrm{C}$ and the reaction of water on the anhydrous calcium silicates. BS J. Research 12 , 751 (1934) RP687.

[263] Wells, L. S., Clarke, W. F., and McMurdie, H. F., Study of the systcm $\mathrm{CaO}-\mathrm{Al}_{2} \mathrm{O}_{3}-\mathrm{H}_{2} \mathrm{O}$ at temperatures of $21^{\circ} \mathrm{C}$ and $90^{\circ} \mathrm{C}$, J. Research NBS 30, 367 (1943), RP1539.

[264] Flint, E. P., Wells, L. S., and McMurdie, H. F., Formation of hydrated calcium silicates at elevated temperatures and pressures. J. Research NBS 21, 617 (1938) RP1147.

[265] Kalousek, Geo., L., Studiès of portions of the quater. nary system soda lime-silica-water at $25^{\circ} \mathrm{C}$. J. Research NBS 32, 285 (1944) RP1590.

[266] Carlson, Elmer T., Hydrogarnet formation in the system lime-alumina-silica water. J. Research NBS 56, 327 (1956) RP2683.

[267] Berman, H. A., and Newman, E. S., Heats of formation of calcium trisulfoaluminate at $25{ }^{\circ} \mathrm{C}$, Nat. Bur. Stand. (U.S.), Monogr. 43, vol. 1247 (Aug. 1962).

[268] Hunt, C. M., Infrared Absorption of Some Compounds in the $\mathrm{CaO}-\mathrm{SiO}_{2}-\mathrm{H}_{2} \mathrm{O}$ System, Nat. Bur. Stand. (U.S.), Monogr. 43, vol. I, 249 (Aug. 1962).

[269] Blaine, R. L., Proton Magnetic Resonance in Hydrated Portland Cements, Nat. Bur. Stand. (U.S.), Monogr. 43, vol. I, 301, (Aug. 1962).

[270] Hunt, C. M., Dantzler, Vernon, Tomes, L. A., and Blaine, R. L., Reaction of portland cement with carbon dioxide. J. Research NBS 60, 441 (1958) RP2858.

[271] Ward, George, Research Reports, Portland Cement Assn. Fellowship (April 1944).

[272] Blaine, R. L., and Valis, H. J., Surface available to nitrogen in hydrated portland cements, J. Research NBS 42, 257 (1949) RP1967.

[273] Tomes, L. A., Hunt, C. M., and Blaine, R. L., Some factors affecting the surface area of hydrated portland cement as determined by water-vapor and nitrogen adsorption. J. Research NBS 59, 357 (1957) RP2806.

[274] Hunt, C. M., Tomes, L. A., and Blaine, R. L. Some effects of aging on the surface area of portland cement paste, J. Res. Nat. Bur. Stand. (U.S.), 64A (Phys. and Chem.), No. 2, 163-169 (Mar.-Apr. 1960).

[275] Bates, P. H., Phillips, A. J., and Wig, R. J., Action of the Salts in Alkali Water and Sea Water on Cement, Tech. Pap. BS 2 (1912) T12.

[276] Wig, R. J., Williams, G. M., and Finn, A. N., Durability of Cement Drain Tile and Concrete in Alkali Soils, Tech. Pap. BS 9, (1917) T95. 
[277] Lerch, W., Ashton, F. W., and Bogue, R. H., The sulphoaluminates of calcium, BS J. Research 4, 55 (1930) RP233.

[278] Flint, E. P., and Wells, L. S., Relationship of the garnet-hydrogarnet series to the sulfate resistance of portland cement, J. Research NBS 27, 71 (1941) RP 1411.

[279] Insley, Herbert, Flint, E. P., Newman, E. S., and Swenson, J. A., Relation of composition and heats of solution of portland cement clinker, J. Research NBS 21, 355 (1938) RP1135.

[280] Lerch, William, Effect of Glass Content upon the Heat of Hydration of Portland Cement, PCA Fellowship Paper 36 (1938).

[281] Bogue, R. H., and Lerch, W., PCA Fellowship Research Reports (Jan. 1944).

[282] Blaine, R. L., Arni, H. T., and Foster, B. E., Interrelations Between Cement and Concrete Properties, Part 1, Section 1, Nat. Bur. Stand. (U.S.), Bldg. Sci. Ser. 2, 36 pages (Aug. 1965).

[283] Schuman, Louis, Ten-year tests of high-early-strength cement concretes, J. Research NBS 29, 397 (1942) RP1508.

[284] Bates, P. H., The effect of fine grinding and a higher $\mathrm{SO}_{3}$ content upon the physical properties of portland cement, Proc. Am. Soc. Testing Mater. 15, Pt. II, 126 (1915)

[285] Bates, P. H., Long-time tests of high-magnesia cements, Proc. Am. Soc. Testing Mater. 27, Pt. II, 324 (1927).

[286] Bates, P. H., Some properties of high alumina cements from six countries, Proc. New Intern. Assoc Testing Mater. (NIATM, Leonhardstrasse 27, Zurich, Switzerland) Group B, 210 (1930).

[287] Wells, L. S., and Carlson, Elmer T., Hydration of aluminous cements and its relation to the phase equilibria in the system lime-alumina-water, J. Research NBS 57, 335 (1956) RP2723.

[288] Rogers, J. S., and Blaine, R. L., Investigation of com. mercial masonry cements, BS J. Research 13, 811 (1934) RP746.

[289] Evans, D. N., Litvin, A., Figlia, A. C., and Blaine, R. L., Properties of some masonry cement, J. Research NBS 51, 11 (1953) RP2427.

[290] Kelly, Thomas, Schuman, L., and Hornibrook, F. B. A study of alkali-aggregate reactivity by means of mortarbar expansions, J. Am. Concrete Inst., 20, No. 1,57 (1949).

[291] Pike, R. G., Hubbard, D., and Insley, H., Mechanisms of alkali-aggregate reaction, J. Am. Concrete Inst. 27, No. 1,13 (1955).

[292] Pike, R. G., and Hubbard, D., Miscellaneous Observations on the Alkali-aggregate Reaction and the Ionic Charge on Hydrated Cement, NAS-NRC Publ., Hwy. Res. Bd. Bull. 171, p. 16 (1958).

[293] Pike, R. G., Pressures Developed in Cement Pastes and Mortars by the Alkali-aggregate Reaction, NAS. NRC Publ., Hwy. Res. Bd. Bull. 171, p. 34 (1958).

[294] Johnson, Walter H., and Parsons, W. H., Thermal expansion of concrete aggregate materials, J. Research NBS 32, 101 (1944) RP1578.

[295] Blaine, R. L., Hunt, C. M., and Tomes, L. A., Use of Internal-surface-area Measurements in Research on Freezing and Thawing of Materials, NAS-NRC Publ, Hwy. Res. Bd. Proc. 32nd Ann. Meeting, 32, 298-306, (Jan. 13.16, 1953)

[296] Valore, R. C., Jr., Volume changes in small concrete cylinders during freezing and thawing, J. Am. Concrete Inst. 21, 417.434 (1950); also J. Research NBS 43, 1 (1949) RP2000.

[297] Arni, H. T., Foster, B. E., and Clevenger, R. A., Automatic equipment and comparative test results for the 4 ASTM freezing and thawing methods for concrete, Proc. Am. Soc. Testing Mater. 56 (1956).

[298] Jumper, C. H., Tests of integral and surface waterproofings for concrete, BS J. Research 7, 1147 (1931) RP394.

[299] Hornibrook, F. B., Freiberger, H., and Litvin, A., A study of durability and void characteristics of concretes containing admixtures, principally of the air-entraining type, Proc. Am. Soc. Testing Mater. 46, 1320 (1946).

[300] Vollmer, H. C., Effect of Calcium Chloride on the Water Requirements, Specific Weight, and Compressive Strengths of Concretes Made with Plain and Treated Cements, NAS-NRC Publ. Hwy. Res. Bd. Proc. 23, 296 (1943)

[301] Herschel, W. H., and Pisapia, E. A., Factors of workability of portland cement concrete, Proc. Am. Concretc Inst. 32641 (1936).

[302] Tucker, J., Jr., Pigman, G. L., Pisapia, E. A., and Rogers, J. S., A study of vibrated concrete, J. Research NBS 19, 575 (1937) RP1048.

[303] Wig, R. J., The Effect of High-pressure Steam on the Crushing Strength of Portland Cement Mortars and Concretes, Together with Tests of Dampproofing and Waterproofing Compounds and Materials, Tech. Pap. BS 1 (1911) T5.

[304] Rosa, E. B., McCollum, B, and Peters, O. S., Electrolysis in Concrete, Tech. Pap. BS 2 (1913) T18.

[305] Wig, R. J., Williams, G. M., and Gates, E. R., Strength and Other Properties of Concretes as Affected by Materials and Methods of Preparation, Tech. Pap. BS 6 (1916) T58.

[306] Tucker, J., Jr., Effect of dimensions of specimens upon the precision of strength data, Proc. Am. Soc. Testing Mater. 45, 952 (1945).

[307] Tucker, J., Jr., The maximum stresses present at failure of brittle materials, Proc. Am. Soc. Testing Mater. 45, 961 (1945).

[308] Tucker, J., Jr., Effect of length on the strength of compressive test specimens, Proc. Am. Soc. Testing Mater. 45, 976 (1945).

[309] Kaplan, M. F., Crack propagation and the fracture of concrete, Proc. Am. Concrete Inst. 58, 591 (Nov. 1961).

[310] Schuman, Louis, and Tucker, John, Jr., Tensile and other properties of concretes made with various types of cement, J. Research NBS 31, 107 (1943) RP1552.

[311] Hornibrook, F. B., Application of Sonic Method to Freezing and Thawing Studies of Concrete, Am' Soc. Testing Mater. Bull. 101, 5, (1939)

[312] Williams, G. M., and Furlong, I., Durability of Cement Drain Tile and Concrete in Alkali Soils: Fourth Prog. Report (1923), Tech. Pap. BS 20, 191 (192526) T307.

[313] Tucker, John, Jr., and Walker, G. W., The physical properties of commercial cast stone, Proc. Am. Concrete Inst. 25, 501 (1929).

[314] Report on Cooperative Freezing and Thawing Tests of Concrete, Hwy. Res. Bd. Special Report 47, (1959).

[315] Bogue, R. H., and Eubank, William R., Studies on the Flame Photometer for the Determination of $\mathrm{Na}_{2} \mathrm{O}$ and $\mathrm{K}_{2} \mathrm{O}$ in portland cement, J. Research NBS 43, 173 (1949) RP2019.

[316] Bean, B. Leonard, and Diamond, J. J., Use of the Beckman and Perkin-Elmer Instruments for the Flame Photometric Determinations of Alkalies in Portland Cement, ASTM Spec. Tech. Publ. 116, Symposium on Flame Photometry, p. 28-32 (1952).

[317] Helz, Armin W., Spectrographic determination of sodium, potassium, and lithium in portland cement with the direct-current carbon arc, J. Research NBS 34, 129 (1945) RP1633.

[318] Maczkowske, Edwin E., A rapid method for the de. termination of silica in portland cement, BS J. Research 16, 549 (1936) RP891.

[319] Rudy, Robert B., Determination of sulphuric anhydride in portland cement by means of the Wagner turbidi. meter, BS J. Research 16, 555 (1936) RP893.

[320] Bright, Harry A., Determination of sulphur occurring as sulphide in portland cement, BS J. Research 18, 137 (1937) RP938.

[321] Diamond, J. J., Spectrophotometric determination of titania in portland cement, Rock Products (309 W. Jackson Blvd., Chicago, Ill.) 49, No. 4, 103 (April 1946) 
[322] Redmond, J. C., The precipitation and titration of magnesium oxyquinolate in the presence of calcium oxalate, and its application in the analysis of portland cement and similar silicates, BS J. Research 10, 823 (1933) RP569.

[323] Lerch, William, and Bogue, R. H., Revised procedure for the determination of uncombined lime in portland cement, Indus. \& Eng. Chem. (Anal. Ed.), 2, 296 (1930).

[324] Bean, B. L., and Mulligan, B. W., X-ray spectrochemical analysis of materials; Cement and dental alloys, Am. Soc. Testing Mater. STP 373, 25-45 (1964).

[325] Wig, R. J., and Pearson, J. C., Standardization of No. 200 Cement Sieves. Tech. Pap. BS 4 (1914) T42.

[326] Wagner, L. A., A rapid method for determination of the specific surface of portland cement. Proc. Am. Soc. Testing Mater. 33, Pt. II, 553 (1933).

[327] Blaine, R. L., A Simplified Air Permeability Fineness Apparatus, Am. Soc. Testing Mater. Bull. No. 123, 51 (1943).

[328] Williams, G. M., Time of setting of cement, Proc. Am. Soc. Testing Mater. 14, Pt. II, 200 (1914).

[329] Dwyer, J. R., Effect of age of test pieces in soundness tests of portland cement, Concrete-Cement Mill Ed. (Concrete Publ. Co., 400 W. Madison St., Chicago, Ill.) $17,87(1920)$.

[330] Dwyer, J. R., Effect of departure from planeness of bearing surfaces on the compressive strength of 2 -in mortar cubes, Proc. Am. Soc. Testing Mater. 36 Pt. II, 351 (1936).

[331] Blaine, R. L., Valore, R. C., Jr., and Bowling, J. E., The direct and continuous measurement of bleeding in portland cement-water mixtures. Proc. Am. Soc. Testing Mater. 49 (1949).

[332] Dwyer, J. R., The Cement Reference Laboratory, Am. Soc. Testing Mater. Bull. No. 87, 12 (1937).

[333] Youden, W. J., Statistical aspects of the cement testing program, Proc. Am. Soc. Testing Mater. 59 (1959).

[334] Crandall, J. R., and Blaine, R. L., Statistical cvaluation of interlaboratory cement tests, Proc. Am. Soc. Testing Mater. 59, 1129 (1959).

[335] Bishop, D. L., A sedimentation method for the determination of the particle size of finely divided materials (such as Hydrated Limes), BS J. Research 12. 173 (1934) RP642.

[336] Fink, G. J., and Trattner, Emil, Properties of highly hydrated dolomitic masonry limes and certain of their cement-lime mortars, Proc. Am. Soc. Testing Mater. 45,723 (1945).

[337] Emley, W. E. Method of indicating the rate of set of lime mortar. Trans. Am. Ceram. Soc. 16, 117 (1914).

[338] Emley, W. E., Properties of cement-lime-sand mortars, Trans. Am. Ceram. Soc. 17, Pt. II, 261 (1917).

[339] Emley, W. E., Panel tcsts of lime plaster, J. An. Ceram. Soc. 6, 1007 (1923)

[340] Emley, W. E., An instrument for measuring plasticity, Trans. Am. Ceram. Soc. 19, 523-533 (1917); also Tech. Publ. 169, Nat. Lime Assoc., 175 (1916)

[341] Whitson, Alice I., Determination of available lime in quicklime and hydrated lime, Chem. \& Met. Eng. (330 W. 42nd St., N.Y., N.Y.) 25, 32 (1922) ; also Proc. Nat. Lime Assoc. 57 (1922).

[342] Wells, Lansing S., and Taylor, Kenneth, Hydration of magnesia in dolomitic limes and putties, J. Research NBS 19, 215 (1937) RP1022.

[343] Wells, L. S., Clarke, W. F., Newman, E. S., and Bishop, D. L., Investigation of Failures of White-coat Plaster, NBS Building Materials and Structures Report. 121, (1951).

[344] Wells, L. S., Clarke, W. F., and Levin, E. M., Expansive characteristics of hydrated limes and the development of an autoclave test for soundness, J. Research NBS 41, 179 (1948) RP1917.

[345] Emley, W. E., Measuring the time of set of calcined gypsum, Trans. Am. Ceram. Soc. 19, 573-584 (1917).

[346] Emley, W. E., and Welch, F. C.. Effect of fineness on other properties of calcined gypsum, J. Am. Ceram. Soc. 4, 301 (1921).
[347] Murray, J. A., and Foster, H. D., Adhesion of plaster and stucco to hollow clay tile, Am. Architect (Intern. Publications, 372 Madison Ave., N.Y., N.Y.) 132, 829 (1927).

[348] Bishop, D. L., Function of carbon dioxide in producing efflorescence on plaster and cement products, J. Research NBS 30, 361 (1943) RP1538.

[349] Smith, L. E., Some properties of gypsum.lime mixes, Rock Products, 29, 39 (1926).

[350] Porter, J. M., Volumetric changes of gypsum, Proc. Am. Soc. Testing Mater. 23, Pt. I., 244-253 (1923).

[351] Murray, J. A., Expansion of a calcined gypsum on setting, Rock Products, 31, 88 (1928).

[352] Newman, E. S., Behavior of calcium sulfate at high temperature, J. Research NBS 27, 191 (1941) RP1413.

\subsection{Ceramic and Metallic Materials}

[353] Staley, H. F., Materials and Methods Used in the Manufacture of Enameled Cast-iron Wares, Tech. Pap. BS 12, (1919) T142.

[354] Shaw, J. B., Enamels for Sheet Metal and Steel, Tech. Pap. BS 13, (1920) T165.

[355] Danielson, R. R., and Reinecker, H. P., Wet-process Enamels for Cast-iron, Tech. Pap. BS 17, (1923) T246.

[356] Harrison, W. N., Controlling the Consistency of Enamel Slips, Tech. Pap. BS 22, 91 (1927) T356.

[357] Burgess, G. K., and Crowe, J. J., Critical ranges A2 and A3 of pure iron, Bull. BS 10, 315, (1914) S213.

[358] Merica, P. D., Waltenburg, R. G., and Scott, H., The heat treatment of duralumin, BS Sci. Pap. 15, 271, (1919) S347.

[359] French, H. J., and Klopsch, O. Z., Initial Temperature and Mass Effects in Quenching, Tech. Pap. BS 19, 589 , (1925) T295.

[360] Logan, K. H., Ewing, S. P., and Yeomans, C. D., Bureau of Standards Soil-corrosion Studies, I. Soils, Materials, and Results of Early Observations, Tech. Pap. BS 22, 447, (1928) T368.

[361] Denison, I. A., Correlation of certain soil character. istics with pipe line corrosion, BS J. Research 7, 631, (1931) RP363.

[362] Harrison, W. N., and Moore, D. G., Weather resistance of porcelain-enameled iron structural units, J. Research NBS 28, 735, (1942) RP1476.

[363] Harrison, W. N., and Moore, D. G., Weather resistance of porcelain-enamels exposed for seven years, J. Research NBS 42, 43, (1949) RP1949.

[364] Moore, D. G., and Harrison, W. N., Fifteen-year Exposure Test of Porcelain Enamels, NBS Building Materials and Structures Report 148, (1957).

[365] Book of ASTM Standards, Part 13, Amer. Soc. Testing Mater. (1966).

[366] Geller, R. F., and Creamer, A. S., Moisture expansion of ceramic white ware, BS J. Research 9, 291 (1932) $\mathrm{RP} 472$.

[367] Harrison, W. N., Moore, D. G., and Richmond, J. C., Ceramic coatings for high-temperature protection of steel, J. Research NBS 38, 293 (1947) RP1773.

[368] Moore, D. G., and Potter, A., Effect of Exposure Site on Weather Resistance of Porcelain Enamels Exposed for Three Years, Nat. Bur. Stand. (U.S.), Monogr. 44, 13 pages (Apr. 1962).

[369] Pitts, J. W., and Moore, D. G., Apparatus for studying the effects of atmospheric pollution and cyclic dew formation on the deterioration of materials, J. Am. Soc. Testing Mater., Materials Res, and Standards, 6, No. 7 (1966)

\subsection{Building Systems and Subsystems}

[370] Performance Characteristics for Sanitary Plumbing Fixtures, Building Research Advisory Board, NASNAE-NRC (Feb. 1968).

[371] Public Building Service, Building Systems Project Status Report PB 176959 (1967). (Clearing House for Federal Scientific and Technical Information, 5285 Port Royal Road, Springfield, Virginia 22151). 


\section{Index}

A

abrasion resistance, 20

accelerated laboratory tests, 3, 21, 25

accelerated weathering, $4,20,35$

Achenbach, P. R., 14, 15, 16

acoustical instrumentation, 18, 19

acoustical performance, 18

building materials, 18

floor constructions, 18

plasters, 18

wall constructions, 18

Acoustical Society of America, 19

acoustical terminology, 19

adhesives, flooring, 22

advisory services, 2,5

Agnew, P. G., 28

air circulation, 16

air cleaners, 14,42

air conditioning calorimetry, 15,35

air exchange through doors, 17

air infiltration, 2,16

air mixers, 15,35

air pollutants, 36

aircraft cabin materials, 34

American Bridge Co., 7

American Concrete Institute, 9, 26

American Engineering Standards Committee, 28

American Gas Association, 14

American Institute of Electrical Engineers, 28

American Institutc of Mining Engineers, 28

American Iron and Steel Institute, 8, 32

American National Standards Institute (ANSI), 16

American Railway Engineering Association, 7

American Society of Civil Engineers, 7, 28

American Society of Heating, Refrigerating, and Air-Conditioning Engineers, 12, 16, 34

American Society of Heating and Ventilating Engineers, 11

American Society of Mechanical Enigneers, 28

American Society for Refrigerating Engineers, 11

American Society for Testing and Materials, 10, 11, 19, 24, 25, 26,28

standards, 9, 13, 21, 27, 36

American Standards Association, 7, 11, 16, 28, 29, 38

incorporation, 28

standards, 9, 19, 28, 29

American Standard Plumbing Code, 19, 20

amoebic dysentery, 19

anechoic chamber, 41

architectural acoustics, 17, 19, 41, 43

architectural panels, 27

architectural porcelain, 27

Armco Iron, 35

asphalt, 21,28

asphalt films, 36

Asphalt Roofing Industry Bureau, 21, 36

asphalt shingles, 21

asphalt tile, 23

Associated Factory Mutual Fire Insurance Co., 9

atmospheric corrosion, 27

Audio Engineering Society, 19

auditory environment, 41

\section{B}

backflow, 19

back siphonage, 19

baseboard heating units, 14

Basquin, O. H., 7

Bates, A. A., 30

Bates, P. H., 23

behavioral science, 38

Berendt, R. D., 18

Best, A. S., 22

Blaine fineness meter, 25

Blaine, R. L., 24
Bogue, R. H., 23

boilcrs, 14

Bragg, J. C., 7

branch laboratories, 24

brick, 7,26

clay, 7

effect of wctting, 7

freezing and thawing, 7, 27

piers, 7

sand-lime, 7

strength, 7

workmanship, 7

Brown, C. B., 10

Buckingham, E., 18

Building and Housing Division, 28

Building and Housing Reports, 28

building characteristics, 43

Building Code Committee, 7, 19, 28

Building Code Correlating Committcc, 28

building codes, $1,4,6,7,11,27,28,30,38,42$,

building design and construction, $5,28,30$

building industry, $5,30,42$

building materials, 1, 2

ceramic materials, 26

inorganic materials, 22

metallic materials, 26

organic materials, 20

physical properties, 6

specifications, 27,30

Building Materials and Structures Reports, 6, 8, 9, 12, 14, 16, 18,22

Building Research Division, 1, 2, 6, 17, 30, 38, 39, 40, 41, 42

mission, 1,39

history, 6

organization, 30,38

Building Science Series, 5, 42

building standards, $7,11,28,30,38,39,42$

building stone, 8

building systems and subsystems, 1, 3, 4, 7

Building Systems Section, 38

building technology, 7

Building Technology, Division, 7, 8

built-up roofs, 22,36

Bureau of Reclamation, 25

Burgess, G. K., 27, 28

Burroughs, C. B., 18

\section{C}

Calcium Chloride Association, 24

calibration of equipment, 4

calorimetry, 12,35

Campbell, P. G., 22

carpet testing, 22

cement, 23, 24, 25

cement clinker, 23

cement-lime mortars, 26

cement testing, 23, 24, 30

cement testing laboratories, 26

Central Housing Committee, 6, 20

ceramic building materials, 26

ceramic whiteware, 27

Ceramics Division, 26

chemistry of asphalts, 22

Chemistry of Mineral Products Section, 23

Chicago World's Fair, 19

chilled air distribution, 17

chimneys, 10

draft, 14

masonry, 10

prefabricated, 10

Chrisler, V. L., 18

civilian industrial activities, 30

Clark, A. P., 8

clays, 26

climatic exposure, 43

coatings, 3 
high temperature, 27 organic, 37

protective, 36

Coblentz, C. W., 16

Cole, S. D., 15, 16

columns, 7, 12

fire protection, 9

slenderness, 7

strength, 7

combustible content of buildings, 11

combustion gases, 33,34

combustion processes, 33

commercial standards, 6,14

Common Brick Manufacturers' Association, 7

composites, 4, 20,31, 33

composite structural elements, 33

computer applications, $12,17,30,32,33,34,39,42$

concrete, 24

concrete admixtures, 24

concrete aggregate, 24

concrete, light weight aggregate, 9

concrete testing, 23, 24, 30

Concreting Materials Section, 23

condensation on walls, 14

Construction Standards Board, 28, 38

consultation services, 5

convection, interior, 34

Convector Manufacturers' Association, 14

convectors, 14

copper plumbing, 20

Corps of Engineers, 17, 25, 30

corrosion, 27

cost analysis, 31,39

cost synthesis, 39

Cottony, H. V., 14

cover plates, perforated, 7

creep of concrete, 33

Crittenden, E. C., 29

Cullen, W. C., 22

\section{D}

Danielson, R. R., 27

Davis, J. C., 15

deflections, 3

Department of Agriculture, 10, 17

Department of Commerce, 6, 7, 20, 28, 30

Department of Defense, 15, 31, 41

Department of Housing and Urban Development, 42

deterioration of materials, $3,35,36$

Dickinson, H. C., 11

differential movement, 12

diffusion flames, 34

Dill, R. S., 12, 14

diversity of loads, 15

Division of Building and Housing, 6

Division of Simplified Practice, 6

Division of Specifications, 6

Division of Trade Standards, 6

doors, 33

drainage systems, 35

ducts, 16

durability of materials, $2,3,7,35$

E

Eaton, H. N., 20

economic evaluation, 38

edge insulation of floors, 14

elastomers, 37

electrical hazards, 28

electrical resistivity, 35

emergency plumbing standards, 20

Emley plasticimeter, 26

Emley, W. E., 22

Enameled Metals Section, 27

enameling process, 27

energy usage, 15,34

engineering properties, 6

environmental engineering, 1, 2, 11, 34 environmental facilities, 31

environmental systems, 7

European chemists, 23

exploratory research, 4

exposure-site testing, 27, 36

exposure tests, 20

exterior wall systems, 37

extinguishment of fire, 11

extreme weather conditions, 17

factory prefabrication, 31,32

Federal Aviation Administration, 34

Federal construction agencies, 16, 18, 20, 25, 41

Federal Housing Administration, 14, 16, 18, 37, 41

Federal insurance programs, 6

Federal office space, 39

Federal specifications, 15, 21, 36

Federal Specifications Board, 21

field assembly, 31

fire doors, 33, 34

fire endurance ratings, 9,18

fire gases, 33

fire loads, 32,41

fire research, 1, 7, 9

extinguishment, 11, 33

fire detection, 33

fire endurance, 9

fire penetration, 3,9

fire suppression, 33

flame inhibition, 4,33

flame spread, $3,11,33$

growth of fire, 41

ignition, 3,10

self-heating, 10

smoke distribution, $3,33,41$

structural failure under fire, $3,9,41$

toxic combustion products, 3,33

fire research facilities, 31,43

Fire Research Section, 9

fire safety, 2,6

domestic heating equipment, 14

fireplaces, 14

Fishburn, C. C., 8

fixture trap seals, 20

fixture-unit ratings, 20

flammability of materials, 33

floor condensation, 14

floor coverings, $7,22,36,42$

electrical conductance, 22

bonding agents, 22,36

floor-materials, 22

floor ceiling constructions, 40,42

floors, 3,36

foundations, 3

freezing and thawing, 7, 24, 26

French, J. L., 20

frost closure of vents, 20

full-scale house, 40

functional requirements, 4

furniture arrangements, 42

Gallup, B. E., 22

gas burners, 14

gas chromatography, 4,34

gas stoves, 27

Geological Survey, 23

glazing, 28

granite, 8

grease deposits, 35

Griffith crack theory, 24

guarded hot-plate apparatus, 11, 12

gypsum, 23, 26 
hail resistance, 36

Hansen, W. C., 23

Harrison, W. N., 27

Harrington, E. A., 23

heat and mass transfer, 34

heat flow meters, 12

heat pumps, air-to-air, 15

heat transfer, $4,7,11,14,34,35,41$

heat transmission, $11,12,14$

Heating, Air-Conditioning, and Refrigeration Standards Board, 38

heating and cooling loads, 15, 17, 34

heating equipment, 14

heating systems, 16

Hickson, E. F., 20

highway laboratories, 26

highway materials, 26

Highway Research Board, 26

Hofer, C. E., 22

Hoover, Herbert, 6, 19, 28

hospital floors, 42

hot-box apparatus, 12

household appliances, 27

Hull, W. A., 9

humidity in buildings, 34

Humphrey, R. L., 7

Hunter, R. B., 20

\section{I}

ignition temperature, 10

industrial laboratories, 11

industrial technology, 28

industrialization of building, 39

industry standards, 14

industry-sponsored research, 6

information classification, 5

information exchange, $4,39,42$

Ingberg, S. H., 9

inhibition of fire, 11

innovative systems, $4,39,42$

inorganic building materials, $3,7,22$

Insley, H., 23

insulating materials, 11,34

insulated roof constructions, $12,13,14$

Institute for Applied Technology, 1, 7, 30

Institute for Basic Standards, 30

Institute for Materials Research, 30

Institute of Boiler and Radiator Manufacturers, 14

Institute of Cooling and Heating Appliance Manufacturers, 14 integrated systems, 32

interdisciplinary seminars, 5

International Standardization Organization, 19

international standards, $4,18,19,38$

\section{$\mathbf{J}$}

Jakkula, A. A., 7

joint sealants, 37

$\mathbf{K}$

Kaplan, M. F., 24

katharometer, portable, 16

Kessler, D. W., 22

Klein, P. A., 23

Kusuda, T., 17

L

lime, 26, 28

limestone, 8

lime testing, 23,26

linseed oil, 20

long-range planning, 30, 43

Lorenz number, 35

Losse, L. H., 7

low-cost housing, $7,14,16,20,22$ manufacturcrs' associations, 4, 5, 17

marblc, 8

masonry, 7, 24, 28, 32

Masonry Construction Section, 7

Matcrials Durability and Analysis Section, 21, 22

mathematical models, 39

Mathcy, R. G., 9

McBurney, J. W., 7, 22

mechanical cquipment, 6

mcchanical systems, 14

metallic building materials, $3,7,26$

metallurgy, 27

Metallurgy Division, 27

metals tcchnology, 27

Microscopic Constitution of Mineral Products Section, 23

Minimum Property Standards, FHA, 14, 41

Mitchell, N. D. 9, 10

mobile acoustical laboratory, 41

model building codes, 7,9

model plumbing codes, 20

modcling techniques, $4,34,40$

moisture condensation, 14, 34

moisture transfer, $4,14,15,34$

mortar, 7, 33

mortar joints, 7

N

National Academy of Sciences, 15

National Board of Fire Underwriters, 9

National Bureau of Standards, 1, 7, 9, 38

establishment, 1, 27

Gaithersburg laboratories, 31

organizational structure, 6

Pittsburgh laboratories, 9

reorganization, 7,30

National Conference on Building Codes and Standards, 38

National Electric Safety Code, 28

National Fire Protection Association, 11

National Institute of Mental Health, 42

national standards, 18,38

national standards organizations, 4, 14, 20

National Warm Air Heating and Air Conditioning Assn., 14

natural convection, 4

Navy Department, 28

new laboratory facilities, $30,31,43$

noise problems, $3,18,19,41$

non-combustibility, 10

\section{0}

occupant activity, 34

office buildings, 32

Office of Civil Defense, 17, 35

organic building materials, $3,7,20$

outdoor exposure, 7

paint manual, 37

paints, $7,20,21,28$

Pan-American standards, 4

Parsons, D. E., 8

partitions, 9

performance concepts, $4,32,37,39,42$

performance criteria, 27,37

performance language, 32

performance requirements, $32,36,37,38,39$

performance specifications, $4,38,41$

performance standards, 39

performance tcsts, 37,39

Phillips, C. W., 17

photooxidation, 22,36

plasters, 26

plaster failures, 26

plumbing fixtures, 37

plumbing manual, 20 
plumbing research, 19, 31, 42

plumbing systems, $3,19,28$

porcelain enamel, 27

Porcelain Enamel Institute, 27

Porter, W. C., 20

Portland Cement Association, 23

post office building, $32,39,42$

Post Office Department, 22, 39, 42

Powell, F. J., 13, 14

prefabrication of buildings, 39

product development, 2

professional societies, $4,14,28$

program planning and budgeting, 31

program subelements, 2,31

building codes and standards, 2, 14, 30

consultation and advisory services, 2,5

exploratory research, 2,4

materials durability and analysis, 2, 3, 30

physical and functional environment, 2, 30

professional training and information exchange, 2, 4

strength and safety in structures, 2, 3, 30

systems engineering, 2, 4, 30

Properties of Materials Section, 22

proscenium curtains, 9

protective coatings, 36

protective structures, 17

psychophysical concepts, 2, 40

Public Buildings Service, 38, 40, 42

Public Health Service, 42

publication of information, 4

\section{$\mathbf{R}$}

radiator accessories, 14

radiators, 14

rainwater gutters, 20

reference laboratories, 4, 26

cement and concrete, 4, 26

Cement Reference Laboratory, 26

highway materials, 4, 26

reference samples, 4

refrigerant flow rates, 16

refrigerated vehicles, 17

refrigerated warehouses, 17,38

refrigerating system components, 15

refrigeration equipment, 15,38

Reichard, T. W., 9

reinforced concrete, 7,8

reinforcing bars, 8

Research Associate Program, 5, 6, 8, 21, 23, 24, 27, 41, 42

reverberation chamber, 19, 39

Richmond, J. C. 7

Roberts, A. G. 20

Robertson, A. F., 10

Robinson, H. E., 11, 12, 13, 14

roof constructions, $3,14,21,26$

roof coverings, $7,21,36$

roof failure, 22

roof ventilators, 14

room temperature control, 16

Rosa, E. B., 28

safety, $2,3,28$

safety codes, 28

Safety Standards Board, 38

Sale, P. D., 9

sanitary drainage systems, 20

Schiefer, H. F., 22

sealants, 6,37

Sigler, P. A., 22

self-drying roof constructions, 14

self-heating of materials, 10

sensory environment, 3,41

Sentil, C., 20

Setchkin, N. P., 10

Shaw, J. B., 27 shear-stud spacing, 33

simplified practice, 6

slate, 8

smoke phenomena, 33

Snoke, H. S., 22

solar radiation, 17

sound absorption, 18, 19

sound fields, 18

sound generation, 18

sound insulating properties, 18

Sound Laboratories, 41

Sound section, 18

sound transmission, 18, 19

sound transmission laboratories, 31, 42

space heaters, 14,27

space utilization, 42

specifications, $4,15,19,27,36$

Staley, H. F., 27

Stang, A. H., 7

standard samples, $12,25,26,35$

standard test methods, $26,27,28$

standardization of building materials, 6,28

standardization of refrigeration components, 15

standards, 4, 6, 28, 36

standards of practice, 27

Statistical Engineering Section, 26

steel columns, 7

Stephenson, H. K., 7

strategic materials, 6

Stratton, S. W., 28

Streiter, O. C., 21

structural engineering, 6

structural laboratory, 31

structural loads, $3,6,32,42$

cyclic loads, 31

dead load, 3,40

design load, 9

dynamic loads, 41

edge loads, 32

high-level sustained loads, 31,33

live load, $3,9,28,32,40$

racking loads, 32

seismic load, 3

shock and vibration, 3,41

statistical analysis, 32

wind load, 3, 33, 40, 41

structures, $1,3,7$

subjective response, 41

surface roughness, 36

surface wetness, 36

systems engineering, $4,30,39,41,42$

T

technical information, 41,42

temperature distribution, 16,34

temperature measurement, 16,35

terra cotta, 26

testing services, 5

thermal conductivity of materials, 11,35

thermal conductivity test methods, 12

thermal environment, 16

thermal expansion, 12

thermal insulation, 11

thermal shock resistance factor, 36

thermal transmittance, 11

thermistors, 35

thermocouples, 35

thermometers, 35

thermophysical properties, 41

thin-shell construction, 9

Thompson, G. N., 28

tile, 26,27

time-temperature curve, standard, 9

trade associations, 28

transport systems, 41

Tucker, J., Jr., 24

Tuckerman, L. B., 7

turpentine, 20 
$\mathbf{U}$

ultraviolet radiation, 36

underground corrosion, 27

underground heat distribution systems, 15

underground shelters, 17, 34

Underwriters' Laboratories, 9, 22, 36

uniform building standards, $4,38,39$

U.S. Congress, 6,28

House of Representatives, 23

U.S.A. Standards Institute, 16, 19, 22, 28, 38 users' needs, $2,37,43$

\section{V}

Valore, R. C., Jr., 25

Van Dusen, M. S., 11, 12

varnish, 28

venting of plumbing, 20

Veterans' Administration, 20

vibration loads, 41

visual environment, 41

W

Walker, P. H., 20

wall eonstruetion performanee, $3,7,33,37$ walls, 3,37

War Department, 28

Ward, G. W., 23

water heaters, 14

water permeability of walls, 7

water distributing systems, 20

Watson, T. W., 11, 12

Watstein, D., 8, 9

Weather Bureau, 9

weather parameters, 34

weatherability of materials, 35,36

Whittemore, H. L., 7

Wig, R. J., 24

wind pressures, 9, 41

windows, 3

Woodward, M. B., 22

Woolley, H. W., 14

World War II, 6, 8, 15, 20,27

Wright, J. R., 22, 39

Wyly, R. S., 20, 39

yield point, 7

yield strength, 8 



\section{Announcement of New Publications in Building Science Series}

Superintendent of Documents,

Government Printing Office,

Washington, D. C. 20402

Dear Sir :

Please add my name to the announcement list of new publications to be issued in the series: National Bureau of Standards Building Science Series.

Name

Company

Address

City __.__ State

Zip Code

(Notification key N-339) 



\section{.}




\section{U.S. DEPARTMENT OF COMMERCE}

WASHINGTON, D.C. 20230

OFFICIAL BUSINESS

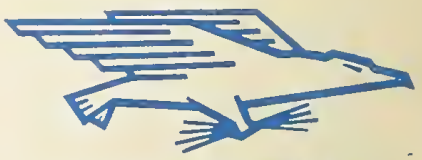

POSTAGE AND FEES PAIO

U.S. DEPARTMENT OF COMMERCE 